\title{
MRsive: an Augmented Reality Tool \\ for Enhancing Wayfinding and Engagement With Art in Museums \\ by
}

Jad Al Rabbaa

A thesis exhibition presented to OCAD University

in partial fulfillment of the requirements for the degree of

Master of Design in Digital Futures

TMAC, Toronto Media Arts Center

April 12-14, 2019

Toronto, Ontario, Canada

April, 2019

(C) Jad Al Rabbaa 2019 


\section{AUTHOR'S DECLARATION}

I hereby declare that I am the sole author of this thesis. This is a true copy of the thesis, including any required final revisions, as accepted by my examiners.

I authorize OCAD University to lend this thesis to other institutions or individuals for the purpose of scholarly research.

I understand that my thesis may be made electronically available to the public. I further authorize OCAD University to reproduce this thesis by photocopying or by other means, in total or in part, at the request of other institutions or individuals for the purpose of scholarly research. 


\section{ABSTRACT}

Jad Al Rabbaa

OCAD University

MRsive: an Augmented Reality Tool for Enhancing Wayfinding and Engagement With Art in Museums

Master of Design, Digital Futures - April, 2019

Most museums use printed methods to support indoor navigation and visitor engagement. However, modern museum visitors' needs are not always met using such static approaches. This thesis investigates how indoor wayfinding and visitor engagement in museums might be improved through augmented reality (AR). I design "MRsive", a handheld AR tool using a user-centered design approach. The goal is twofold: simplifying the required cognitive effort in navigating the museum space, and boosting visitor engagement with artifacts through multisensory interactions. MRsive uses computer vision to detect visual features of the space and locate visitors indoors and recognize exhibits. To evaluate my design, I conduct user-testing at the Art Gallery of Ontario (AGO) followed by semi-structured interviews. The participants' responses showed a considerable improvement in the speed, accuracy and ease-of-use when completing wayfinding or engagement tasks. I hope the findings will contribute to the future development of other AR systems with similar goals. 


\section{ACKNOWLEDGMENTS}

I would like to express a big gratitude to several people that were a source of inspiration, motivation and support through my graduate years.

I am fortunate to have worked with two wonderful advisors. Alexis Morris and Sowmya Somanath, thank you for your guidance, supervision and continuous encouragement. You consistently allowed this paper to be my own work and I appreciate your abilities to ask hard questions and steer me in the right direction while always being kind.

I am very thankful to Melissa Smith, the program coordinator at the Art Gallery of Ontario for facilitating the process of joining the AGO as an intern. Thank you for the encouragement. I also want to thank the AGO's digital department, directed by Mark McKay, for welcoming me in their office and giving me the freedom to experiment and conduct my research.

Finally, a huge thank you to my family and friends. I am so grateful for your patience and emotional support over the past two years. 
In loving memory of my father, Victor.

Thank you for inspiring me to always move forward.

To my mother, Mona, and my brother, Rawad, thank you for believing in me and supporting my choices.

To my cousin and friend, Elham, thank you for the motivation, and for being such a fan of my work. 


\section{CONTENTS}

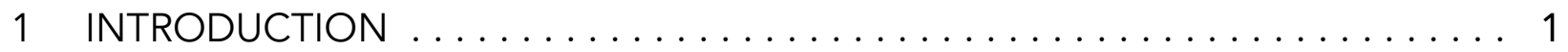

1.1 Motivation ................................. 1

1.2 Research Goals ............................. 4

1.3 Research Scope and Audience .................... 7

1.4 Research Contributions ............................. 9

1.5 Chapter Overview .......................... 11

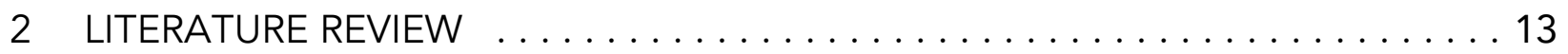

2.1 Theoretical Concept and Taxonomy of Wayfinding Tasks ......... 14

2.1.1 Definition 14

2.1.2 Types of Wayfinding tasks 15

2.2 Wayfinding Approaches and Related Cognitive Processes ........ 19

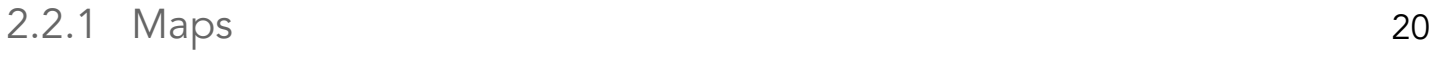

2.2.2 Signage 24

2.2.3 Digital Navigational Assistants 26

2.3 Visitor Engagement Approaches in Museums . . . . . . . . . . . 31

2.3.1 Types of Museum Visitors 31

2.3.2 Digital Approaches 33

2.4 Augmented Reality (AR) Platforms .................... 37 
$\begin{array}{lll}2.4 .1 & \text { Introduction } & 38\end{array}$

2.4.2 Potential for Growth in Consumer-level AR 40

2.4.3 AR Applications Supporting Wayfinding 42

2.4.4 AR Applications Supporting Engagement 47

2.5 Summary and Design Space . . . . . . . . . . . . . . . . . 51

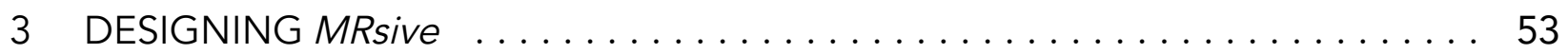

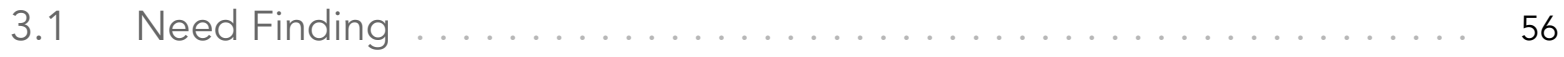

3.1.1 Observations and Note Taking 57

3.1.2 Semi-structured Interviews 60

$\begin{array}{lll}3.1 .3 & \text { Summary } & 63\end{array}$

3.2 Prototyping: Ideation, Design And Development ............. 63

3.2.1 Ideation 64

3.2.2 UI/UX Design: Paper Prototype 66

3.2.3 Development: Digital Prototype 67

3.3 Evaluation of Mrsive ......................... 75

3.4 Chapter Summary ............................ 76

4 FINDINGS AND DISCUSSION $\ldots \ldots \ldots \ldots \ldots \ldots \ldots \ldots \ldots \ldots \ldots \ldots$

4.1 Evaluation Group ............................ 79

$4.2 \quad$ Results . . . . . . . . . . . . . . . . . . . . . . 80

4.2.1 Findings: Wayfinding Experiment 82

4.2.2 Findings: Engagement Experiment 86 
MRsive: an Augmented Reality Tool for Enhancing Wayfinding and Engagement With Art in Museums

4.3 Lessons Learned ............................. . . 91

4.4 Limitations: Technological, Access, and Skills ... . . . . . . . . . 93

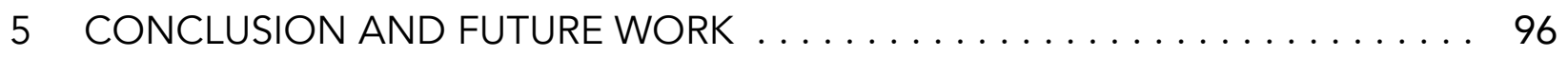

5.1 Revisiting Thesis Goals . . . . . . . . . . . . . . . . . 96

5.2 Revisiting Thesis Contributions . . . . . . . . . . . . . . 97

5.3 Future Work ................................ 98

$5.4 \quad$ Closing Remarks ............................ 100

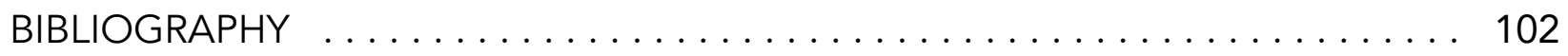

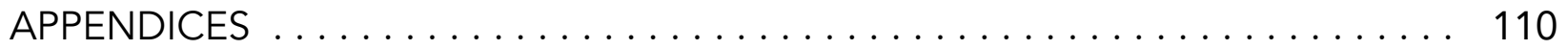

PUBLICATIONS ............................ 119 


\section{LIST OF TABLES}

Table 2.1 Virtual Reality and Augmented Reality technology requirements.

(Billinghurst, 2017)

Table 2.2 Comparison of heterogeneous positioning technologies (Huey, 2011). 44

Table 3.1 Demographics of the 36 randomly selected participants

Table 3.2 Answers to the scores questions in the need-finding interview

Table 3.3 The frequency of use of wayfinding methods at the AGO 
MRsive: an Augmented Reality Tool for Enhancing Wayfinding and Engagement With Art in Museums

Table 4.1 Demographics of the 12 participants of the user testing stage 80

Table 4.2 Average time needed to complete wayfinding task 1 and task 2 82 


\section{LIST OF FIGURES}

Figure 2.1 Proposed Taxonomy of wayfinding tasks (Wiener, 2009, p.6)

Figure 2.2 Proposed additions to Wiener et al. (2009) wayfinding taxonomy indicating where the strong/weak and synchronous/asynchronous types of social wayfinding would fit. (Dalton, 2019, p.10)

Figure 2.3 Two identical maps showing how misalignment (left) and alignment (right) are produced simply by placement. (Levine, 1984)

Figure 2.4 Screenshots of the "My Visit to the Louvre" application showing the navigation interface and features (2016)

Figure 2.5 Milgram's Mixed Reality continuum (Milgram and Kishino, 1994)

Figure 2.6 Rekimoto's comparison of $\mathrm{HCl}$ styles $(\mathrm{R}=$ real world, $\mathrm{C}=$ computer $)$ (Rekimoto, 1995)

Figure 2.7 Smart augmented reality glasses unit shipments worldwide from 2016 to 2022 (in 1,000s) (Statista, 2019) 
Figure 2.8 Methodology of AR-based wayfinding mechanism and testbed (Kim, 2015)

Figure 2.9 Promotional image for ReBlink. (C) Art Gallery of Ontario (AGO)

Figure 2.10 Image on the AGO website promoting the Anthropocene Exhibition . 50

Figure 3.1 Theory-Practice Process Map of Designing MRsive

Figure 3.2 Top view map of the AGO's main level found on the museum's brochure and website. (a) North direction of the compass points towards the bottom. (b) Main entrance points towards the top

Figure 3.3 Top view map of the AGO's first floor, found on the brochure and website.

(a) North direction of the compass points towards the bottom. (b) Floor entrance points towards the bottom.

Figure 3.4 Different AR displays. (a) Handheld device's display. (b) Video seethrough display. (c) Optical see-through display (Smart eyeglasses)

Figure 3.5 Wayfinding paper prototype. (a) Left: View without AR, (b) Right: View with AR 
Figure 3.6 MRsive system architecture. (Left) Technologies and plugins used as input for wayfinding in grey, and engagement in white. (Right) Technologies and different of AR outputs for wayfinding in grey and engagement in white.

Figure 3.7 3D point cloud and planes representing the scan of the real world. Green arrows and other virtual elements are manually added to the model in Unity.

Figure 3.8 MRsive screenshots by order of user-flow: (a) Language selection. (b) Destination selection. (c) and (d) AR wayfinding directions. (e) Interaction with a 3D artifact. (f) Interaction with a painting.

Figure 4.1 Paths to be followed by participants during the user testing experiment. (a) Welcome desk. (b) Elevators to the upper levels. (c) Elevator to Concourse and Level 2 only

Figure 4.2 Initial icon asking users to scan the surrounding space to detect indoor localization

Figure 4.3 Data visualization of the wayfinding scores answers

Figure 4.4 (a) selection of the destination. (b) Scanning to find localization. (c) AR directions 
MRsive: an Augmented Reality Tool for Enhancing Wayfinding and Engagement With Art in Museums

Figure 4.5 (a) "View with AR" button. (b) Scanning the art. (c) AR interactions . . 87

Figure 4.6 The Storm: Oil painting at the AGO that was AR activated through MRsive and the corresponding description label on the side 89

Figure 4.7 Data visualization of the engagement scores answers 89 


\section{Chapter 1. INTRODUCTION}

\subsection{Motivation}

I was born in Lebanon where I lived for the majority of my life. Lebanon is a beautiful country but unfortunately lacks advanced infrastructure and organized urban planning. For example, the country does not have clear numbered addresses. Like every child growing up in Lebanon, I started learning about directions and how to get from point A to point B using landmark cues. Growing up, "next to the middle school", "close to the big palm tree" and "right before the grocery store" were the common terms I was accustomed to hearing when asking for directions. It was a time before the spread of smartphones and Global Positioning System (GPS). Even the simplest of aids like signs and maps were not frequently used. My sense of direction quickly developed to depend heavily on my eyes, ears, and sometimes even my nose. My sight would help me detect a landmark, while my hearing and smell would help single out cues specific to that landmark or what is close to it. Sometimes, navigating to point B was as difficult as solving a complicated riddle, so those cues required an extra layer of logic and problem-solving. 
The development of the transportation sector throughout the world and in Lebanon requires clearer visual aids and more intuitive directions. The same can be applied when travelling to an unknown destination or a foreign country. During my late teen years, I developed a passion for backpacking around the world, in particular, travelling to remote countries and visiting museums to explore different cultures. As a tourist, directions were crucial for the success of my trip. I was always fascinated when I visited advanced countries where mobile technologies such as "Google Maps" were supported. Such digital and dynamic approaches to navigation provided precise addresses and displayed points of interest which facilitated the life of locals and tourists. Locating oneself on the digital map and visualizing the path to the desired destination saved time, energy and frustration. On the other hand, many of my museum visits - a hobby that became united with my passion for travel - were not always enjoyable experiences. Like many, it was not uncommon for me to find myself lost in indoor complex spaces. For me, finding my way through foreign cities was made possible by the use of digital dynamic maps on my mobile phone. Unfortunately, in indoor spaces such as museums, it is a different story and the experience is never as intuitive as outdoors. GPS does not work for indoor localization as the accuracy level is not reliable enough. Technological limitations make it a difficult and complex task to create an indoor version of "Google Maps". Using static navigation methods such as printed maps and signs, I came to realize that museums require the allocation of at least a day of one's vacation time due to their usually complex architectural layout. The museum experience for me became a dual-edged sword, I enjoyed visiting various 
museums but I was repetitively frustrated with two things; the time I spent inside to decode the space as well as a sense of detachment from the artifacts that were being exhibited.

It was at this point, that I was struck with a question that seemed to have an innovative answer behind it. The reason why I was spending long periods in museums was twofold; I kept getting lost in the nooks and crannies, and any artifact, painting, or relic that was of interest was always hard to find. I was very keen on the idea that museums need to have a more intuitive, digital and dynamic tool like Google Maps to help visitors move more efficiently from point $A$ to point B. On the engagement side, there are several reasons I never felt fully interested in the printed text descriptions or audio guides provided. The printed media was usually long, too detailed and boring, while the audio usually had a monotonous delivery. I also found it extremely frustrating that my position in the museum could not be tracked, which often lead to the information being delivered after or prior to me reaching the artifact. Despite the standard maps and the guided audio tours, no intelligent and interactive technology was available to guide me to where I wanted to go in the museum and help me feel submerged in the presented culture and the exhibited artifacts.

This realization was highlighted during one of my trips to Spain. I went to Madrid on a vacation and visited the Museo Reina Sofia to see Picasso's most famous work "Guernica", I had been eager to lay my eyes on the masterpiece. As anticipated, I got lost. I wandered for hours touring as I wanted to explore the space until I stumble upon the painting. After three hours, the museum was about to close and I had not 
seen the painting yet. I tried my hardest to find it depending on the map provided but I did not understand what the different elements meant nor could I crack the colour codes for the different sections. I had to ask for directions from the person who worked there. The disappointment came when I finally found the masterpiece. I found myself gazing at a big famous painting of many symbols and details with no real understanding. The label on the side including a short description was not helpful, it was too static to trigger any interaction or learning. This was worsened by my frustration with the time it took to locate it. Finally, I was escorted out of the museum as it was closing. This visit was obviously not the ideal museum experience. I later became aware of the fact that I was not alone in this struggle. Each time I shared this story, it was obvious that many people related and shared my frustration. Time wasted combined with no real immersion in a museum were definitely key issues.

\subsection{Research Goals}

I began my research, first by understanding wayfinding and how it has become a popular need in our modern day society. According to SEGD (the Society for Experiential Graphic Design) "Wayfinding can be defined as spatial problem-solving. It is knowing where you are in a building or an environment, knowing where your desired location is, and knowing how to get there from your present location" (SEGD.org, 2019). Many museums are extremely complex spaces, and according to Hughes (2015), this is due to the historic buildings where they are housed. These buildings served different purposes and were extended and adapted over the years to host art galleries. 
Wayfinding is a notoriously difficult challenge to get right and the limited budgets and countless regulations in museums add to the complexity of the task. As times changed and technology advanced, timeliness and effectiveness became of the essence. The need for an interactive guidance and support system that is user-friendly became a must. Any wayfinding system, integrated into museums nowadays needs to be effective or the repercussions can be detrimental. Effectiveness in museums mainly lies in providing a wholesome engaging and rewarding experience. Considerable budgets go into the implementation of any wayfinding system hence the importance of evaluating the design and the usability. When people find the system undependable, they will resort to assistance from staff; which could possibly lead to higher staffing needs. The user experience also plays a crucial role and like any "business", customer satisfaction is paramount. Lost, frustrated, disconnected, confused customers, and for the purpose of this research, museum patrons, tend not to return. Museums such as the Metropolitan Museum of Art, "the MET" which is one of the largest museums in the world, have recently been attempting to enhance their wayfinding methods and increase their visitors' satisfaction. According to the MET's website, wayfinding and the digital experience as a whole was one of their most recent struggles: "Helping visitors navigate The Met Fifth Avenue has long been a challenge at the Museum... We've seen digital as part of a potential solution for some time; the challenge, though, has been to deliver a scalable and sustainable digital map" (Tallon, 2016). The traditional maps and standard signage are no longer sufficient. Adding other multi-sensory elements such as audio guides were a notable attempt to improve visitor navigation 
and engagement with the arts, and I believe that similar attempts should be encouraged. Unfortunately, a gap exists today as most museums shift to digital when attempting to improve their visitors' wayfinding and engagement experience. This gap is due to technological limitations, precisely indoor positioning and tracking which is a hard nut to crack.

After locating the cognitive demands of static wayfinding aids, the main goal of this work is to create and evaluate MRsive, an augmented reality (AR) system that provides the museum visitors with an intuitive and accurate sense of their location indoors and a clear direction to their desired destination. This system would hopefully facilitate the navigation of the space in a timely manner. I believe a fulfilling museum experience is not limited to mere easy navigation, but also requires an engaging interaction with the art. Some exhibitions resorted to augmented reality as an intuitive interaction to augment the physical objects in the galleries (Van Der Vaart, 2016). This technology showed so much potential and it is worth being explored even more. It is also worth studying the connectivity and visual tracking capabilities needed for indoor positioning using augmented reality. The multisensory outputs are also interesting opportunities for creating compelling and engaging museum experiences that encourage learning, fun, and awe. I would like to investigate the effect of an intuitive AR user experience on wayfinding and the effect of the multisensory approach on engagement as an overarching goal. 


\subsection{Research Scope and Audience}

My research is an attempt to fill the gap discussed above and offer the museum visitors a digital solution that enhances wayfinding and engagement with the arts. Wayfinding is a broad concept. Sometimes it is visible, like signs in outdoor and indoor spaces. Other times, it is invisible as when exploring a space for pleasure or following a path in nature. In theory, the technology brought forth in this research can be applied to any indoor space. To list a few, it can be useful for employees at their workplace, students at their educational facilities, and for travellers at airports, amongst others. However, as a scope of wayfinding, and due to my experience with museums, I use the galleries space as the main focus of this work and situate my research at the Art Gallery of Ontario (AGO) in Toronto.

It is important to note that the community of museum visitors is a diverse one. Tourists, first-time visitors, and members, all differ in backgrounds and in the main purpose of their museum visit. Commonly, museum visitors consist mainly of first-time visitors or tourists, who are there to explore or see a particular piece of art. The remaining visitors are art fanatics who usually are museum members and repeat visitors. These people display slight differences in why they visit a museum and what kind of experience they are hoping to achieve during their visit. Nonetheless, they obviously all share one desire which is an ultimate event, a fulfilling, informative, and pleasurable experience. For the sake of this research, I am targeting all museum visitors and I focus on first-time visitors and "Generation $Y$ " that are explorers in nature as a 
target audience. These types of visitors are known for their search for novel experiences and multisensory interactions that they can share with their peers (Falk, 2016). Many of the target audience are tourists so language definitely plays a crucial role in the application. The challenge is not only due to the directions being in a foreign language, but also the audio-visual cues that serve to explain the exhibited artifacts. To add to the point, the static museum's signage system and map most likely lack the appropriate language translation. To address this, the MRsive application provides the experience in the language that the end user chooses.

Space and audience are both taken into consideration and the related concerns are addressed through MRsive. Augmented Reality is broadly defined as "augmenting natural feedback to the operator with simulated cues" (Milgram, 1994). Milgram explains that $A R$ is related to a larger class of technologies which are referred to as "Mixed Reality" (MR). MR is defined as an environment in which real world and virtual world objects are presented together within a single display. Through these technologies, MRsive allows the visitor to locate any artifact or section of interest in the museum and intuitively navigate to it. Upon arriving at the desired location, the application augments the artifact through virtual elements and multisensory information and allows the visitor to interact with it. The displayed digital elements can be interesting quotes, photos, short clips, 2D animations, 3D movie-like experiences accompanied by sound and haptic response. This would bring life to a rather static item that hangs or stands in that space. 
The application is used on a mobile phone but ideally would be integrated into a smart glass. Unfortunately, Head-mounted AR technology and the few supporting devices that are currently available in the market are still under development and have not matured yet to be mainstream or mass adopted. This adds an element of difficulty when developing content for a wearable like smart glasses, especially when the hardware is not yet ready. Currently, the most advanced AR smart glasses or see-through head-mounted-displays such as "Hololens" by Microsoft and "Magic Leap" are very expensive and mostly available for corporate organizations and developers only. They are also chunky and have a limited field of view (FOV) that does not surpass the $43^{\circ}$ horizontal opposed to the human visual system that has a binocular FOV exceeding $180^{\circ}$ horizontally. This restricted FOV limits the immersive potential of mixed-reality systems and reduces the situational awareness of the person (Xiao, 2016). In order to simulate the ultimate smart glasses experience, and to add to the contributions of this research, MRsive is built on a mobile device and offers the potential to be implemented on a DIY head mounted display discussed in details in the future work section of the last chapter.

\subsection{Research Contributions}

This thesis makes different contributions to the research of indoor wayfinding and the study of the digital museum experience and visitor engagement: 
It first provides a preliminary scan of a broad set of literature combining three different fields: psychology, cognitive science, and computer science. The discussion dives into the science of wayfinding, the cognitive demands of different wayfinding aids, museum visitors types and evaluates different augmented reality approaches in museums.

It contributes with a detailed system architecture design of a novel augmented reality application, MRsive. The application uses computer vision and different sensors to support visual tracking as a solution for indoor positioning and wayfinding, as well as multisensory interaction with arts in museums. Technical diagrams and sample code are provided (see Appendix C). The process and the user-centred design approach to building the system are explained in detail.

The research provides a preliminary evaluation of the AGO (Art Gallery of Ontario) visitors' wayfinding needs and what kind of museum experiences they are interested in.

It also unpacks the benefits of markerless AR and the positive impact of perspective-display of digital objects on accuracy, intuition and speed of wayfinding task completion. It also confirms the influence of AR multisensory interactions on engagement and satisfaction of museum visitors by conducting user testing of MRsive at the AGO.

It highlights a new outlook and opportunities for museums to look into when building audiences and thinking of new channels to generate revenue). 
Finally, it presents the different potentials of the created design for future work. It sheds the light on opportunities for future researchers to take this system from mobile-based to head-mounted based AR and evaluate the positioning of digital elements within the line of sight (LOS) of the user and the use of body and hand gestures as input.

\subsection{Chapter Overview}

This chapter introduced the MRsive project and thesis and the inspiration behind it as well as the research goals and contribution.

Chapter 2 begins with a literature review that addresses several important points. It starts by presenting the theoretical concept of wayfinding as a general overview. It then narrows the focus to museums, specifically through discussing wayfinding methods as well as approaches to enhance visitor engagement with exhibited artifacts. The discussion ties those approaches to augmented reality (AR) which is defined and then illustrated through a scan of related projects in museums. I finally summarize the chapter by emphasizing the opportunities and the potentially positive impact of $A R$ on wayfinding and visitor engagement experiences.

Chapter 3 discusses the adopted methodology to create MRsive. It addresses the human-centered design approach and the different stages of the process. It starts with the museum visitor need finding which was the main driver of the initial design decisions and then expands on the development stage. The discussion illustrates the 
MRsive: an Augmented Reality Tool for Enhancing Wayfinding and Engagement With Art in Museums

system architecture in details and presents the technology involved. Finally, a clear explanation of the evaluation criteria concludes this chapter.

Chapter 4 of this work presents all the evaluation methods and related findings that were generated from the user testing. The results are analyzed and discussed to highlight the successes and limitations of the design.

Finally, chapter 5 concludes this thesis by revisiting its goals and contributions. The discussion finally highlights the future work and design iterations vis-a-vis the findings of the previous chapter as well as potential futuristic technological advancement. 


\section{Chapter 2. LITERATURE REVIEW}

The intersection of wayfinding and engagement behaviours in museums with technological solutions is a complex concept where research about human cognition and museum visitor research come into play. In this chapter, I give an overview of the related literature to my research and present related works and projects that are under development. First, I introduce the concept of wayfinding through the different definitions that appeared in literature as well as the latest taxonomies of wayfinding tasks. I highlight the common wayfinding issues related to static conventional approaches such as printed maps and signs and the related cognitive processes that often cause visitors a spatial frustration in indoor spaces in general and specifically museums. I also point out the usual obstacles that limit museum visitors' engagement with exhibits through a quick scan of the current digital approaches. Then, I provide a snapshot of the current use cases and research in the field of augmented reality (AR) and indoor localization of users. Lastly, I discuss the potential opportunities offered by digital media and interactive tools such as augmented reality, specifically for enhancing wayfinding and visitor engagement with arts in museum environments. Through this theoretical overview, I present some projects as examples for different use cases of AR 
that enhance navigation and engagement with artifacts in galleries. To differentiate my project from the currently existing literature and technological solutions, I revisit the mentioned research projects in the following chapters of this thesis.

\subsection{Theoretical Concept and Taxonomy of Wayfinding Tasks}

In this section, I present the main definitions of wayfinding, the different types of wayfinding tasks, and finally the required cognitive processes to navigate spaces especially in indoor spaces such as museums.

\subsubsection{Definition}

Finding one's way is a daily ubiquitous need (going from home to work or school) and it was thoroughly studied and discussed in the research literature over the past 60 years. Many authors tried to define the word "wayfinding" and numerous classifications of human navigation behaviour have been proposed. Allen (1999) defines it as "purposeful movement to a specific destination that is distal and, thus, cannot be perceived directly by the traveller" and he bases this definition on previous mentions of the word by Baker (1981), Blades (1991), Gärling (1984); Gluck (1991), Colledge (1992) and Heft (1983). Not too different from this definition, Colledge (1999) refers to wayfinding as "the process of determining and following a path or route between an origin and destination". Montello (2005) defines it as "the planning required for efficient and 
goal-directed navigation". For Emo (2012), it is the "decision-making process stage of navigation, where navigation is composed of locomotion and wayfinding". After all these definitions, it seems obvious that wayfinding is, in other words, a purposive behaviour through decision-making to navigate an environment from point $A$ to point $B$. This behaviour is highly dependent on the types of wayfinding tasks, better explained in the following subsection.

\subsubsection{Types of Wayfinding Tasks}

Allen (1999) identifies the most typical wayfinding tasks: exploratory navigation (i.e. walk in nature), travel to a familiar destination (i.e. going to work), and travel to novel destinations (i.e. moving to a new neighbourhood). Two years later, Montello (2001) defines the three wayfinding tasks: search (i.e looking for a specific gate in an airport), exploration (i.e. wandering in an unknown city), and route planning (i.e. hike in a natural reserve). Wiener, Büchner, \& Hölscher's article "Towards a Taxonomy of Wayfinding Tasks: A Knowledge-Based Approach" (2009) extends earlier accounts (Mallot, 1999; Allen, 1999; and Montello, 2001). Those previous taxonomies only identified two main high-level navigation tasks: locomotion and wayfinding. The article proposes a novel taxonomy that distinguishes wayfinding tasks by external constraints as well as by the level of spatial knowledge that is available to the navigator (Fig 2.1). 


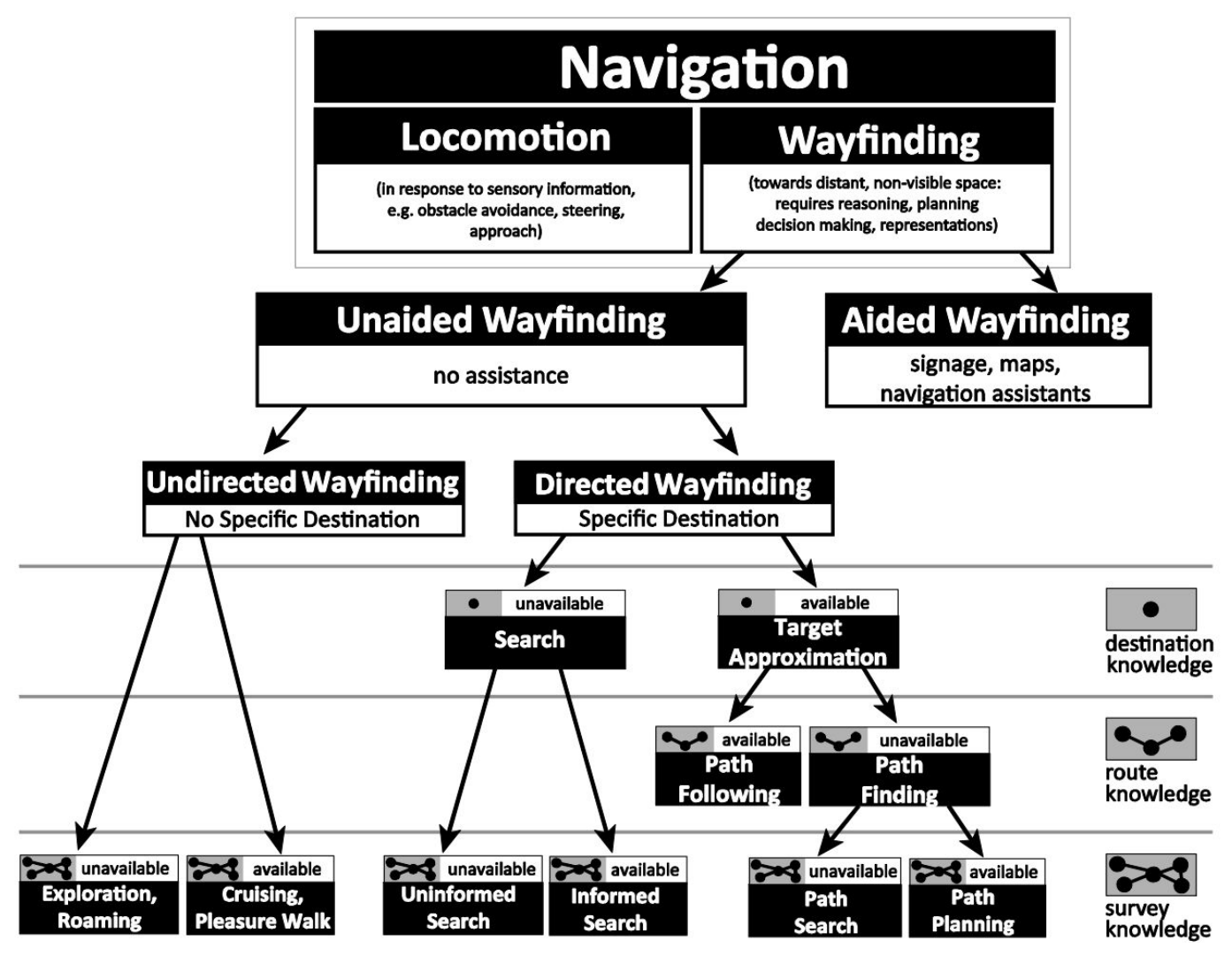

Figure 2.1: Proposed Taxonomy of wayfinding tasks (Wiener, 2009, p.6)

As seen in Figure 2.1, the different tasks and skills that come into play in wayfinding can be divided between aided and unaided navigation, in other words, with and without the help of external media such as signage, maps and navigation assistants. On the unaided side, the chart shows the comparison between directed and undirected wayfinding which is the difference between when a user has a specific destination or just exploring a certain space for fun. Directed wayfinding refers to the navigation process to approach one or multiple destinations. The search itself is also divided into two types: informed when the navigator is knowledgeable about the environment and uninformed 
search when this environment is unknown. I am situating my research in a museum and targeting first-time visitors who intend to optimize their museum visit by enriching their experience and education within the limited time they have. Wiener discusses: "navigation is not performed without intention..." and, for the sake of this thesis, I focus on wayfinding that is typically directed and aided by external wayfinding tools. Unfortunately, the aided wayfinding section in Wiener's taxonomy was not fully developed. It is likely because Wiener considers it to be rather simple in some cases like in the event of following a trail. He mentions Raubal (2001) who speaks to the same idea saying: "sign-following does not require considerable cognitive effort". I suggest that static wayfinding aids such as signs could sometimes be in fact very confusing in complex indoor spaces and I will expand on that more in the second section of this chapter. Wiener et al. reason that the cognitive demands of aided wayfinding differ dramatically from unaided wayfinding and it would be valuable to develop a related analysis.

Ten years later, Dalton, Hölscher and Montello (2019) proposed some extensions to Wiener's taxonomy, especially to the aided wayfinding section (Fig. 2.2). 

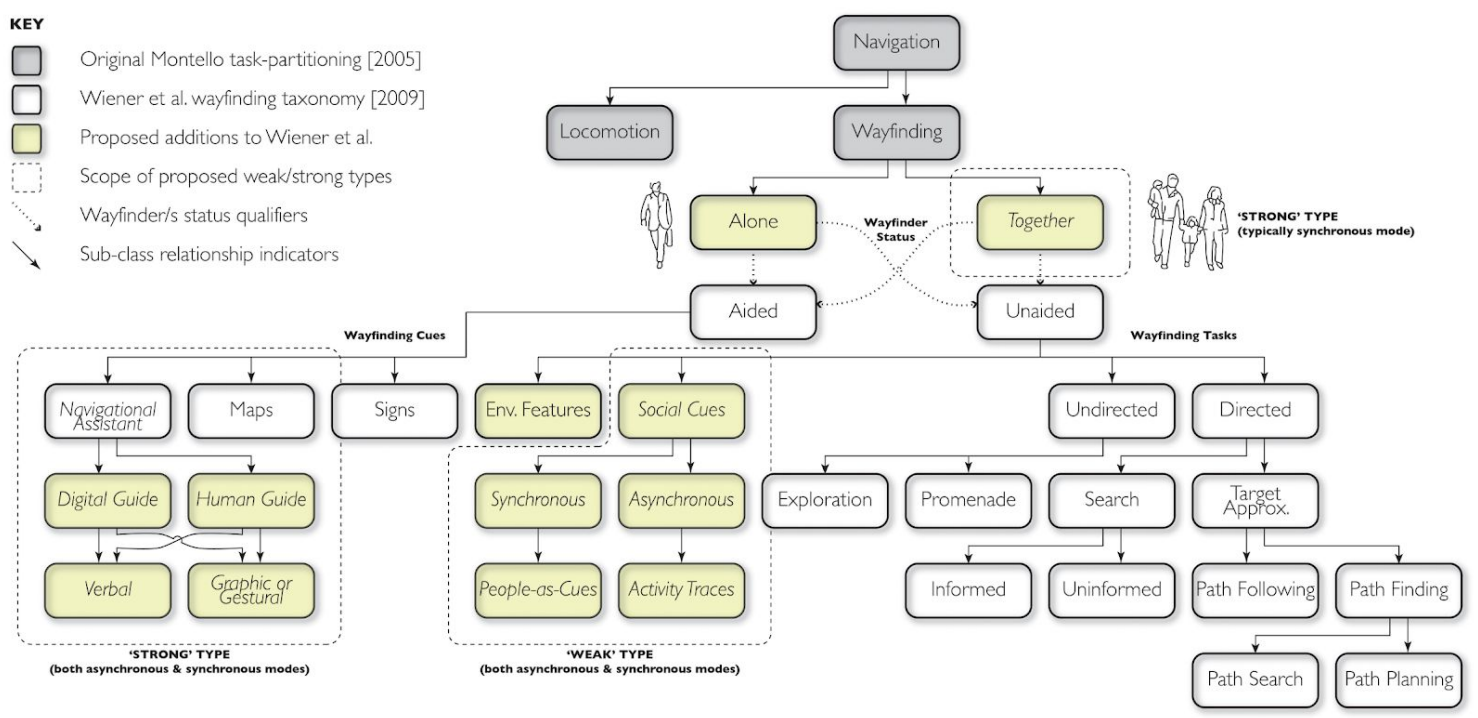

Figure 2.2: Proposed additions to Wiener et al. (2009) wayfinding taxonomy indicating where the strong/weak and synchronous/asynchronous types of social wayfinding would fit.

(Dalton, 2019, p.10)

While this new taxonomy takes the social activity of wayfinding into consideration, this social aspect is out of the scope of this research. In this thesis, I mainly focus on the added extension which is related to the aided wayfinding. Next to signs and maps, navigational assistants are now differentiated between digital guides and human guides that produce verbal, graphic or gestural cues. I propose the addition of haptic cues that could be valuable for visually impaired individuals. Task characteristics of aided wayfinding approaches differ dramatically from those of unaided wayfinding: "Taken together, decision-making processes, memory processes, learning processes, and planning processes that are necessary to successfully solve unaided wayfinding tasks have been externalized in aided wayfinding" (Wiener, 2009 , p.6). While we can agree that the cognitive demands of aided wayfinding 
are fundamentally different from those of unaided wayfinding, Wiener reassures that in an extreme case of great signage design "sign following can be reduced to a locomotion task". I agree with the latter, but I argue that in complex museums this might not be attainable. With the individual differences of visitors and the complexity of the space, current wayfinding aids would still require a considerable spatial reasoning and different cognitive processes are needed to complete a wayfinding task depending on those visual aids. These approaches and their related cognitive processes are better explained in the following section.

\subsection{Wayfinding Approaches and Related Cognitive Processes}

The study of wayfinding has been attracting interest since the late 1940s.

Different researchers from different fields such as psychology, geography, and urban design have been trying to unpack the cognitive processes that go into wayfinding decisions. According to SEGD, (the Society for Experiential Graphic Design) wayfinding system refers to the tools and methods used to facilitate this decision-making such as maps, direction signs, navigational assistants, and symbols to help guide people to their destinations. Maps, signage, photographs, videotape, verbal directions, and recently virtual environments are many approaches that have been used for spatial knowledge achievement (Shamsuddin, 2015). Using those wayfinding tools 
encompasses different complex tasks that involve different cognitive processes (Wiener, 2009).

In the case of museums, Hughes (2015) highlights the fact that many are hosted in historic buildings that were renovated and adapted over the years, which makes their layout complex and hard to navigate. The structure of the Art Gallery of Ontario (AGO) for example, where the research of this thesis takes place, has undergone six previous expansions since the 1920s. Most museums today, the AGO included, rely on maps and signs and in some cases digital applications to facilitate this navigation. The wayfinding challenge gets intricate and difficult to manage due to the limited budgets and the endless list of museum rules and regulations.

In the following subsections, I discuss the current static and digital approaches for enhancing wayfinding in museums and I highlight the cognitive demands that go into using them. I try to assess the advantages and shortcomings of those approaches to better locate new opportunities and develop more appropriate digital solutions.

\subsubsection{Maps}

The most common approach to indoor navigation is using maps. Today, most museums mainly rely on printed maps incorporated in their brochures as a primary tool for guiding their visitors around the different galleries and floors. Nevertheless, the simplest of maps remain a static approach in the face of a constantly changing input which is the position of the navigator. They require 
cognitive effort and spatial reasoning. Decoding maps is not always intuitive and easy to accomplish. Previous research (Passini, 1992) proved that wayfinding in a complex environment such as museums often causes first-time visitors and occasionally frequent visitors uncertainty and stress or spatial anxiety, even with the assistance of wayfinding aids. Maps and other static visual cues are frequently confusing and not presented in an appropriate position or logical sequence as they "have no dynamics and lack of interactive properties compared to electronic map devices" (Shamsuddin, 2015).

Different cognitive processes are crucial to using maps, namely object rotation, symbol identification, and map/environment interaction to establish a match between the allocentric view provided by the map (usually birds-eye-view) and the ego-centric view (perspective angle) that is experienced while moving through the environment (Lobben, 2004). Printed maps use an allocentric spatial representation (mainly two-dimensional) that involves an object-to-object system and encodes information about the location of one object with respect to other objects. On the other hand, our human eye uses an egocentric view in perspective (three-dimensional) that involves a self-object representational system.

Object Rotation: Most paper maps are not multi-oriented, meaning that one map maintains only one direction toward the top, usually north. Mentally rotating a two-dimensional object appears to be an integral process associated with reading those paper maps and it is proven that this process gets more 
complicated in complex spaces and affects the speed and accuracy of navigation (Levine, 1984). In some cases, a wrong rotation or placement of a map could cause a misalignment of the map with the real space. For example, the position of the "toys" region in the physical world in Fig. 2.3 does not align with the map's representation when placed on the left.

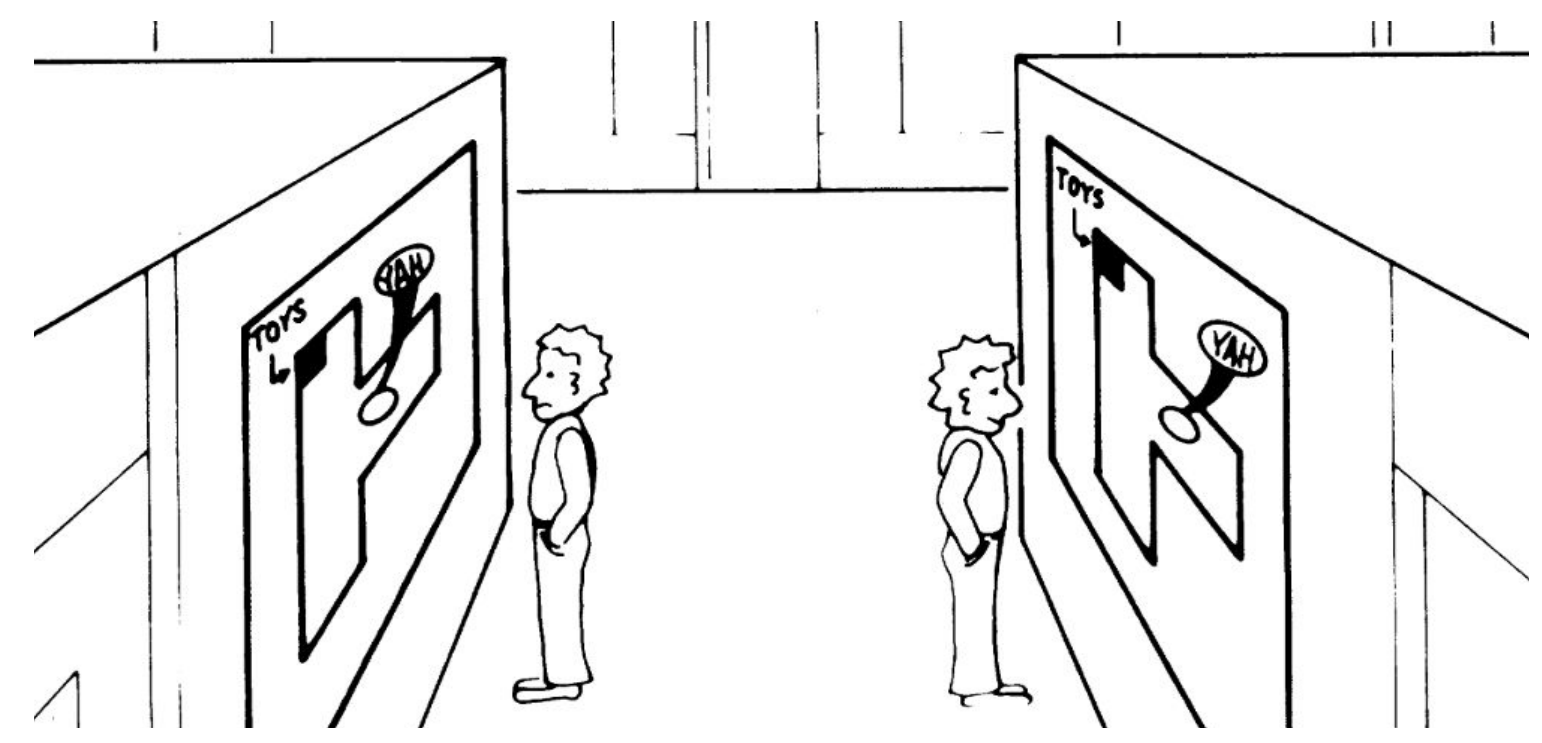

Figure 2.3: Two identical maps showing how misalignment (left) and alignment(right) are produced simply by placement. (Levine, 1984)

Symbol identification: Maps are scaled representation of the real world, therefore they contain symbols that represent real three-dimensional environmental objects (Robinson, 1995) and (Bluestein, 1979). Symbol identification is another cognitive process that is faced every time a person reads a map. Studies have shown that the complexity of the map affects the amount and accuracy of encoding of symbols and information into the spatial memory system (Winn, 1989). 
Map/environment interaction: Allen (2004) explains that the map reader needs to interact and relate the map and the environment with and between one another. He identifies two main processes: visualization and self-location that govern this interaction. Both Processes require the reader to continuously work between the two-dimensional map and the three-dimensional world while navigating the space.

Based off of the notions of these cognitive processes, a person visiting a museum for the first time and using a printed map to successfully navigate the space would need to answer the following questions: where am I on this map? What direction am I facing? Where do I want to go and what is the path that I need to follow to get there? Things get more complicated with the complexity of the indoor space and when using the map while navigating and moving around the museum (Shamsuddin, 2015).

The You-Are-Here maps try to answer the "where am I " question but none of the other questions. By moving from a static to a dynamic approach, not only the self-localization question is answered but also the live rotation or direction of the navigator. Similar to outdoor GPS operated city maps such as "Google maps", I suggest a similar dynamic approach for the indoor space. Providing this solution could offer the visitor in-situ information about where they are in the building and what direction they are looking at, and would supposedly require less cognitive effort. However, In enclosed places such as museums, GPS satellite signals become significantly weak and inaccurate, 
making this approach not suitable for indoor positioning and navigation (Alnabhan, 2014). There are other ways around this technical problem, and even though they differ in accuracy, they make it possible to locate users indoors. I revisit this idea in a later section and discuss its technological limitations and potential development.

\subsubsection{Signage}

Another conventional wayfinding tool is signage which is a map's best friend. Signs are static also and they are prominently used in so many fields, but are they enough for indoor wayfinding? Raubal (2001) states that aids like signs don't require a lot of cognitive effort and the agent has to only identify the meaning of the signs and follow the directions: "In sign-following the path planning has already been done by the designer and as long as signs are put up reliably at every decision point the agent faces very little efforts of spatial reasoning. In the extreme case, sign following can be reduced to a locomotion task." From a designer point of view, this is very difficult and sometimes impossible to accomplish. Despite the serious attempts of intuitive design, static aids and specifically signs remain at many occasions difficult to read in complex indoor spaces. Other researchers such as Passini (1992) consider signs to be frequently confusing if not presented in appropriate positions or a logical sequence. Without any logic, signage implementation is reduced to a random placement of physical objects, or worse, a series of visual pollutants. This is a 
common outcome when signs are an afterthought to the architectural project, making it a real challenge for museums that are hosted in repurposed buildings. Furthermore, signage is supported by text, graphics, pictograms, colours and shapes. Other than identifying the locations of signs, people experience difficulty understanding pictures and terminologies written on them (especially when they speak a foreign language) (Kim, 2015).

Thus, three significant factors challenge the cognitive processes needed to decode and follow signs: (1) accessibility (i.e. the placement of signs in the space), (2) identifiability (i.e. the clarity of signs and room numbers from distance), and (3) comprehensivity (i.e. level of complexity of terminology, pictograms and arrows pointing signs) (Kim, 2015). These aids are sometimes missing in vital sections along a route and it is often overly time-consuming to interpret them (Passini, 1992). In the event a navigator loses their path and depending on the complexity of the space, it could be challenging to find and read signs to go back to the right path, especially amid navigation and moving around. In her article, Hughes (2015), clarifies the misconception about wayfinding and signs: "Wayfinding does not equal signage" (p.2). She suggests that the combination of signage, maps, guides, digital applications, intuitive design and pre-acquired knowledge would be the best way of orienting visitors. 


\subsubsection{Digital Navigational Assistants}

With the digitization and democratization of museums, many digital solutions such as mobile applications were recently integrated to orient visitors indoors and facilitate the museum experience as a whole. Digital navigational assistants offer dynamic algorithms and interactive elements (Yokoi, 2015). This is crucial to the nature of the dialogue between a constantly changing input and the multiple possible outputs. The searched spatial directions directly depend on the position of the visitor in space and the path leading to the desired destination. The navigation in a museum highly depends on the space and the placement of exhibits. The goal is to solve the museum visitors' wayfinding problems, outlined by Nicholas (2000):

1- Getting lost

2- Not knowing what is available

3- Not being able to plan the visit effectively

4- Misunderstanding the nature of an exhibition.

In the last decades, various malls and airports implemented different digital approaches. They installed stationary interactive touch screens or kiosks that offer the visitor a simulation of the path they need to follow to get to their destination. The simulation was often a 3D animated representation of that journey. Before smartphones became so ubiquitous, some museums adopted a similar digital approach to wayfinding, i.e. the science museum in London in 
1998. A network of touch-screen information points was located strategically in what was identified as key decision-making points throughout the science museum, i.e. elevators and stairs on all floors. In an evaluation conducted after the installation, all users had a generally positive attitude about how the system worked: each point displays a screen through which visitors can access an interactive software system designed to enable them to orient themselves. The goal of the technology was to enable information to be more timely, accurate, accessible and informative, to ensure that each visitor can get the most out of their visit. "Visitors can find out up-to-the-minute information on exhibitions, events and facilities as well as see sections and plans showing their route to desired destinations ensuring them to not get lost but instead are able to decide what they want to see, pace themselves and savour the viewing" (Nicholas, 2000).

Mobile applications have started being introduced to the visitor experience in museums since 2009 (Economou, 2011). The advantages and capacities of the mobile phone as a device that rapidly gained ubiquity and popularity, were exploited. This development presented new possibilities of communications between the museum and the visitor or the visitor and the museum space. Even though technological limitations were in the way at first, novel digital tools for rewarding wayfinding solutions started to be developed and as the capabilities of the mobile phone got more powerful, wayfinding 
mobile apps became more and more present such as the "My Visit" application on iOS and Android for The Louvre Museum in Paris, France (Fig. 2.4).
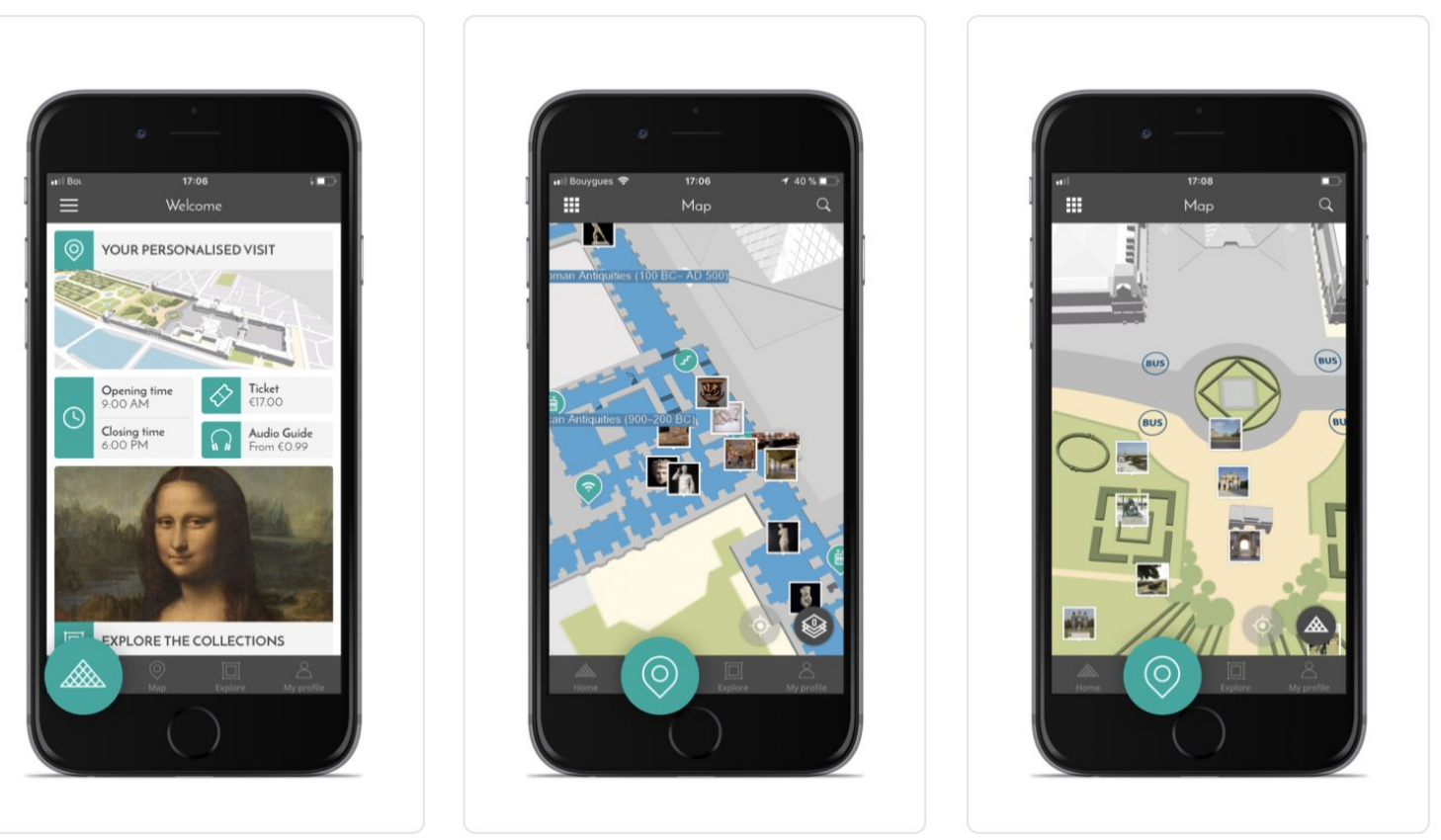

Figure 2.4: Screenshots of the "My Visit to the Louvre" application showing the navigation interface and features (2016). Retrieved from https://itunes.apple.com/ca/app/my-visit-to-the-louvre/id1100629786?mt=8

One of the biggest limitations was the indoor localization of the visitor. Outdoor applications did not face such a challenge as they can use GPS. These application types are perfect to guide the user outdoors by revealing the directions and distance between the user and their destination. In enclosed places such as buildings, airports, and markets, however, GPS satellite signals become weak or non-existent; therefore, GPS is not suitable for indoor positioning and navigation (Alnabhan, 2014). 64 museum mobile applications from around the world were evaluated in 2011 in the survey "Promising beginnings? Evaluating museum mobile phone apps"; 54 applications out of 64 
fell under the guided tours type. What is interesting about those 54 applications is that the navigation they used was following the spatial layout of the exhibits or their chronological or alphabetical order which doesn't take the indoor position of the visitor into consideration (Economou, 2011). We seem to still be on the look for the best way to build the "Google Maps" of the indoor spaces. According to Roussou (2018), the reason is that user's indoor location has to be accurate enough for the tool to be helpful. Suggested technologies such as Wi-Fi fingerprinting or Bluetooth beacons do not seem to offer a sufficient level of accuracy, "Location awareness in cultural settings remains an open issue for museum mobile applications, particularly in the case of indoor settings, in which automatic solutions are not mature enough to support accuracy of less than a 2-3 m range"(p.4). Alnabhan (2014) elaborates on that from the technological side: "these system types need to implement complex and accurate calculations to determine routing paths before navigation starts - which could be affected by unstable Wi-Fi signals" (p.1).

If indoor localization can be digitally solved, a dynamic digital map could then be considerably useful. Adding the user's indoor position and rotation to a map would obviously decrease the cognitive load that conventional printed maps normally require. The focus of these computational models lies primarily in the creation and exploration of the cognitive map (Raubal, 2001). An interesting computational approach was by $\mathrm{O}^{\prime} \mathrm{Neill}$ who created an artificial neural network of choice points and connecting paths from a textual list of places. A search for a 
route starts by stimulating the start and goal nodes. The activity propagates from these two nodes through the network until it intersects creating the shortest and fastest route (Raubal, 2001). This route is what navigators try to mentally draw and imagine on the printed maps.

What about the cognitive demands generated by static and conventional signs? Augmented reality (which is the technology that superimposes computer-generated objects over a real scene that is captured in real-time) is another digital solution that could provide the user with virtual signs that can be displayed whenever needed, wherever needed, and in the preferred language of the user. A similar approach might then reduce the related cognitive processes. Signs would be accessible on the requested path, identifiable when they appear on the visitor's eye level, and understandable in the chosen language. The computer-generated elements can be 2D or 3D graphics, text, audio or video that augment and integrate with the physical world to reveal useful information to the user (Alnabhan, 2014).

Hence, the information provided by a digital approach might have the best impact on wayfinding speed and accuracy. It is dynamic and interchangeable and offers the opportunity to be available in different languages, an idea that I revisit through the development of my prototype. To develop an improved wayfinding solution, especially an augmented reality application, the next thing to look at is how to solve the accuracy problem of indoor positioning. I believe the latter to be crucial for an intuitive wayfinding 
experience. In the next section, I discuss the motives and expectations of visitors facing the digital approaches adopted by museums.

\subsection{Visitor Engagement Approaches in Museums}

How do museums build their audience and what are the digital approaches that they follow to engage their visitors every time? What are the strategies that most museums have been following to enhance the experience and interaction of their visitors with the artifacts exhibited in their space? In this section, I discuss the research that identifies the different types of museum visitors based on their interests and needs. I also present projects and examples that illustrate current digital approaches for encouraging visitor engagement.

\subsubsection{Types of Museum Visitors}

Museum management priorities have been subject to a significant shift in recent years (Falk, 2016). Museums have responded to the intense financial pressure by seeking ways to broaden their visitor appeal and attract a more diverse audience through enhancing their visitor engagement and encouraging a balanced use of resources (Barron, 2017). Knowing the museum audience's needs became the focus of many researchers. Falk (2009) identifies five identity types for museum visitors based on individuals roles that they play at certain times during a museum visit. These types are: 
1- The explorer: the typical museum visitor who likes to experience and learn something new.

2- The experience seeker: the tourist who wants to see an iconic place or item, in order to check it off a personal passport of "been there, done that".

3- The facilitator: the person who is at the museum for the benefit of another person's experience, such as a mother with a child or a local resident with visitors from out of town.

4- The professional/ hobbyist: someone who has great knowledge of a topic and wants to see what the museum has or knows, or if the museum would like to learn from him.

5- The recharger: someone seeking a place of beauty or quiet or inspiration to refresh personal life, often in a relaxing manner and generally not linked to information gain.

Those roles are affected by their interests and their visit's objectives. A person may demonstrate one interest or another at different times and to some degree, everyone plays out the different roles through time, depending on a variety of factors. To better engage as many visitors as possible, Falk recommends applying different strategies to satisfy each of the different types in exhibits marketing, advertising, programming and evaluations. It is crucial to consider the differences between those five types to engage diverse audiences such as museum visitors. 
Audience's interests are also affected by age and generation. There has been recent interest from museums to target Generation $Y$ or 'Gen $Y$ ' by creating activities specifically developed for this group of visitors (Barron, 2017). Gen Y (1982-2002) are frequently described as the 'hero' and 'net generation'. They are good at learning new things and are technologically advanced. Many of them are even living a completely immersive online existence (Nusair, 2011). Museums are focusing on visitors from this age group as a means of evolving and extending their brand identities. Gen $\mathrm{Y}$ is identified with very different characteristics from preceding generations like the Baby Boomers and Generation X with respect to their particular mindset, attitudes, behaviours and beliefs. Gen Y appreciates instant gratification and possesses a corresponding short attention span (Leask, 2013). In research about Gen Y's behaviour when visiting museums, It was found that this group prefers to interact with exhibits as opposed to being passive participants in the experience (Moscardo, 2010). Subsequently, digital and interactive approaches in museum engagement and involvement with the arts seem to be the answer to this visitors group's needs and interests.

\subsubsection{Digital Approaches}

Van Der Vaart's study (2016) suggests that text labels are often not thought to be attractive interpretation tools, and most visitors have more 
interest in interacting with 3D objects. On museum management and curatorship, Barron (2017) encourages museums to engage Gen Y visitors through an interactive digital approach as this generation is known by the close relationship with technology. He recommends the combination of large exhibits, an element of technology, some interaction, and opportunities for co-creation as a guiding principle when developing methods of engaging this audience. Therefore, museums might wish to consider the provision of activities to encourage exploration of different exhibits and galleries, perhaps through the provision of planned 'selfie-spots' or self-curated interactive tours. Furthermore The visitors' extensive use of digital communications pre-, during and post-event could be used further to develop recommendations to friends and family and encourage the intention to revisit and develop an ongoing relationship with the museum.

Mobile applications are one of the most personable digital approaches that museums started adopting since 2009. Economou (2011), evaluates 64 museum mobile apps based on their content. A few of those apps were game based, a couple allowed content manipulation and few others were devoted to a single artwork. The goal of all these apps is to extend the museum experience beyond the museum walls. Another more recent study "Quel est le rôle de I'application mobile dans la valorisation de l'expérience muséale?" in 2017 confirmed that participants especially the young ones who are used to smartphones were in favour of the museum mobile apps. They highlighted the 
positive features into 4 different values:

1- Recreational, such as accessing a dematerialized truth through the use of augmented reality for example.

2- Educational, such as researching complementary information about an artifact.

3- Social, such as sharing information and experience with friends.

4- Personalization and appropriation, by living a unique and personalized experience. (Ben Asr, 2017).

Digital solutions can also open the door for new audiences based on a field study about the attitudes and behaviours of Canadian cultural consumers (Culture Track: Canada, 2018). The report showed that visible minorities are more likely to identify with a digital or virtual component that fits with their cultural experience, suggesting digital can be used as an even broader tool to facilitate engagement for diverse audiences. The new technologies in the mobile phone provide the potential to enhance museum communications within the gallery space and with the visitors, but that is not always easy to accomplish. Roussou (2018) states: "The dominance of the device with regards to the user's attention and the challenge to balance the visitors' attention between handheld devices and the exhibition space is a known and fairly well-explored issue" (p.3). Roussou's study in the Acropolis Museum in Greece extracted interesting insights. The findings of the interactive digital experience through personalized mobile apps usage outlined the positives and drawbacks of the design. Among 
the main positive comments: The increase of learning and attention, the source of motivation and inspiration to try new ways to interact with the art, $2 \mathrm{D}$ and $3 \mathrm{D}$ images helped visitors better approach the work and better connect to it in a new and intriguing way even for visitors who have been in this same museum before. On the other hand, some shortcomings were also clearly defined: things were fragmented for example, static, too much looking at the screen, confusion on how and when to use the screen, and limitation of the social interaction due to the distraction exerted by the handheld device. Based on those takeaways one can sum up some of the design guidelines for digital approaches:

1- Use the immersive and engagement power of fiction to spark visitors' interest in the facts without overflowing the visitor with information.

2- Keep story sections short, provide a "story progress bar", and inform visitors whether the content is related or not to the exhibit.

3- Give the visitor (the illusion of) control, as museum visitors are increasingly demanding a digital agency and expecting instant gratification.

As discussed above, digital approaches generally aim to enhance visitors' understanding, and engagement with a museum's exhibits, but visitors often find themselves in a position where they have to choose whether to focus their attention on the digital offer, or the physical object itself. Augmented Reality $(A R)$ is one digital approach that allows the close combination of object and information together, as it augments physical objects or exhibits with additional digital content (Van Der Vaart, 2016). After their study, Van Der Vaart concludes 
that the most positive museum experience seems to combine physical and digital interaction with the object itself and engagement with information that provide visitors with a fuller understanding of the object.

In the following section, I discuss Augmented Reality and its uses for indoor wayfinding as well as for interaction and engagement with arts and exhibits in museums. This will be the final segway toward creating my proposed digital solution.

\subsection{Augmented Reality (AR) Platforms}

As discussed in the previous section, digital solutions in museums could distract the visitor from the surrounding physical world. Since the 1960s, computer input has been tangible and physical (e.g. mouse, keyboard, screen, etc.). When a computer interface is visible, it creates a gap between the real world and the digital information. This gap could hold back the intuitive interaction of the museum visitor with the real world and the physical objects existent within it. Although the technology itself is not new, Augmented Reality (AR) has recently become more popular and has been seeing a lot of improvement from hardware as well as software standpoints. The overarching goal of $A R$ is to make computer input and interfaces invisible and enhance user interaction with the real world (Billinghurst, 2017). Following this logic, digital navigation directions, as well as informative interactions with art in museums, could then be made more intuitive using augmented reality. In this section, I introduce the 
technology of Augmented Reality (AR) and its current application and potential in the field of indoor navigation as well as engagement with arts in museums.

\subsubsection{Introduction}

Ron Azuma (1997) defines Augmented Reality as a technology that has three key requirements:

- It combines real and virtual content

- It is interactive in real time

- It is registered in 3D

Azuma's definition seems to be the most commonly accepted among researchers, but not many references mention augmented reality or try to define it without comparing it to virtual reality. Augmented Reality researchers constantly base their definition on Milgram's mixed reality continuum which is a one-dimensional spectrum from real environment to virtual environment (Fig. 2.5).

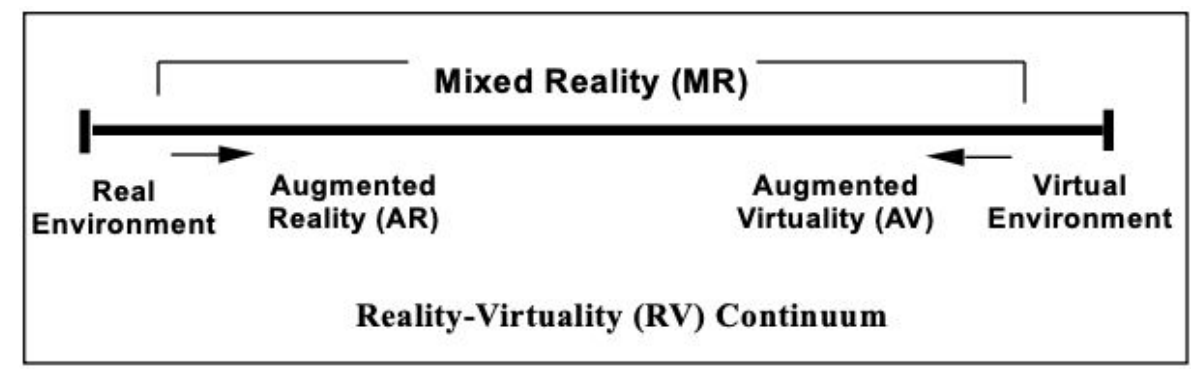

Figure 2.5: Milgram's Mixed Reality continuum (Milgram and Kishino, 1994)

While the relation of augmented reality to virtual reality is understandable from a technical and semantic point of view, I debate that each of their 
applications in the world is extremely distinct which means the implications and design requirements of the user interface and user experience are also distinct and need to be studied separately and without comparison. In a VR system the user is completely separated from the real world (Billinghurst, 2017), while augmented reality is registered in $3 D$ in the real space (Azuma, 1997). So in a physical and real world wayfinding setting, virtual reality cannot relate and highly differs from augmented reality due to the locomotion of the user in the physical space and the constantly changing viewpoint. Billinghurst's (2017) comparison shows that In a VR system the display device should be fully immersive and the 3D graphics as realistic as possible. In contrast, in an AR system, the display can be non-immersive but the tracking must be as accurate as possible to create the illusion that the virtual content is fixed in the real world. (Table 2.1).

\begin{tabular}{c|c|c}
\hline \hline & $\begin{array}{c}\text { Virtual Reality } \\
\text { Replacing Reality }\end{array}$ & $\begin{array}{c}\text { Augmented Reality } \\
\text { Augmenting Reality }\end{array}$ \\
\hline Scene Generation & requires realistic images & minimal rendering okay \\
\hline Display Device & fully immersive, wide FOV & non-immersive, small FOV \\
\hline Tracking and Sensing & low accuracy is okay & high accuracy needed \\
\hline \hline
\end{tabular}

Table 2.1: Virtual Reality and Augmented Reality technology requirements. (Billinghurst, 2017)

Rekimoto's (1995) comparison of $\mathrm{HCl}$ styles seems to better clarify this distinction between traditional desktop computer interfaces and those that attempt to make the computer interface invisible such as augmented reality (Fig. 2.6). This is when the physical world and the computer interface are in the same 
line of sight, which is ideal for a wayfinding setting, where the physical and virtual merge (Fig. 2.6.d).

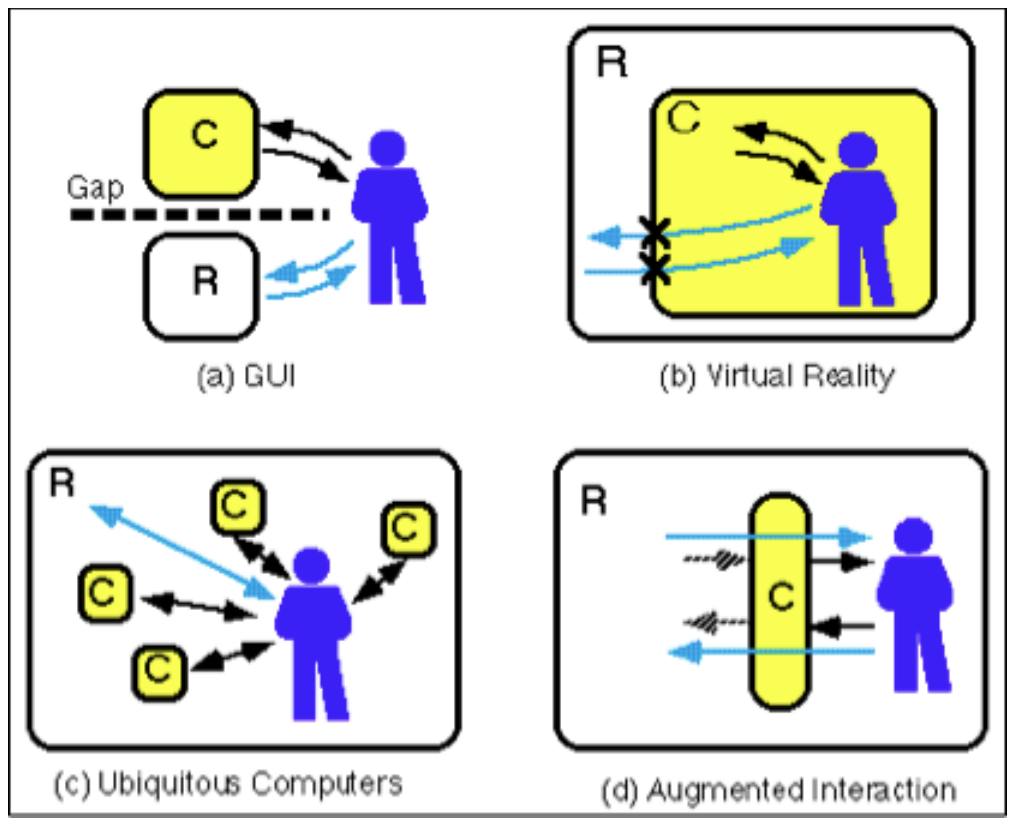

Figure 2.6: Rekimoto's comparison of $\mathrm{HCl}$ styles $(\mathrm{R}=$ real world, $\mathrm{C}=$ computer $)$ (Rekimoto, 1995)

\subsubsection{Potential for Growth in Consumer-level AR}

In the past few decades, most of the AR research was focused on military and government research labs, rather than academic or industrial settings. Today augmented reality is evolving rapidly and showing promise of mass adoption (Billinghurst,2017). Industry analysts are expecting Augmented Reality to acquire 1 billion users by 2020 and the worldwide user base of AR and VR games to grow to 216 million users and be worth 11.6 billion U.S. dollars by 2025. In 2016, 150 thousand shipments of AR glasses were shipped. This number is expected to rise to 22.8 million units by 2022 (Fig. 2.7). These 
statistics give a clear picture of the market potential and worth of AR. With startups and tech giants both taking initiatives to leverage this technology, it is obvious that the future of augmented reality is bright and lucrative.

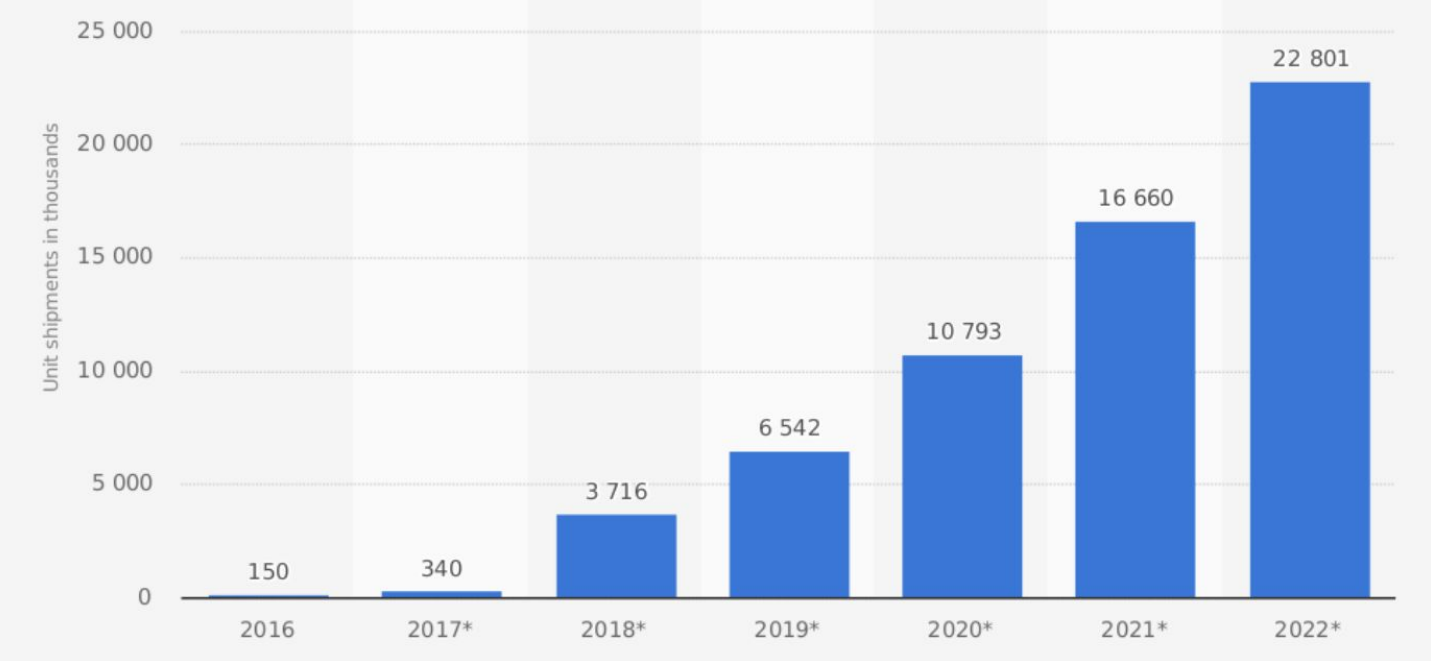

Figure 2.7: Smart augmented reality glasses unit shipments worldwide from 2016 to 2022 (in 1,000s) (Statista, 2019)

The first AR headset was developed by Ivan Sutherland in 1968 to display simple wireframe drawings. The public development of AR started in 1998 which leads to the establishment of the first couple of AR dedicated companies. Since then many AR toolkits were created for developers and several companies joined the hype. The rise of the smartphone and particularly the iPhone in 2007 offered real-time computer vision tracking and powerful 3D graphics. In 2017, Apple released ARKit, a public AR development platform allowing developers to create AR experiences for iPhones and iPads. Later, in 2018, the Android platform released ARCore which offered more opportunities for AR 
development, especially outdoors, through combining the different mobile sensors such as camera, graphics, GPS, and inertial compass. This helped mobile phone-based AR experiences become more and more popular.

Thanks to consumers' access to technology, ranging from web to smartphones, and head-worn displays such as "Google Glass", it became easier to develop AR applications. Free available tracking libraries such as ARToolKit and the Qualcomm's Vuforia SDK made it possible for even non-programmers to create AR experiences (Billinghurst, 2017). According to Bimber (2012), earlier research on AR focused on head-mounted displays and backpack computers; currently, it includes a variety of enabling technologies, such as camera phones and other handhelds, advanced projector-camera systems, and AR-extended professional devices, such as $\mathrm{x}$-ray scanners. Therefore, $A R$ is evolving to soon become a solution that is used in our everyday routine (Shamsuddin, 2015).

Today, AR is becoming on the verge of widespread commercial acceptance as it is being available in numerous application areas such as gaming, medicine, mobile, marketing, retail and of course museums.

\subsubsection{AR Applications Supporting Wayfinding}

As discussed in previous sections, wayfinding is a complex cognitive process, especially in complex indoor spaces like museums for example. People experience difficulties in identifying the locations of wayfinding aids (e.g. signs, 
maps etc.), understanding terminologies and pictograms on signs and being assured of the destination while following a series of signs. According to Kim (2015), current wayfinding aids are insufficient to support a person's natural navigational behaviours, and Augmented Reality (AR) has great potential to supplement those aids. The research included an AR-enabled system in a hospital hosted on a mobile device to enable ubiquity and portability of the wayfinding services. The design was informed by what they outlined as the general wayfinding requirements in a complex environment:

1- Identifying current location, orientation and destination

2- Identifying elevators and stairs and room numbers from a distance

3- Being reassured of the destination while navigating the space

4- Being accessible and portable through mobile devices such as handheld devices.

AR applications can possibly enhance a user's experience when navigating the space by providing real-time information about the destination and its features using graphics, text, audio, and video. The possibilities of the experience multiply when the application is constantly informed by the indoor localization of the visitor in the physical space and visualizing this position as the visitor moves around. The two main approaches to solve this task are: wireless connectivity and visual tracking.

Wireless Connectivity: Since 2011, the most common solutions for indoor positioning were through wireless technologies such as GSM, WLAN, 
Bluetooth, Infrared, and RFID. Unfortunately, the low accuracy and low signal rate of these technologies are a big obstacle for an approach like augmented reality (Table 2.2). Alnabhan (2014) lists the following possible techniques: ultrasound, optical marker-based, optical markerless, magnetic, inertial, ultra-wide-band (UWB), hybrid, accelerometer, active RFID, passive RFID, and Wi-Fi fingerprinting. Many of those technologies are not feasible because of their infrastructure's cost, the complexity of implementation, their accuracy level, update rates, operating range, portability and so on. In addition, Huey (2011) negatively highlights the facts these approaches make indoor navigation highly dependent on the availability of a wireless connection in the building. For the project "INSAR" hosted on Android devices, Alnabhan (2014) used the WiFi fingerprinting technique as a positioning system which is more accurate than GPS, but with a considerable margin error that could reach 7.2 meters, it needed a lot of improvements.

\begin{tabular}{|l|l|l|l|l|l|l|}
\hline & GPS & GSM & WLAN & Bluetooth & Infrared & RFID \\
\hline Range & $\begin{array}{l}\text { Wide } \\
\text { area }\end{array}$ & $\begin{array}{l}\text { Wide } \\
\text { area }\end{array}$ & $\begin{array}{l}\text { Micro } \\
\text { area }\end{array}$ & $\begin{array}{l}\text { Micro } \\
\text { area }\end{array}$ & $\begin{array}{l}\text { Pico } \\
\text { area }\end{array}$ & $\begin{array}{l}\text { Pico } \\
\text { area }\end{array}$ \\
\hline Accuracy & $\begin{array}{l}\text { No } \\
\text { signal }\end{array}$ & Low & Low & Low & High & High \\
\hline $\begin{array}{l}\text { Signal } \\
\text { Error } \\
\text { Rate }\end{array}$ & $\begin{array}{l}\text { No } \\
\text { signal }\end{array}$ & Low & Mid & Low & Lowest & Lowest \\
\hline
\end{tabular}

Table 2.2: Comparison of heterogeneous positioning technologies (Huey, 2011) 
Visual Tracking: It is agreeable that for augmented directions to be intuitive, accuracy is crucial when superimposing virtual elements in the space. From a technological standpoint, superior tracking ability could stabilize the virtual counterparts in real space, while poor tracking ability typically incurs image flipping or fidgeting. Ventura (2014) introduces the Visual Simultaneous Localization And Mapping (vSLAM) which uses computer vision to triangulate and track thousands of points related to surface landmark features in the physical environment through the use of a monoscopic camera. This allows the system to provide an accurate pose estimation of the handheld device's viewpoint across a wide range of viewpoints in the scene. The state-of-the-art tracking visual techniques include (1) marker tracking, (2) markerless tracking and (3) extensible tracking which allow the computer to calibrate the visitor's spatial positions relative to the physical space and know whereabouts the virtual model should be placed. Kim (2015) developed an AR application that relies on a marker that the user needs to scan at every turn or decision point. While this approach achieved much more accurate results and provided a more precise localization of virtual elements than wireless tracking, it is debatable if a similar experience that relies heavily on manually scanning visual markers can be claimed to allow seamless navigation of the real world. Although not a viable solution, Kim's system architecture is a good inspiration for future improvements (Fig. 2.8). 


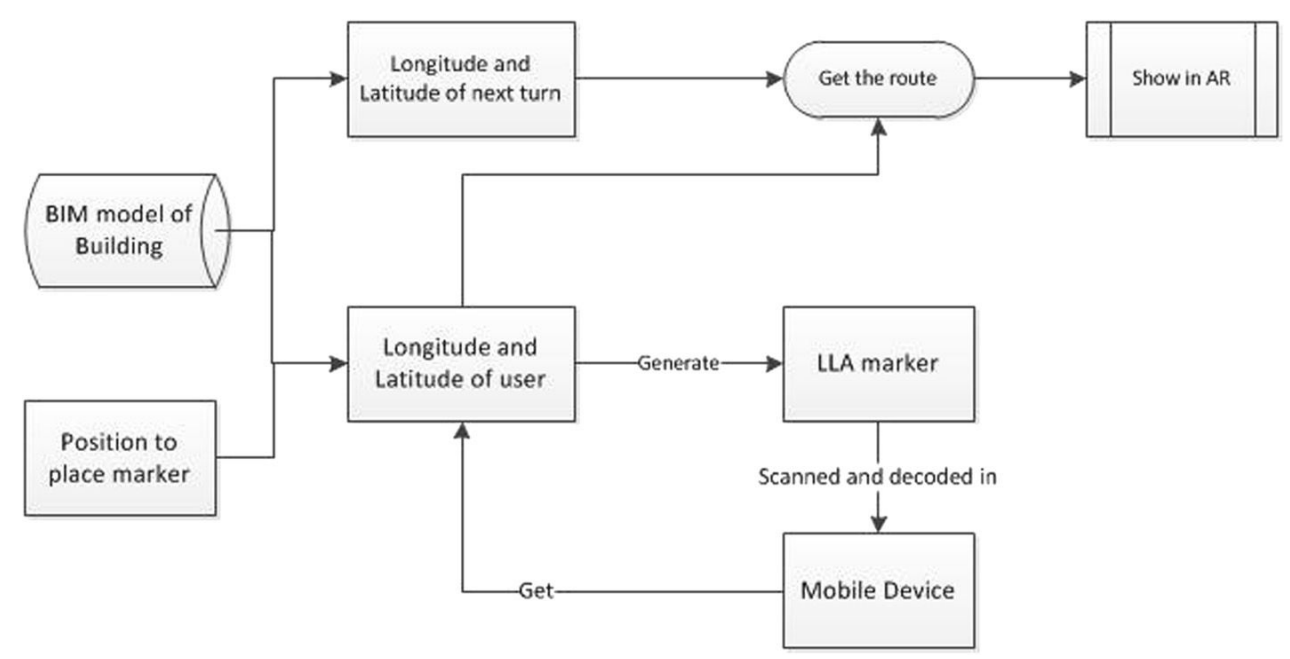

Figure 2.8: Methodology of AR-based wayfinding mechanism and testbed (Kim, 2015).

Can AR based wayfinding overcome the many cognitive processes required in conventional wayfinding? The findings of Shamsuddin (2015) and Kim (2015) have proven the positive impact of AR on wayfinding performance. AR facilitated the participants' coverage of the indoor space and improved the time needed to arrive at the final destination. Shamsuddin (2015) states: "augmentations such as direction indicators, maps, and path restriction can all greatly improve both wayfinding performance and overall user satisfaction". The current wayfinding research using AR seems to encourage the development of methods for analyzing the factors that are affecting wayfinding behaviour. The hope is that augmented information that is superimposed over the real-world can mitigate many problems in identifying and understanding spatial accuracy between the real-world environment and wayfinding aids. What is also beneficial about using this technology in museums is the versatility of the output and the 
endless possibilities for content and visualization. It presents the capability to incorporate other activities in the museum such as interacting with the exhibits to encourage visitor engagement.

\subsubsection{AR Applications Supporting Engagement}

Among the 71 museum applications that were evaluated in the survey "Promising beginnings? Evaluating museum mobile phone apps", Economou (2011) identified only seven that offered Augmented Reality (AR) features. The application "How It Is" of Tate Modern was highlighted as a good example of AR mobile experience in a museum. The application is basically an AR audio tour with an experiential approach borrowing from interactive game features to build an audience. In the previous couple of years, many more museum applications that used augmented reality appeared as a medium to engage, educate, and awe museum visitors. Among the more recent examples, the Museum of London (London, UK) Street Museum application allows visitors to overlay images from the museum's photography collections on present-day London street scenes. The Van Gogh Museum (Amsterdam, the Netherlands), used AR to assist visitors to visualize $x$-rays, infrared and ultraviolet captures on top of original paintings (Van Der Vaart, 2016).

The "ReBlink" is another good example of a successful museum AR application and exhibition that uses intriguing ways to get viewers into the 
gallery and excited about art (Stephenson, 2017). It was hosted at the Art Gallery of Ontario - AGO in 2017. Although information about the art was not the goal of the application, "ReBlink" was very successful in drawing a lot of attention to the $A G O$ and increases visitor engagement time with the activated paintings. It allowed visitors to view traditional paintings in a recontextualized modern twist using Augmented Reality. Visitors either chose to download the free ReBlink application on their mobile device or use the in-gallery tethered iPads to view selected paintings come alive in 3D rendering animations. The experience makes the $2 \mathrm{D}$ painting act as a window to another $3 \mathrm{D}$ world that has depth and perspective that change with the position of the visitor (Fig. 2.9). The application evaluation report shows that most visitors thought the experience was very novel and exciting, many were international visitors and the app had a broader reach than anticipated. Almost half of the users did not mind using their own device, most of which never encountered AR in a museum before. The impact of this exhibit on visitor engagement was studied through a qualitative analysis of the participants' responses. The reaction was overwhelmingly positive; over $84 \%$ of participants felt that ReBlink engaged them with an artwork they would have normally walked past. Many said it made the artwork come to life, and that the remixes were amusing and unexpected. Although some complained that the content was amusing but not informative, the findings show the acceptance of the audience to a novel medium such as AR in museums. 


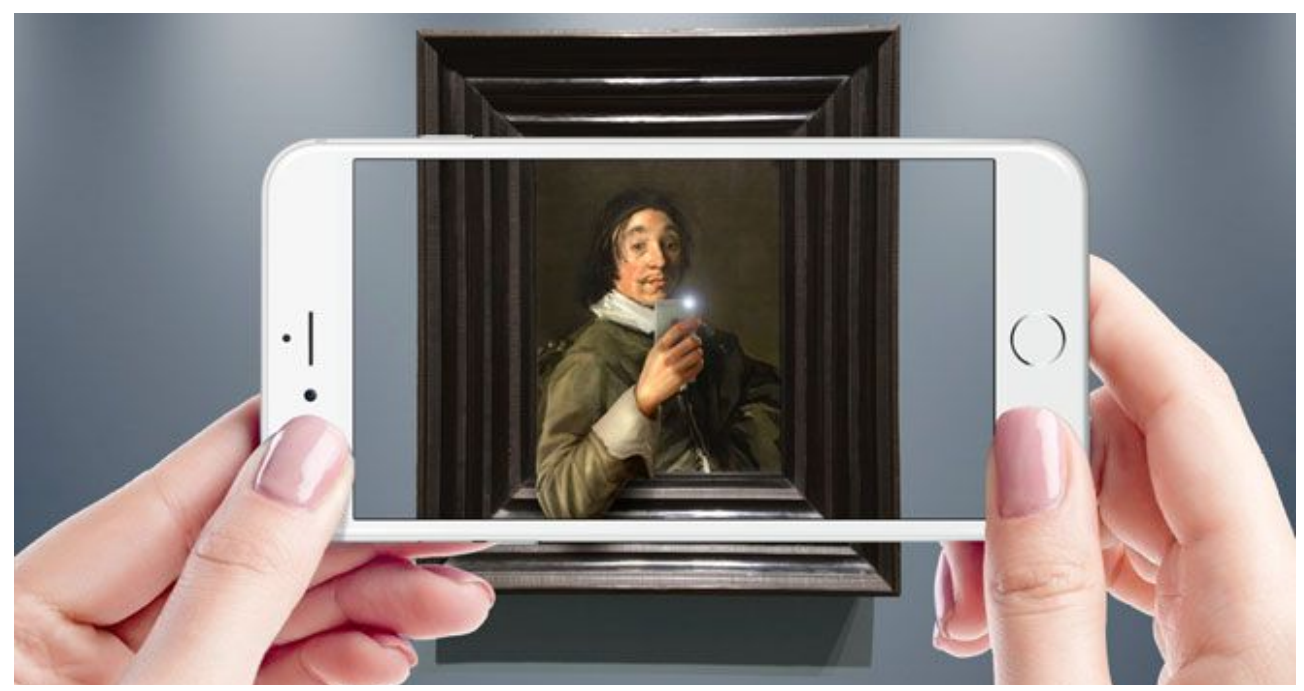

Figure 2.9: Promotional image for ReBlink. (C) Art Gallery of Ontario (AGO). Retrieved from http://www.ago.net/assets/images/555/Reblink-image.jpg

The emergence of ARKit and ARCore by Apple and Google in 2017 made AR development much easier and less costly. More applications started to integrate AR features, and museum applications were no different. One of the most recent AR-activated exhibitions at the AGO was "Anthropocene" in December 2018. It is an installation of different objects and images that are augmented through a particular application called AVARA. The experience brings to life three near-to-life size Augmented Reality $(A R)$ installations and activates film footage in four mural-sized photographs (Fig. 2.10). 


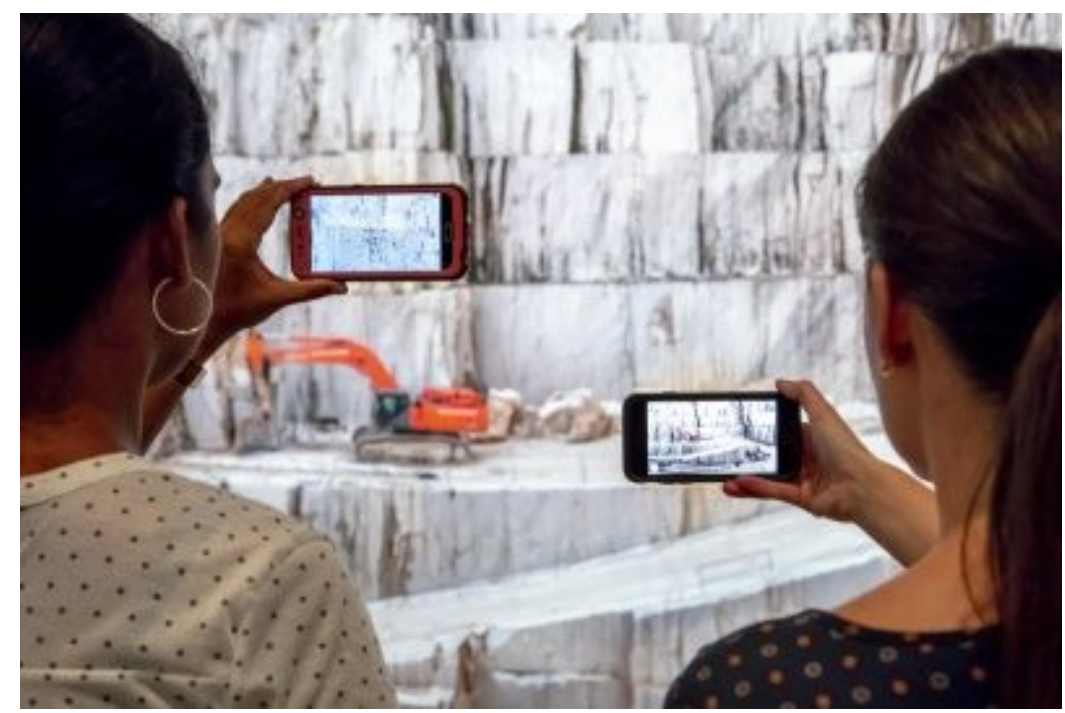

Figure 2.10: Image on the AGO website promoting the Anthropocene Exhibition. Retrieved from https://ago.ca/sites/default/files/styles/image_small/public/2018-10/A-194846.jpg

A User testing of the application was conducted with 20 participants and the experiment showed many issues in the application. Most of those issues were user experience related and centered around pages that were content heavy or unnecessary. Some visitors struggled to use the application and found it confusing. Despite all those issues, the exhibition's audiences of all ages had a good response to the AR experience that the application provided. The combination of art and technology blew everyone away. The experience joined imagery with videos as well as real size 3D models of animals and objects that visitors engaged with from all sides. Though most responses commented on how exciting AR was, the novelty of the technology did not overshadow the work but it complemented it with an extra layer of information. This exhibition was yet again another successful example of AR experiences. 


\subsection{Summary and Design Space}

I intend to build an intuitive indoor wayfinding solution that supports visitors' navigation in museums. The goals of the solution are to intuitively lead visitors to their arts of interest and to offer the opportunity of interaction and engagement with them in a multisensorial manner. This chapter highlighted the main problems and issues that face indoor wayfinding and limit engagement with arts in museums. Firstly, I defined wayfinding and the cognitive processes related to static wayfinding approaches. I differentiated the different types of museum visitors. I highlighted the importance of knowing the interests and preferences of each type to create a relevant and satisfactory experience and to attract more audiences. Finally, I introduced the current ongoing research of augmented reality and the different applications of this technology in the fields of indoor wayfinding as well as engagement with art in museums.

Through my discussion and comparison of different indoor positioning approaches for $A R$, the visual tracking solution is the most accurate and most reliable. This precision is vital to the creation of an augmented reality experience, so I embark in the next chapter on a technological exploration journey of computer vision algorithms and plugins to better detect the world through the device's camera. My goal is to display 3D arrows in perspective and anchored in the physical space to intuitively lead the way when a visitor searches for a particular exhibit.

For the engagement side of my system that I want to build, I consider all the takeaways from the contextual review and use the main design guidelines learnt 
through the evaluation of previous projects. For the sake of this research, and as I mentioned earlier I focus on first-time visitors that are explorers in nature and Gen $\mathrm{Y}$ as a target audience. I aim to create an experience that speaks to most visitors types so I will attempt to awake most of the senses when designing the interaction with the art. I will explore the use of visuals by 2D and 3D graphics, audio through sound and music, and haptics by using the device's vibration motor.

In the next chapter, I follow a user-centered design approach to design and build MRsive, a mobile-based AR solution. I present the adopted research through design methodology and related methods to make and evaluate the system. I incorporate the usability goals and process while explaining the different sides of the methodology rationale. The goal is to study how my use of accurate indoor positioning and augmented interactions impact the museum visitor's spatial ability during wayfinding and engagement with the art. 


\section{Chapter 3. DESIGNING MRsive}

My research focuses on improving the field of indoor wayfinding and engagement with points of interest in the space by creating a novel tool that disrupts, transforms or complements the current state of the field. I call this tool: "MRsive". It is an augmented reality application that helps visitors better navigate the museum galleries and engage with the artifacts in the space. To validate my design, I situate the research in the context of a museum and I take The Art Gallery of Ontario - AGO in Toronto as a use case. In this part of the thesis, I present my methodology by explaining in details the complete process of designing, developing, and evaluating MRsive. Theory and practice equally influenced my methods and shaped my design. I follow the research through design (RTD) methodology which is known to speculate on what the future could and should be based on an empathic understanding of the stakeholders, a synthesis of behavioural theory, and the application of current and near current technology (Zimmerman, 2007). Research through design is very relevant and popular among the $\mathrm{HCl}$ (Human-Computer Interaction) practice community where the new interaction design becomes the object of research and evaluation. Zimmerman states that the research model in this 
methodology allows researchers to study the world and then to make things intended to affect change. The latter aligns with my vision. To create MRsive, RTD proposes three main steps: 1- to identify new technological opportunities that will impact the world; 2- to create novel artifacts; 3- to validate the contribution. I divide my research and creation journey into three stages: need-finding, prototyping, and evaluation as shown in the chart below (Fig. 3.1). This chart illustrates my process which combines theory and practice and displays different related methods.

To evaluate my contribution, research through design proposes four critical lenses and I discuss them further in the last subsection of this chapter: 1- I document my process; 2 - I demonstrate the invention or novelty of the design; 3 - I validate the relevance of this work, and finally 4- I prove the ability of my research outcomes to be extensible and usable as a basis for new research. To highlight the success of my design and outline the shortcomings, I add more layers of validation through user testing. Research through design as a methodology is critiqued to rely strongly on the research traditions of other disciplines (Dirin, 2018), so I reinforce the findings by following a user-centered design approach from the beginning till the end of the project.

The three stages of the project are better illustrated and clarified in depth in the three following subsections of this chapter. First, the need-finding is crucial to bring empathy for museum visitors, mainly newcomers, tourists and first-time visitors. Between October 2018 and December 2018, I was hired as a research intern at the AGO museum where I was able to closely work with the digital team and the visitor 
research department. The internship allowed me to observe and interview the AGO visitors so I can define their wayfinding and engagement pain points in the space. Second, the prototyping stage is where the making and the development of MRsive happens. The results of the need-finding stage inform my design and the project goes through different iterations to move from ideation to a functional prototype. I intend to make the 'right thing' that transforms the museum experience from its current state to a preferred and more enjoyable state. In order to achieve that, I employ my background in user experience design and visual communication. Those skills help me build my tool to be functional and user-friendly and create an aesthetically appealing interface. Finally, for the third stage, the evaluation of the prototype also takes place at the AGO where I conduct user testing. As a final step, I compare the original pain points and needs with the new results and critique the findings. The goal is to validate the interaction design and its contribution to research.

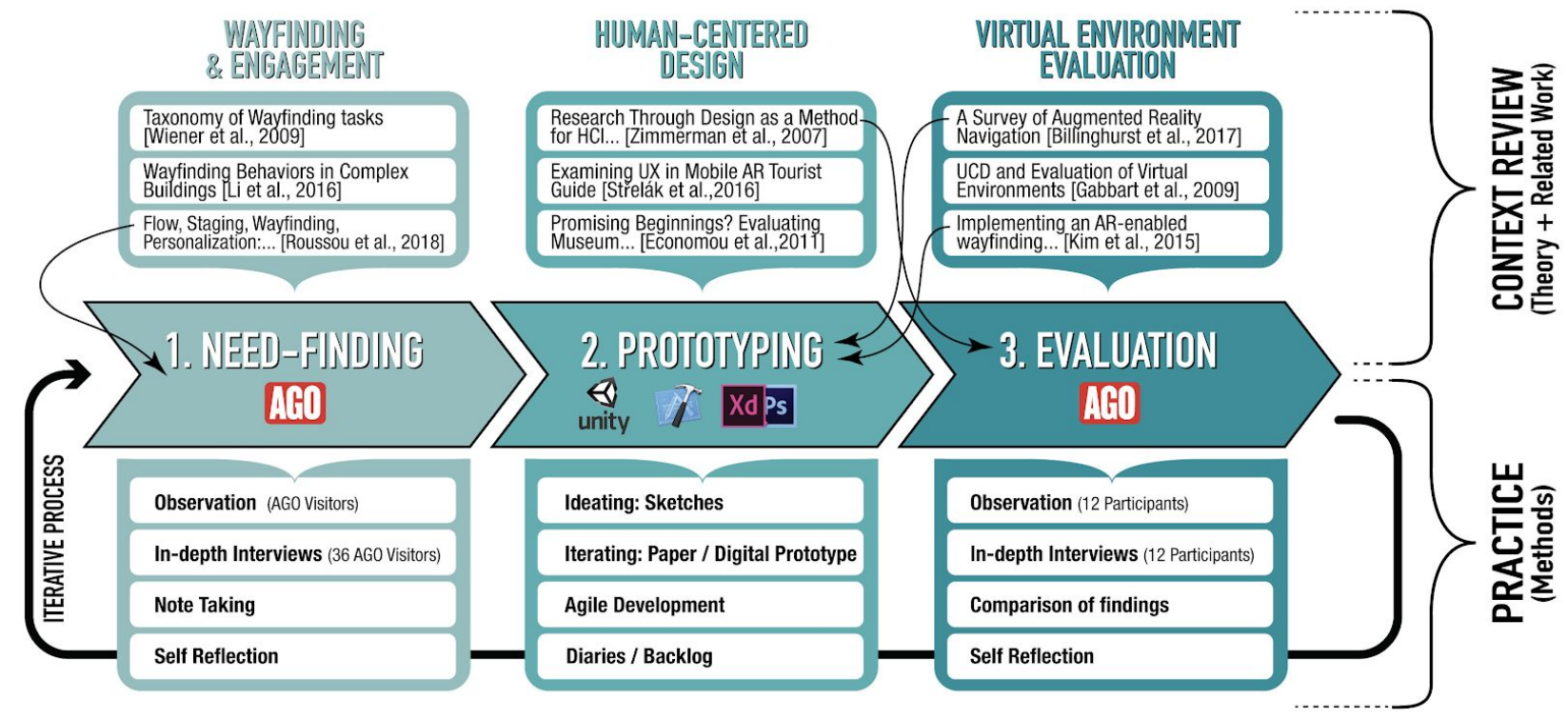

Figure 3.1: Theory-Practice Process Map of Designing MRsive 


\subsection{Need-Finding}

As mentioned in the first chapter of this thesis, my main motivation for this research and project is my personal spatial anxiety in indoor complex spaces. I always find myself lost or confused in big venues such as museums. Since 2015, I have shared with several people my disappointing experience at the Museo Reina Sofia and Guernica. The story of how I got lost and how I couldn't connect with the painting was something everyone could relate to. They said something similar has happened to them at one point. Realizing I'm not the only one who is constantly frustrated with indoor wayfinding and engagement with the arts, I started brainstorming through reflective practice. There must be a more intuitive solution than static methods to enhance the navigation in museums and boost the engagement with the artifacts in the space. As an initial step, my process starts by finding the main pain points of the AGO visitors to ensure their needs are answered through my design.

The methods I decided to use for this need-finding stage are observation accompanied by note taking, and semi-structured interviews. Working closely with the AGO staff during my research internship allowed me to access and scan the previous work that had been done on the visitor wayfinding and visitor engagement research and analyze the results. The weekly meetings and discussions with the digital team and the visitor research department helped me define the two spots that had the most challenging wayfinding experience at the AGO. I decided they will be the stations of observation and interviews of the visitors. The lower floors are big and complex and 
include different collections; this may be too overwhelming for some. As for the second spot, AGO staff collectively agreed, based on previous surveys, that visitors find it difficult to find the fourth or fifth floors where the temporary collections are hosted. The main challenge is to locate the elevators that go up to these floors. There is one elevator right after the main entrance but it only goes up to the second floor. The right elevators are located on the exact opposite side of the museum from the main entrance, hence the confusion. The findings of the employed methods are illustrated in details in the two following subsections. The first subsection expands on the observation method complemented by note taking, while the second subsection discusses the interview questions and answers.

\subsubsection{Observations and Note Taking}

I strolled around a room not too far from the main lobby and also around the elevators of the upper floors. I observed the space and took notes of the visitors' wayfinding and navigation behaviours. I frequently noticed visitors that were rotating the printed map with a frustrating look. Some tilted their heads in an obvious attempt to figure out what direction they were facing. They were clearly struggling in locating their location or the location of their points of interest on the map. After closely examining the museum brochure, this observation was understandable: the orientations of different elements on the map were inconsistent. Unlike the common standards, the AGO map had the 
north directed to the bottom of the page and the south to the top. The map is printed in this direction to place the AGO main entrance at the bottom of the page so the visitor could align what they see ahead with what is on top of the page (Fig. 3.2)

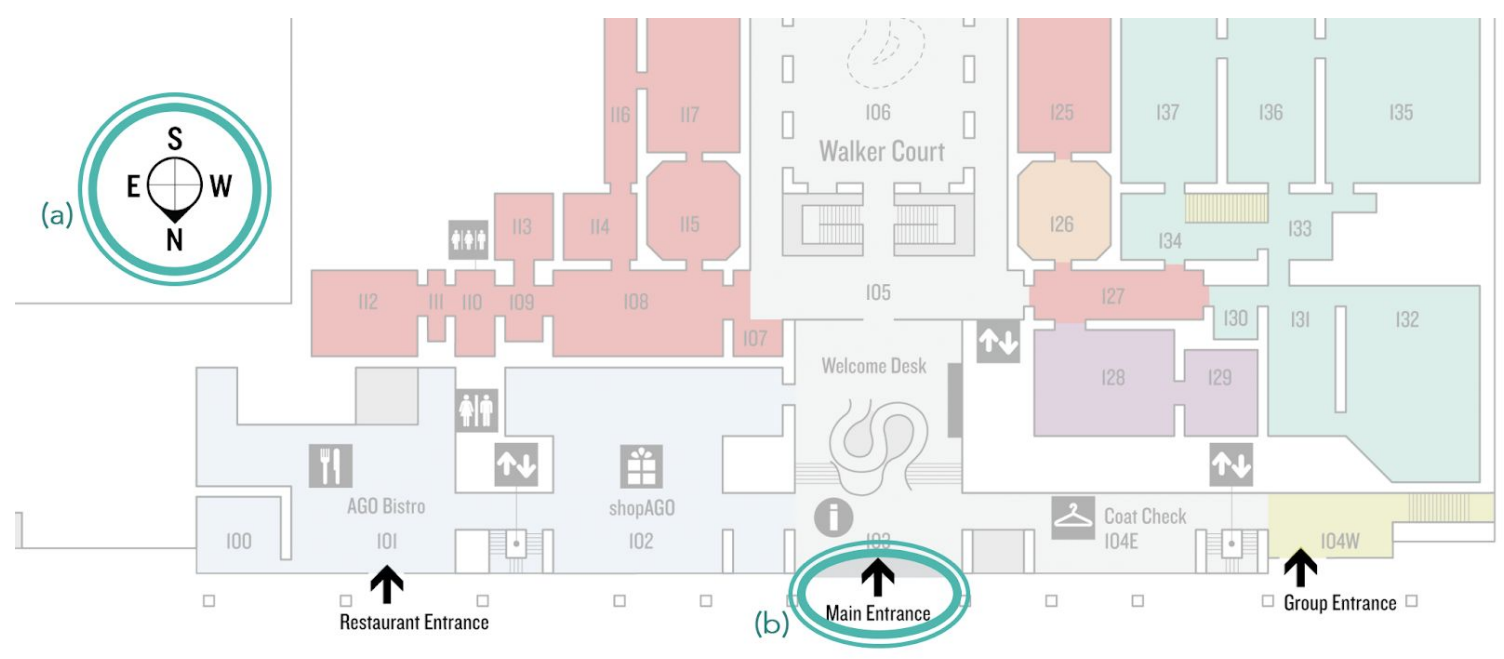

Figure 3.2: Top view map of the AGO's main level found on the museum's brochure and website.

(a) North direction of the compass points towards the bottom. (b) Main entrance points towards the top.

This unconscious shift of attention between the map and space ahead is known in cognitive sciences as "task switching" (Jersild, 1927). It is a common executive function that the map reader needs to relate the static map to the physical environment (Lobben, 2004). All floors were printed in the same direction as the first floor, north direction pointing to the bottom. The obvious reason for this decision is to cater to the main entrance that is located in the south of the building's first floor. Unfortunately, though, the entrances of all the other floors are located in the north of their respective spaces (Fig. 3.3). 


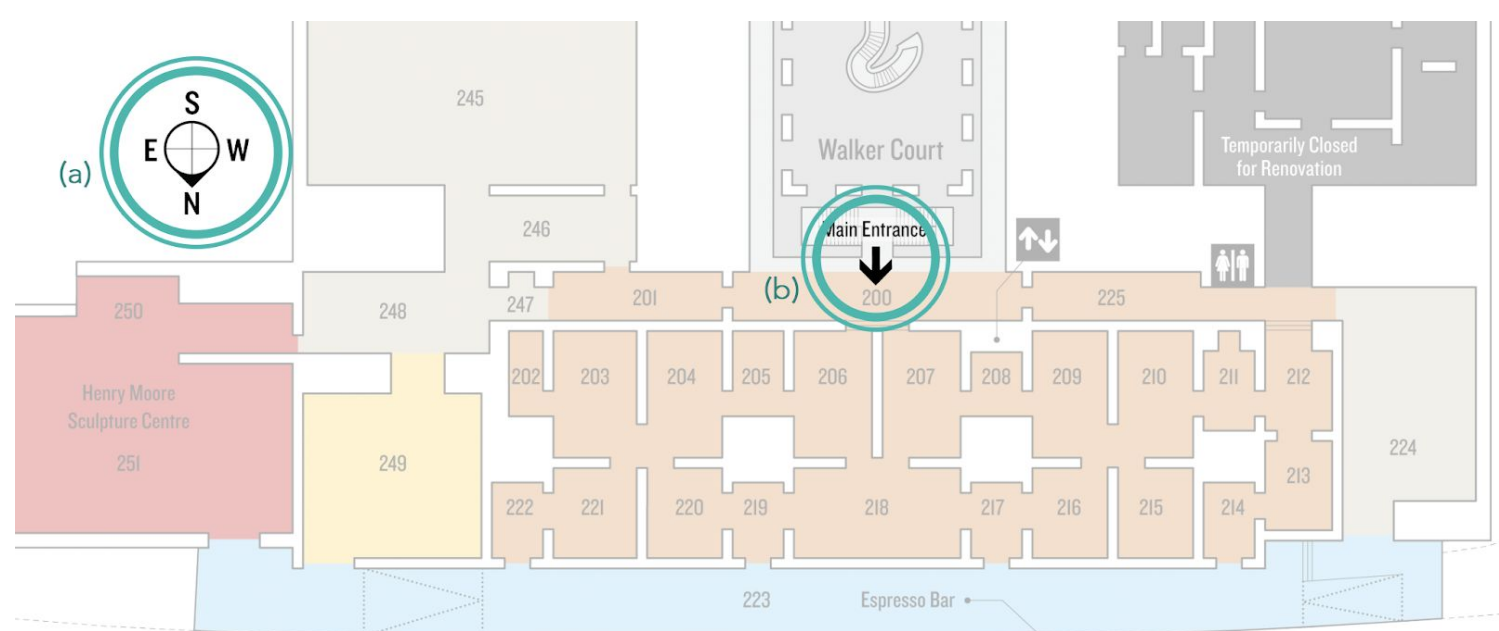

Figure 3.3: Top view map of the AGO's first floor, found on the brochure and website. (a) North direction of the compass points towards the bottom. (b) Floor entrance points towards the bottom.

This misalignment needs a mental "object rotation" which is a cognitive process that, as previously discussed, negatively impacts the visitor's speed and accuracy of map-reading and navigating.

On the other hand, when it comes to engagement, I noticed that only a few people were reading the labels of the artifacts known as "tombstones" in an attentive manner. The few people I spotted reading the labels had to lean sideways or bend forward to better read the descriptions written on the side of the art in a small font. The effort needed for this action was pretty clear. Most other visitors seemed to run through the space gazing at some arts here and there and occasionally stopping at one of them for few more seconds before moving onto the next one. 


\subsubsection{Semi-structured Interviews}

To gain more direct insights, I talked to visitors following a semi-structured interview around the fourth and fifth floors which are agreed to be hard-to-find destinations. I developed my interview questions (see questionnaire in Appendix A) under the supervision of the visitor research department. Table 3.1 summarizes the details and demographics of the 36 participants that were randomly selected at the AGO. I ask participants my intended questions in a casual way to encourage them to naturally share as many insights as possible. The findings are divided between first-time visitors which are the main focus of this need finding stage and non-first-time visitors. No rewards were given to the participants. All collected data were anonymized so that the participants cannot be identified from the results presented in this study.

\begin{tabular}{cc:cccc}
\hline Participants & Total & Males & Females & Age Average & Other Languages? \\
\hline $\begin{array}{c}\text { 1st Time } \\
\text { Visitors }\end{array}$ & 23 & 10 & 13 & 34.5 years & 10 out of 23 \\
$\begin{array}{c}\text { Non-1st Time } \\
\text { Visitors }\end{array}$ & 13 & 5 & 8 & 47.3 years & 2 out of 13 \\
\hline
\end{tabular}

Table 3.1: Demographics of the 36 randomly selected participants

Participants were asked to rate how intuitive the wayfinding approach at the AGO is, on the Likert scale of one to ten. The same question was then asked concerning other museums they have previously visited. Rating one means "not 
intuitive at all" while ten means "extremely intuitive". The same scale and rating questions were asked about the engagement approach as well, for the AGO and also for other museums. Table 3.2 below shows the results and median scores generated from these questions.

\begin{tabular}{|c|c|c|c|c|c|}
\hline \multirow[b]{2}{*}{ Participants } & \multirow[b]{2}{*}{ Total } & \multicolumn{2}{|c|}{ WAYFINDING SCORE } & \multicolumn{2}{|c|}{ ENGAGEMENT SCORE } \\
\hline & & AGO & Other Museums & AGO & Other Museums \\
\hline $\begin{array}{l}\text { 1st Time } \\
\text { Visitors }\end{array}$ & 23 & $2 / 10$ & $7 / 10$ & $4 / 10$ & $8 / 10$ \\
\hline $\begin{array}{l}\text { Non-1st } \\
\text { Time Visitors }\end{array}$ & 13 & $4 / 10$ & $7 / 10$ & $6 / 10$ & $7 / 10$ \\
\hline Visitors & 36 & $3 / 10$ & $7 / 10$ & $5 / 10$ & $8 / 10$ \\
\hline
\end{tabular}

Table 3.2: Answers to the scores questions in the need-finding interview

It was also interesting to note the frequency of use of every wayfinding method. Even though the number of participants is not big enough to consider the results as generalized statistics but it is interesting to note the big difference between the use of printed maps among first-time visitors compared to the use of maps among non-first-time visitors as shown in Table 3.3. It is also notable that most visitors relied on asking volunteers for directions in person rather than consulting the printed map that some had already in their hands. 


\begin{tabular}{|c|c|c|c|c|c|}
\hline \multirow[b]{2}{*}{ Participants } & \multirow[b]{2}{*}{ Total } & \multicolumn{4}{|c|}{ WAYFINDING METHODS } \\
\hline & & Nothing & Signage & Map & $\begin{array}{c}\text { Asked } \\
\text { Volunteers }\end{array}$ \\
\hline $\begin{array}{l}\text { 1st Time } \\
\text { Visitors }\end{array}$ & 23 & 3 & 5 & 7 & 8 \\
\hline $\begin{array}{c}\text { Non-1st } \\
\text { Time Visitors }\end{array}$ & 13 & 2 & 0 & 1 & 10 \\
\hline Visitors & 36 & 5 & 5 & 8 & 18 \\
\hline
\end{tabular}

Table 3.3: The frequency of use of wayfinding methods at the AGO

Furthermore, participants were asked to suggest different solution ideas to make navigation and interaction with the arts at the AGO easier. I highlight some of the verbatims below:

- "A path to follow like IKEA's path to know where to start from because we started this exhibition in the opposite direction." (M, 50s, first-time visitor).

- "I would like an app on my phone that gives me information when I point at things." (F, 60s, Member)

- "I wish there was a wayfinding system in the Museum like what they have at IKEA, I mean arrows on the floor. I also would like clear information." ( $F, 30$ s, first-time visitor) 


\subsubsection{Summary}

In summary, the remarks and answers highlighted important points and needs. After close analysis, the observation notes and interview results helped me generate ideas and inspired my design decisions. The top view map, for example, should preferably rotate dynamically with the orientation of the user. Language support shouldn't be overlooked. Augmenting the art descriptions on tombstones could be helpful to attract more of the visitors' attention. Intuitive signs and directions are needed to find destinations easier. In situ information and interaction with the arts would be valuable to test. The following section will discuss the prototyping process to develop the MRsive system.

\subsection{Prototyping: Ideation, Design And Development}

This stage is an agile and cyclical process including three steps: ideation, user interface (UI) and user experience (UX) design through paper prototyping, and development through digital prototyping. The following three subsections expand on those steps respectively. 


\subsubsection{Ideation}

The previous stage helped in locating the possible pain points of wayfinding and engagement at the AGO. Informed by those results, I started brainstorming and sketching different potential digital solutions until I had the main guidelines and skeleton of my tool that I later called "MRsive". The goal is to show visitors the way around the AGO museum in an intuitive manner while invigorating their senses and inspiring their imagination. MRsive intends to make the usual museum visit an immersive experience, hence the name pronounced "immersive" and the logo design (Table 3.4).

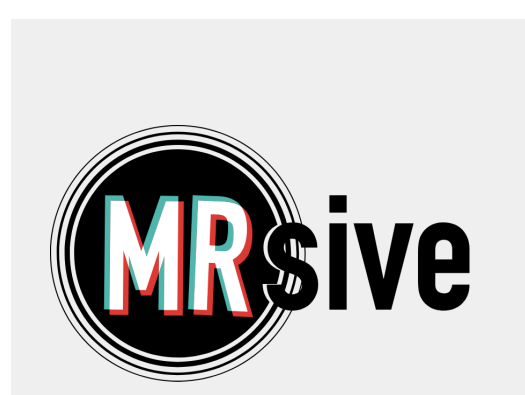

$3 \mathrm{D}$ environments are usually represented with red and green shifted filters which I applied to the letters $M$ and $\mathrm{R}$ of the MRsive logo. The point is to emphasize the embedded acronym MR which stands for mixed reality. The acronym is placed within a black circle representing the location pin seen on GPS maps. The repetitive outlined circles represent the transition from real to virtual.

Table 3.4: Logo design for MRsive

Below are the potential solutions that speak to the needs of the AGO visitors:

- A dynamic tool that is responsive to the user's position and the art they are looking at, rather than a static printed media.

- On-demand display of virtual graphics or augmented reality turn by turn 
directions to consider IKEA's wayfinding approach (arrows on the floor) without compromising the interior aesthetics of the space at the AGO.

- Choice of different languages to help foreign visitors and tourists better communicate and interact with the art in the space using their preferred language.

Technology is at its best when it is invisible: "Machines that fit the human environment instead of forcing humans to enter theirs will make using a computer as refreshing as taking a walk in the woods." (Weiser, 1991). Based on that fact, handheld devices such as mobile phones are not the perfect host for the generated ideas listed above. Using the phone, the visitor will obviously need to worry about the device, and when and where to point the camera during the experience (Fig. 3.4.a). Using an application on the mobile phone would be a great start for prototyping because these devices are ubiquitous and have all the sensors needed. Ideally, I imagine the solution to be more seamless so a wearable device would be preferable. This is possible today using head-mounted displays (HMDs) that uses video see-through displays (Fig. 3.4.b) or optical see-through displays like in the case of smart eyeglasses (Fig. 3.4.C). These devices would provide hands-free interaction but unfortunately, they are clunky, expensive, difficult to develop content for, sometimes lack all the sensors needed and with a limited field of view (FOV). Digital Futures is the name of this Masters program and I am trying to design for the future when hopefully smart 
glasses are widely available in the market. This is to envision even a more futuristic experience through smart lenses as seen in science fiction movies.

(a)

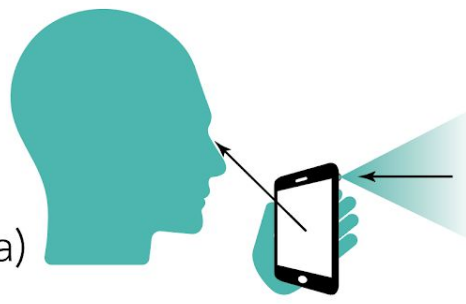

Figure 3.4: Different AR displays. (a) Handheld device's display. (b) Video see-through display. (c) Optical see-through display (Smart eyeglasses)

\subsubsection{UI/UX Design: Paper Prototype}

I first focused on the user interface and user experience of the wayfinding solution and like any UX designer, I decided to first paper prototype my design. I took one trajectory from point A to point $B$, and I photographed different angles through the journey. I then designed an imaginary virtual path laid in perspective on top of the road to the destination or point B (Fig. 3.5.a). I also included a top view map of the area and placed it on the corner of the view (Fig. 3.5.b). I printed all the elements that are supposed to be virtual on clear transparent paper for every angle or decision point. I placed those prints in the right order and made a flip book with all those pages. I asked colleagues to look at each image and to think out loud as they flip the pages one by one. They described what they saw and explained in details what they think is being 
communicated. The responses were a good indication of what was successfully designed and what needed to be modified before it goes to the next step.
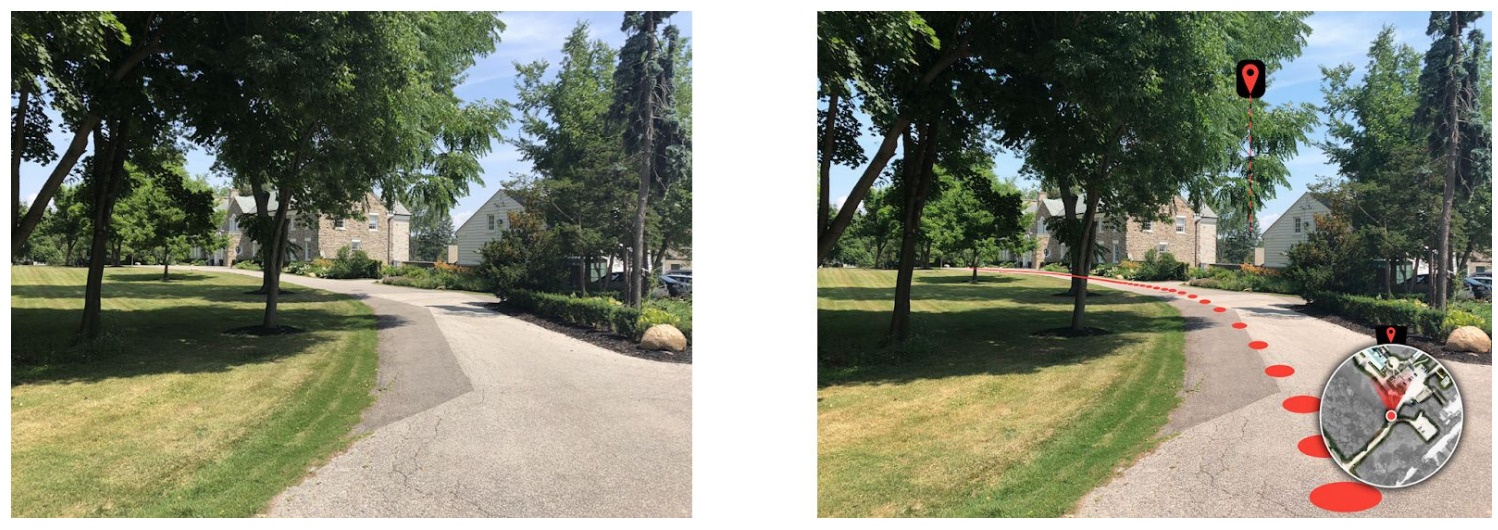

Figure 3.5: Wayfinding paper prototype. (a) Left: View without AR, (b) Right: View with AR

Most participants understood all the visual elements and symbols without any help. Some of them suggested a few minor changes. I altered the interface design based on the comments and started building everything digitally.

\subsubsection{Development: Digital Prototype}

While GPS is the go-to solution for localizing the device outdoors, indoor positioning is not as easy to attain because of the absence and inaccuracy of this approach. To explore the full digital possibilities and leverage all the sensors needed for locating the user in the building, I decided to build for iPhone which I already owned. I used Adobe XD to finalize the user-flow and design the interface. After scanning previous research projects and products, I defined two 
ways to localize the mobile phone indoors: wireless connectivity and visual tracking. For MRsive, it is crucial for virtual elements to be accurately anchored to the physical world as they are placed onto the perspective view of the space. Unfortunately, wireless techniques such as beacons and wifi fingerprinting have a bigger margin error than 1-2 meters so I eliminated this option. After Apple and Google launched ARKit and ARcore around the end of 2017, the capabilities of the mobile phone cameras multiplied and opened so many AR possibilities such as markerless AR and ground plane detection. As previously discussed in chapter 2, visual tracking is the right answer for my project and approach. Computer vision can now provide the device with a visual memory that allows it to recognize and detect previously scanned/saved spaces from any angle. This digital detection and spatial awareness give the phone the full capacity to locate the accurate 3D position of the device within that space. I decided to work with the game engine Unity3D and export for iOS, the operating system of iPhones and iPads. For the success of this plan, I needed to learn new skills such as coding in C\#, use the best of my UI and UX design skills for the interface design, 3D assets creation and a lot of agile iterations. I built the system architecture for MRsive following the diagram below (Fig. 3.6). The diagram was the guide that illustrates the general overview of how MRsive operates. The input and output algorithms needed for this process are coded in C\# (see Appendix C). 


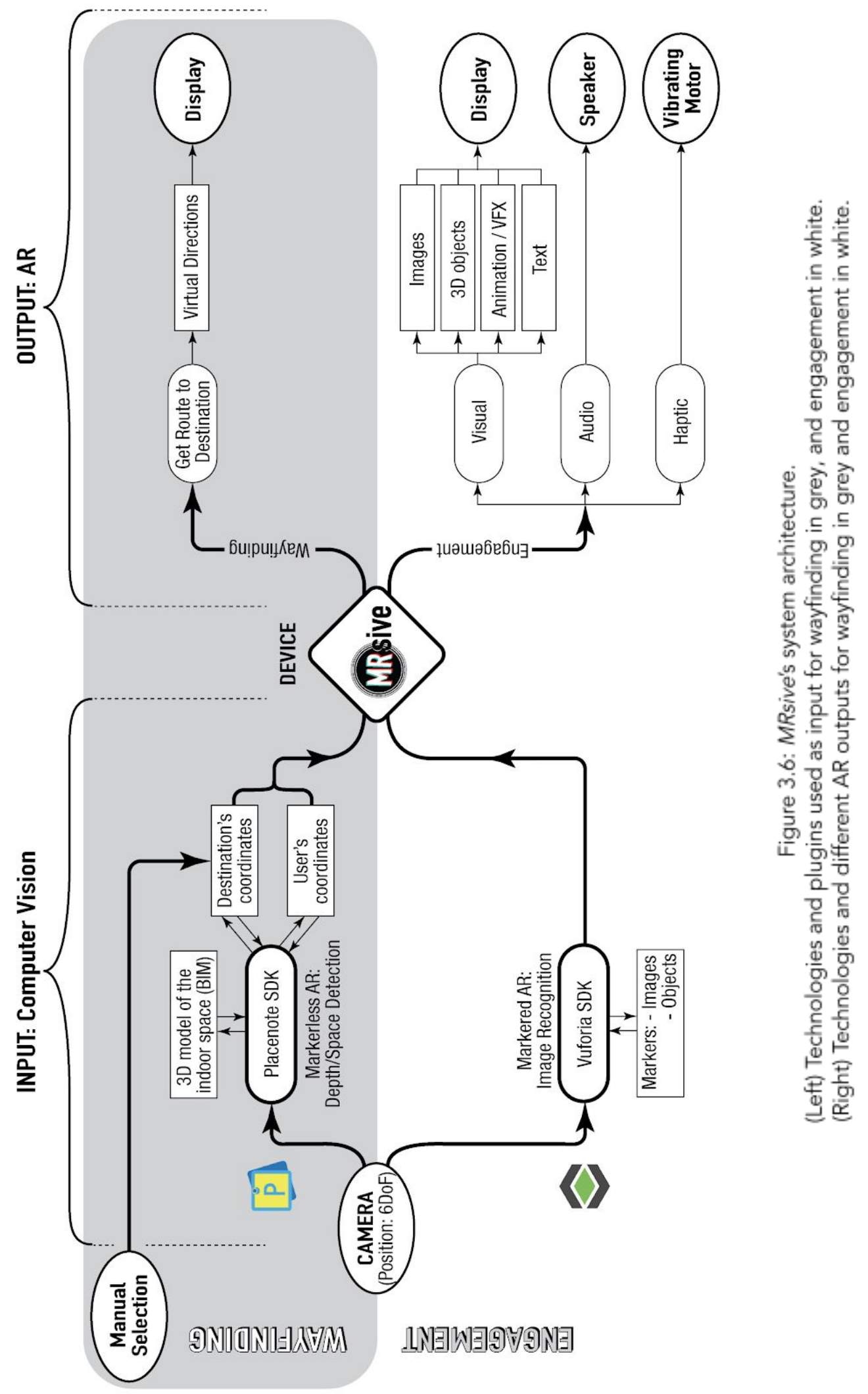


Before building anything, the Placenote SDK allows me to scan the world around using the iPhone camera. The scan collects information about the different depths of the surrounding space and generates a 3D point cloud and a couple of horizontal and vertical planes that represent the details of the scanned space (Fig.3.7). This 3D cloud is my reference to the real world after I import it to Unity. Then, I create the virtual assets and design all of the augmented reality output that occupies the right side of the diagram in figure 3.6. For the wayfinding experience, Placenote allows me to anchor the virtual directions in the form of arrows to the point cloud or the physical space.

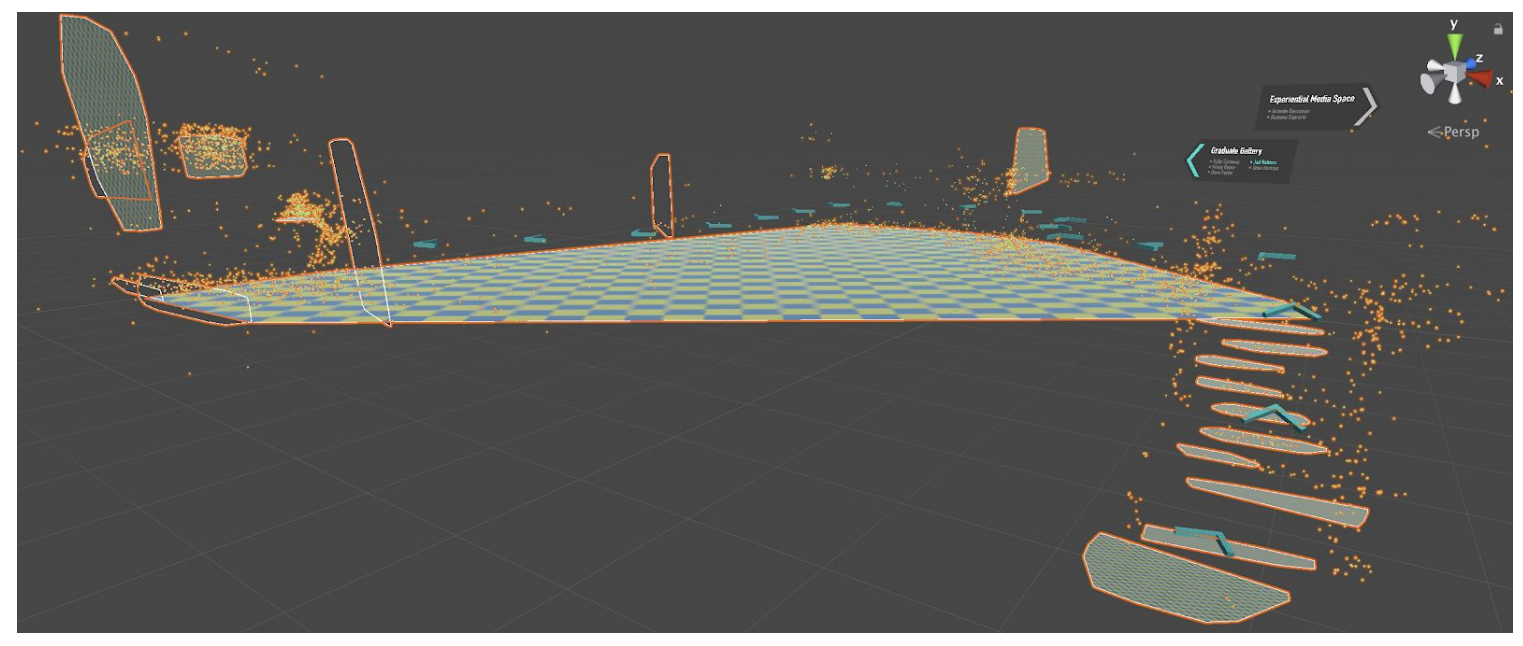

Figure 3.7: 3D point cloud and planes representing the scan of the real world. Green arrows and other virtual elements are manually added to the model in Unity.

As previously explained, the iPhone camera is capable to collect different depths of the world it sees. This type of collection of data was previously possible only through depth sensors such as the Microsoft Kinect using infrared light waves (Zhang, 2012). Today, it is possible for a mobile monoscopic camera 
to gather similar information by tracking and mapping detectable features in the surrounding environment based on light and shade. This method, called SLAM (Simultaneous Localization And Mapping) has lately seen a lot of development within the field of robotics and computer vision (Marck, 2013). As previously discussed, VSLAM triangulates and tracks thousands of points to allow the system to provide an accurate pose estimation across a wide range of viewpoints in the scene. Similarly, the Placenote SDK uses the camera to collect different depths in the space through the detection of feature points. It generates a 3D point cloud and vertical and horizontal planes that are imported to Unity and used as a reference to the real world before accurately anchoring the directional cues in the 3D space as AR objects (Fig.3.7). On the back end, the system records those points and saves them to an online database so they can be retrieved later when the user initiates the navigation.

When the wayfinding feature of MRsive is being operated, the camera opens automatically and gathers visual information about the surrounding space to self locate the device in this environment (Ventura, 2014). Through the V-SLAM method and the computer vision technology, the system is able to compare the live depths and feature points that the camera currently is detecting to previously saved models and choose the correct database partition and viewpoint. In other words, once this detection is triggered, MRsive is then able to locate the coordinates and rotation of the device relatively to the $3 \mathrm{D}$ space. And finally, once the self-localization is achieved, all the visual assets that 
were designed in Unity can now be displayed in their right locations, and accurately anchored to the real world. In the event that the camera loses the position lock, the virtual elements will stay in position, though sometimes they might drift slightly, which has a minor impact on the experience. The system will adjust its position automatically once the automatic localization happens again. This is made possible because the iPhone, like many of the current smartphones, is equipped with gyroscope and accelerometer sensors that continuously inform the system on the relative location and rotation of the device. This six Degrees of Freedom (6 DoF) keep the virtual elements in the right place. On the other hand, the interaction with the art, the detection is more straightforward. I use the "Vuforia" SDK to use any art as a marker which will be in this case the anchor for any output whether visual, auditive or even haptic through the iPhone's vibrations.

To make it easier for the user to operate this tool from the beginning, I decided the first selection to be the language preference to cater to foreign people, tourists and newcomers (Fig. 3.8.a). Afterwards, the user chooses their point of interest, be it a painting, an exhibition, a predefined tour or even services like the restaurant or washrooms (Fig. 3.8.b). Then, the camera opens and asks the user to scan the space around to find localization. Once MRsive finds the user's position, virtual and animated arrows appear on the ground level leading the user, turn by turn, to the location of the previously selected point of interest or destination. During this experience, a dynamic top view minimap of 
the space will be at the bottom of the screen following the rotation of the user. The pin is always accurately positioned in the middle of the moving minimap and directed toward what is in the face of the user (Fig. 3.8.c) and (Fig. 3.8.d). Once arrived at the destined location, the user interacts with the art in the space by clicking on the "View with AR" button. The potential for the content is endless. Virtual elements can be an enlarged 3D model of a small statue for example as shown in figure 3.8.e or possibly extra information about a painting, augmented by images and text and even sound and haptics that automatically play when MRsive recognizes the painting (Fig. 3.8.f). The text would be in the language that was initially selected. 

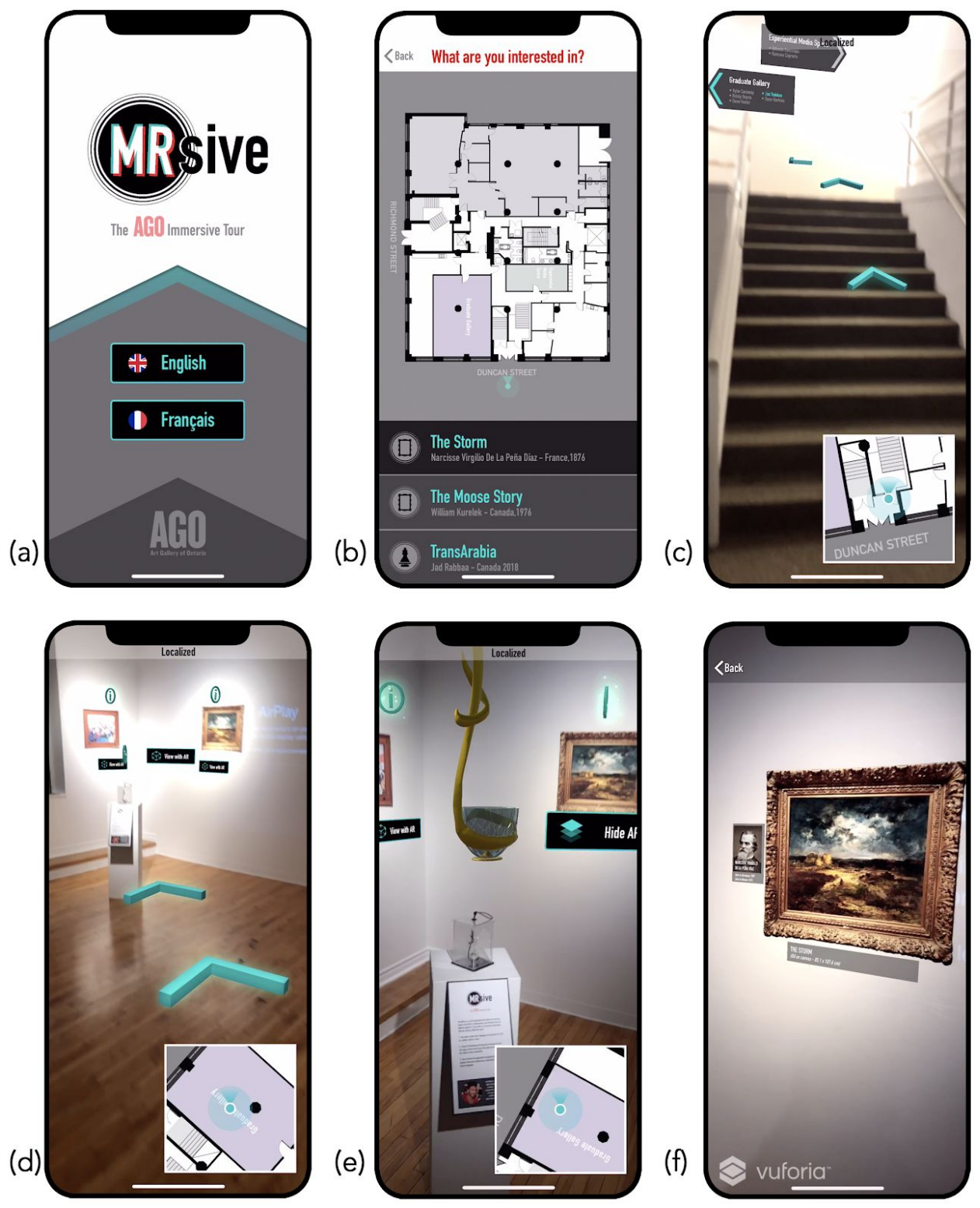

Figure 3.8: MRsive screenshots by order of user-flow:

(a) Language selection. (b) Destination selection. (c) and (d) AR wayfinding directions. (e) Interaction with a 3D artifact. (f) Interaction with a painting.

To design and evaluate the proposed engagement approach, I chose a painting from the AGO called "The Storm" by Narcisse Virgile. I decided to activate the piece and bring it to life through different AR interactions. The augmentation will include virtual graphics to complement the painting style, 
virtual text to display information about the art, sound of rain, wind and thunder to add an auditory layer of narration and storytelling, finally I add vibration to the device when the thunder plays to add a haptic layer and take the interaction to a multisensory immersive level. This experience will be the subject of study and observation that preceded semi-structured interviews with participants (see questionnaire in Appendix B).

Both experiments and the results and findings are explained in extensive details in chapter 4.

\subsection{Evaluation of MRsive}

Following the human-centered design approach that I am adopting, the user is always at the focus of this project so user testing with visitors would be the most logical approach. Once my prototype was complete and functional, I recruited 12 participants of different ages, backgrounds and mother tongues and that have never been to the AGO. In doing this I returned to the AGO to do my experiment, I invited the participants one by one to test MRsive. During the user testing, I noted my observations and then, I invited them for an interview to receive their feedback, comments, and suggestion (see questionnaire in Appendix B). The wayfinding experiment included a comparison between the use of current wayfinding aids at the AGO and the AR wayfinding approach of MRsive. The results were compared by accuracy, speed, and easiness of use. The engagement experiment encompassed a 
think-aloud method, observations and time measurement of the user testing that ended with a semi-structured interview. The direct observation of user testing involved asking users to think out loud as they were using MRsive and were invited to express their thoughts while interacting with the arts. Facial expressions were also noted.

I gathered the answers, comments and suggestions along with the notes that I took during the experiment. I first asked the participants to figure out how to find the elevators that go up to the fifth floor using the map and signs in the space. I observed and timed this task. I then asked them to use MRsive and to just follow the turn-by-turn directions on the screen without them knowing that the application is, in fact, leading them to the same destination. I compared the behaviour and speed of this task to the previous one. Another experiment was conducted for the engagement side. MRsive this time leads participants to the painting "The Storm". Once arrived at the painting, I invited the participants to interact with the art. I observe their engagement and note my observations while tracking the time of the experience. To conclude the user testing, I asked every user for their final thoughts and other comments. All the observations and results of the user testing will be shown and displayed in depth in chapter 4 along with a detailed discussion of the findings.

\subsection{Chapter Summary}

To maximize the contribution of this to research, I tried to follow Zimmerman's method (2007) for evaluating an interaction design research. The method has set 
criteria or four lenses: process, invention, relevance, extensibility.

First, for the process, I tried to provide enough details about my journey, my methods and decision-making process from ideation to evaluation. The sample code is also included in the appendices of this thesis. The hope is that any researcher can take on this research and continue the work where it was left off.

Second, for invention, the integration of markerless augmented reality in the perspective view for wayfinding is a novel approach to 3D wayfinding and indoor self-localization. It is not the only one for sure, yet it is not so common due to the hardware available in the market that hasn't matured yet for this kind of approach. Nevertheless, the design would be so relevant if and when smart glasses become mainstream.

Third, for relevance, and as I have already explained, the preferred host of my design is a head-mounted-display because of all the possible benefits that it offers to the user such as virtual graphics within the line of sight, and the hands-free interaction.

Last, the fourth and last lens or criterion is extensibility. The application of my design shows the many possible integrations such as shared experiences with other friends and family and where the project was left of has all the capabilities to grow and build on the previous outcomes. 


\section{Chapter 4. FINDINGS AND DISCUSSION}

At the end of chapter 3, I discussed the steps of the evaluation stage. I explained in details the experiment that I have conducted with the 12 participants who have never been to the AGO. The experiment as a whole allowed me to compare the usability of current static wayfinding and engagement approaches at the AGO to MRsive which uses a dynamic, digital and interactive approach through augmented reality.

In this chapter, I discussed the results gathered from the user testing stage, which included observations and interviews. The number of participants was chosen based on the most commonly reported sample size within the $\mathrm{HCl}$ community (Kaine, 2016). Although the evaluation sample was small, interesting and considerable results were noted through quantitative and qualitative approaches. Several analysis methods were considered. For the quantitative data, I settled on the use of data visualization to compare and analyze the results and extract valuable findings. For the qualitative data, I used a reflexive process to interpret critical feedback and analyze located patterns within the user responses. 
I discussed the successes and shortcomings of the prototype's design and its impact on wayfinding effectiveness and engagement reinforcement in a museum. Many lessons were learned during the experiment. The results of the user evaluation showed that MRsive was helpful for improving navigation and engagement with the art at the AGO. The findings also showed that the design needs further improvements to better support a seamless and undistracted user experience. On the downside, this research project had a few limitations such as small sample sizes for the study and technological limitations which I discussed in more detail at the end of this chapter.

\subsection{Evaluation Group}

Canada and especially the city of Toronto is known for the diversity of cultures, backgrounds, and languages. Many newcomers move to the city every year and many are more comfortable speaking their mother tongue than English. For the evaluation stage of my project, I target first-time museum visitors. Although I had a preference to study newcomers' experiences when exploring Canadian museums such as the AGO, my main criteria for finding participants was people who had a certain love for museums but have never been to the AGO. I recruited a group of 12 participants composed of seven males and five females. Their ages ranged between 24 and 35 years with an average of 31.4 years. Even though MRsive has the potential to theoretically support an uncountable number of languages, one can select between only English or French in the current prototype. Two of the participants chose the 
French option while the ten others chose English. Nevertheless, seven participants in total stated that they would have been more comfortable or would have preferred to select another language than English if they were available, those languages were Spanish, Mandarin and Arabic (Table 4.1).

\begin{tabular}{ccccccc} 
& Total & Males & Females & Age Average & $\begin{array}{c}\text { Prefer another } \\
\text { language than English }\end{array}$ \\
\hline Participants & 12 & 7 & 5 & 31.4 years & 7 out of 12
\end{tabular}

Table 4.1: Demographics of the 12 participants in user testing

The user testing took place at the AGO. Each participant experienced using MRsive in the AGO separately. Each study session was 45 minutes including 15-20 minutes of using the tool, followed by 15 minutes of semi-structured interviews. (see questionnaire in Appendix B). I took notes of each participant's behaviour during the experiment and wrote down their answers during the interview.

\subsection{Results}

This section is divided into two subsections that clearly outlines the findings extracted from the user testing. The first subsection lists and analyses the observations and answers gathered from the interviews regarding the wayfinding experiment. The second subsection builds on the previous one and presents the findings related to the engagement experiment. Those findings were also based on observations, and participants' remarks and answers regarding their interaction with a selected painting. 


\subsubsection{Findings: Wayfinding Experiment}

The wayfinding experiment started right after the welcome desk (Fig.

4.1.a). Participants had to complete two tasks. For the first task, the participants needed to find the elevators that go to the upper levels using any wayfinding aid currently available at the AGO, from brochure, signs, map or even asking the staff (Fig. 4.1.b). Then, for the second task, the participants had to use MRsive to find a Rodin statue by searching the application and then following on-screen directions and virtual arrows that are anchored to the physical space. Without making it obvious to the user, the statue's position is in fact adjacent to the elevators. The reason for using a similar destination or similar route is to create the fairest comparison when observing the participants complete both tasks. It is good to note that there is more than one way to get to both destinations. Figure 4.1 shows the proposed path to the elevators in green, and the other possible path in orange, though the user might decide to use the green path or the orange one to navigate to any of the two destinations. The goal is to note the participants' wayfinding behaviour and measure the duration of both wayfinding tasks from start to finish using a chronometer and compare the results. 


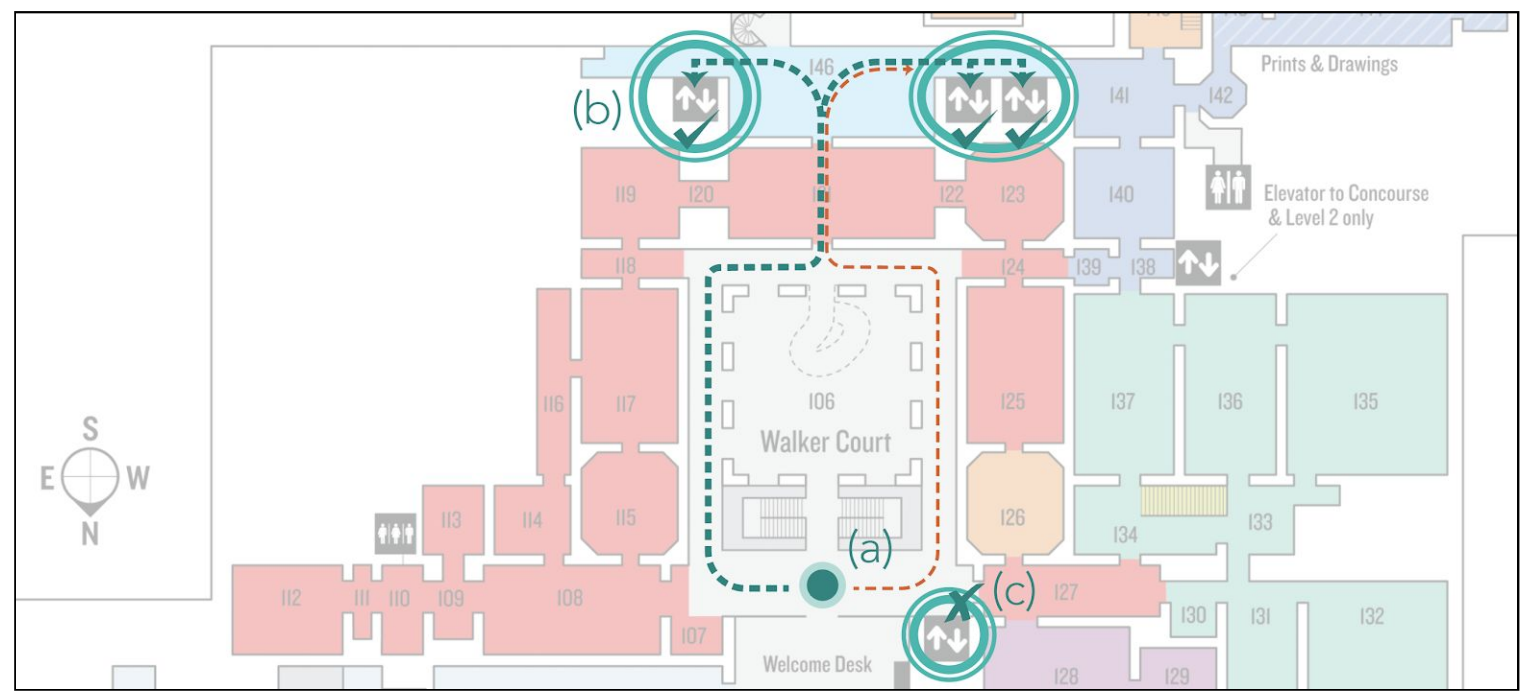

Figure 4.1: Paths to be followed by participants during the user testing experiment. (a) Welcome desk. (b) Elevators to the upper levels. (c) Elevator to Concourse and Level 2 only.

On average, the first task took the participants 154 seconds to complete using static wayfinding aids, while the second task took only 43 seconds (Table 4.2).

\begin{tabular}{ccc} 
& A path connecting the welcome desk to the elevators \\
\hline Wayfinding Approach & AGO Wayfinding Aids & MRsive Wayfinding Feature \\
\hline $\begin{array}{c}\text { Average time needed to } \\
\text { complete the task }\end{array}$ & 154 seconds & 43 seconds
\end{tabular}

Table 4.2: Average time needed to complete wayfinding task 1 and task 2

With the maps and signs, a lot of time was consumed to understand the printed representation of the space and align the representation of elements on the map or direction of a specific sign with the real world. In this case, this approach also required a lot of trial and error due to the confusing repetition of 
symbols on the map (Figure 4.1). The MRsive system, on the other hand, most of the time was spent on the required initial scan of the space before the virtual directions appeared on the screen. Luckily, after the camera starts, an icon shows up on the screen to intuitively ask the user to scan the surroundings in order to detect their exact location in the space (Figure 4.2). Nevertheless, MRsive helped participants complete the same route with significantly less time. The results were a clear indication that MRsive is a time-efficient method to navigate complex museum spaces such as the AGO.

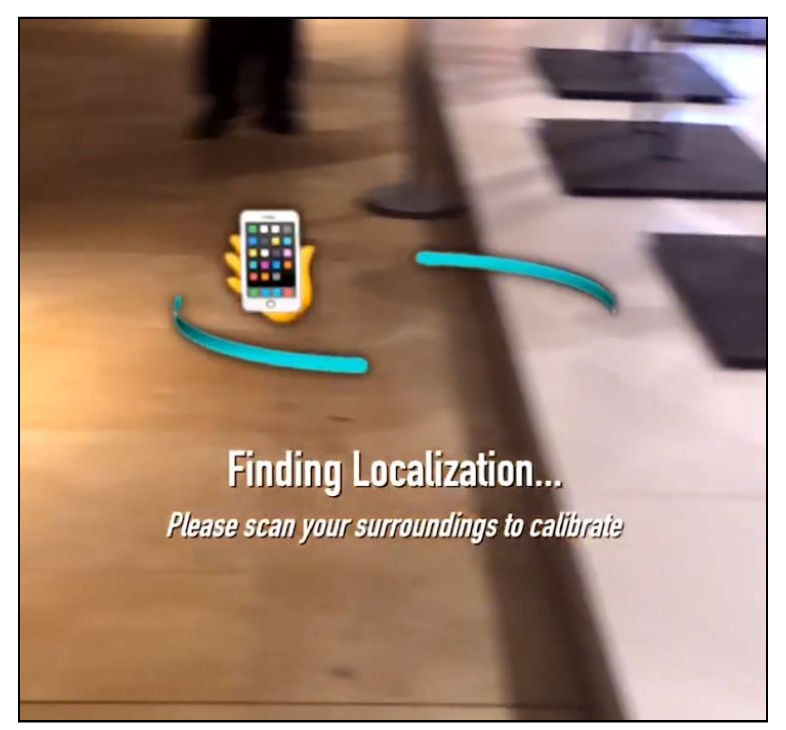

Figure 4.2: Initial icon asking users to scan the surrounding space to detect indoor localization.

I observed each participant's behaviour while they find their paths to the elevators using the static method and then the digital and dynamic method. MRsive simulates the path and virtually displays it using animated 3D arrows anchored in the real world for the participant to follow. Participants seemed to be intuitively following the arrows with ease and confidence due to the accuracy 
of the placement of those virtual graphics. They looked ahead to make sure not to bump into other people but looked down to the screen several times to make sure they are on the right track. However, wayfinding using printed media required participants to mentally draw different potential paths on top of the map and then to follow the one that they assumed to be the best choice. The AGO brochure is provided after the entrance and includes a map for every floor. When using this map, none of the participants navigated in a direct line from the beginning to the end. There were a lot of hesitation moments, and looking back and forth between the space and the map. At times, some of the participants had a frustrated look on their faces. Four of the participants wandered significantly away from the path that leads to the elevators and it wasn't until they gave up that they decided to find a staff member and ask for directions. The four participants that got lost while using the static aids explained that, aside from the many confusing symbols, the placement of several elevators on the map was confusing. One would assume that all these elevators must go up to the fifth floor but that is incorrect, only two of them do (Fig. 4.1.c). Those people were the only four participants that asked staff for directions.

Overall, when the participants were asked about their experience, most of them stated that they prefer relying on the wayfinding aids available to them rather than disrupting a staff member that could probably be not around or who could be busy doing something else. One participant said: "I prefer to figure it out on my own, as I would normally assume it must be simple and there is no 
need to ask anyone". All of the participants agreed that MRsive did not require a lot of thinking about anything other than following the arrows on the floor. Occasionally, some were worried not to trip over stairs or bump into other visitors but in general, things were smooth and straight forward. On the Likert scale of one to ten, one being not intuitive at all and ten being extremely intuitive, participants rated the static wayfinding much less than what they rated MRsive (Fig. 4.3).

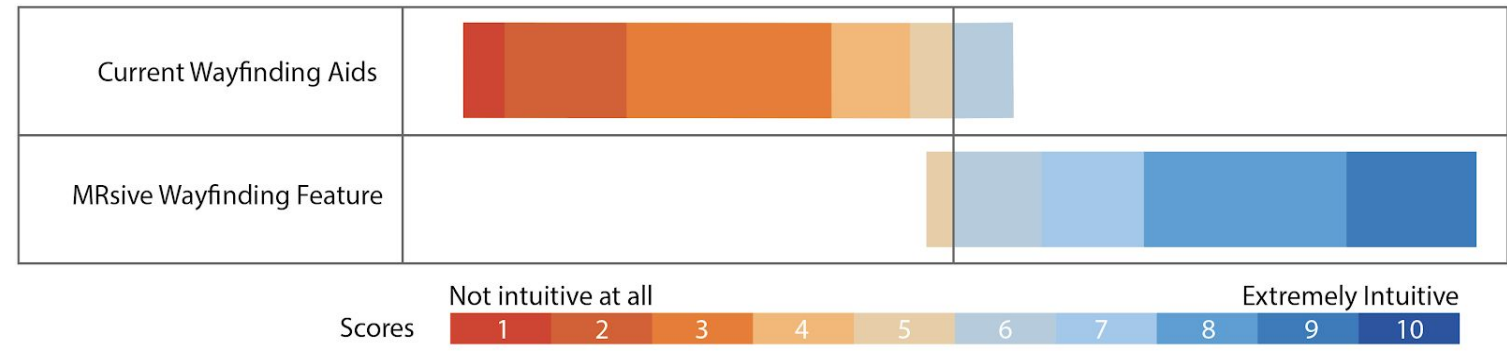

Figure 4.3: Wayfinding scores in both approaches. Current static wayfinding aids were rated between 1 and 6 over 10, while MRsive's scores ranged between 5 and 9 .

Most of the participants were impressed with the easiness of the AR approach. They commended the top view map at the corner of the screen which accurately followed their orientation and localization constantly during the navigation from start to finish. Because MRsive provides spatial knowledge, participants agreed that they were extremely aware of their localization in the physical space, and following the path to the destination was an intuitive experience. It was compared to following a clear trail. By eliminating the choices of different turns, the cognitive processes needed in the wayfinding task were 
reduced to the physical movement and in Raubal's words: "the wayfinding is reduced to a locomotion task" (2001).

\subsubsection{Findings: Engagement Experiment}

For the engagement experiment, the participants used MRsive and started at the same spot as the previous experiment, the welcome desk area. The application first showed a screen displaying the top view map and two destinations on the bottom (Fig.4.4.a). Before the directions appeared, participants were asked to click on the "The Storm" option which is a painting by Narcisse Virgile. They scanned the surrounding space as before (Fig.4.4.b), then followed the wayfinding directions to finally arrive in front of the painting (Fig. 4.4.c).
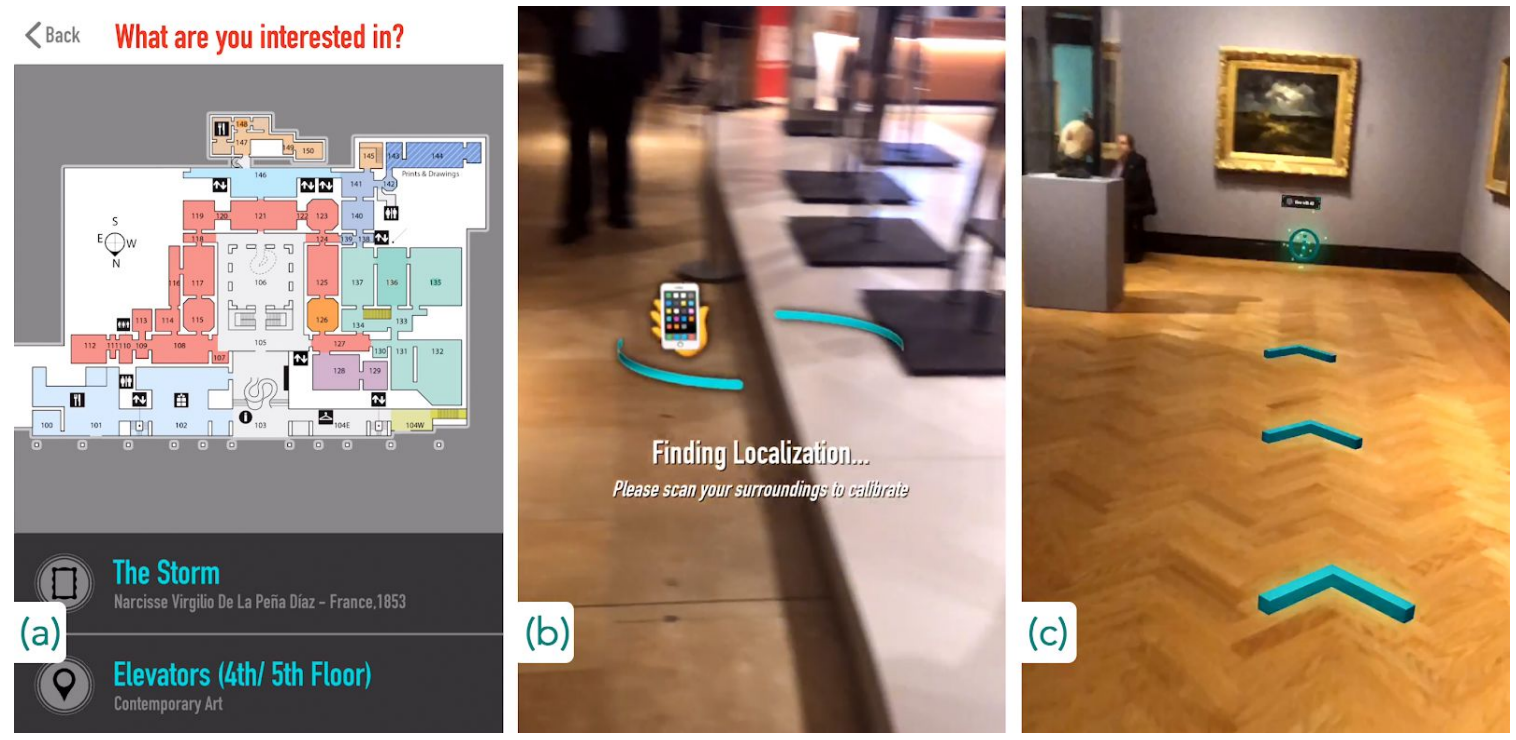

Figure 4.4: (a) selection of the destination. (b) Scanning to find localization. (c) AR directions 
The reason for choosing this art was the possibilities it offers. The theme of the painting and the elements in the landscape have a big potential to be brought to life through an AR multisensory interpretation. It has nice movement through the painting strokes for the wind that are translated into animation, and thunder into sound and vibration (Fig. 4.6). When the participants arrived at the painting, they were prompted with a button "View with AR" (Fig.4.5.a). None of the participants hesitated to press the button and they were eager to interact further with the painting. After the button was pressed, a graphic appeared in the middle of the screen inviting the user to scan the art (Fig.4.5.b). Once MRsive detected the painting, it visualized graphic elements and played the sound of storm, wind, rain and thunder, as well as the steps of a distant shepherd and a sheep in the landscape. To add an extra layer of interaction, the device vibrates every time the thunder's sound plays. (Fig. 4.5.c).
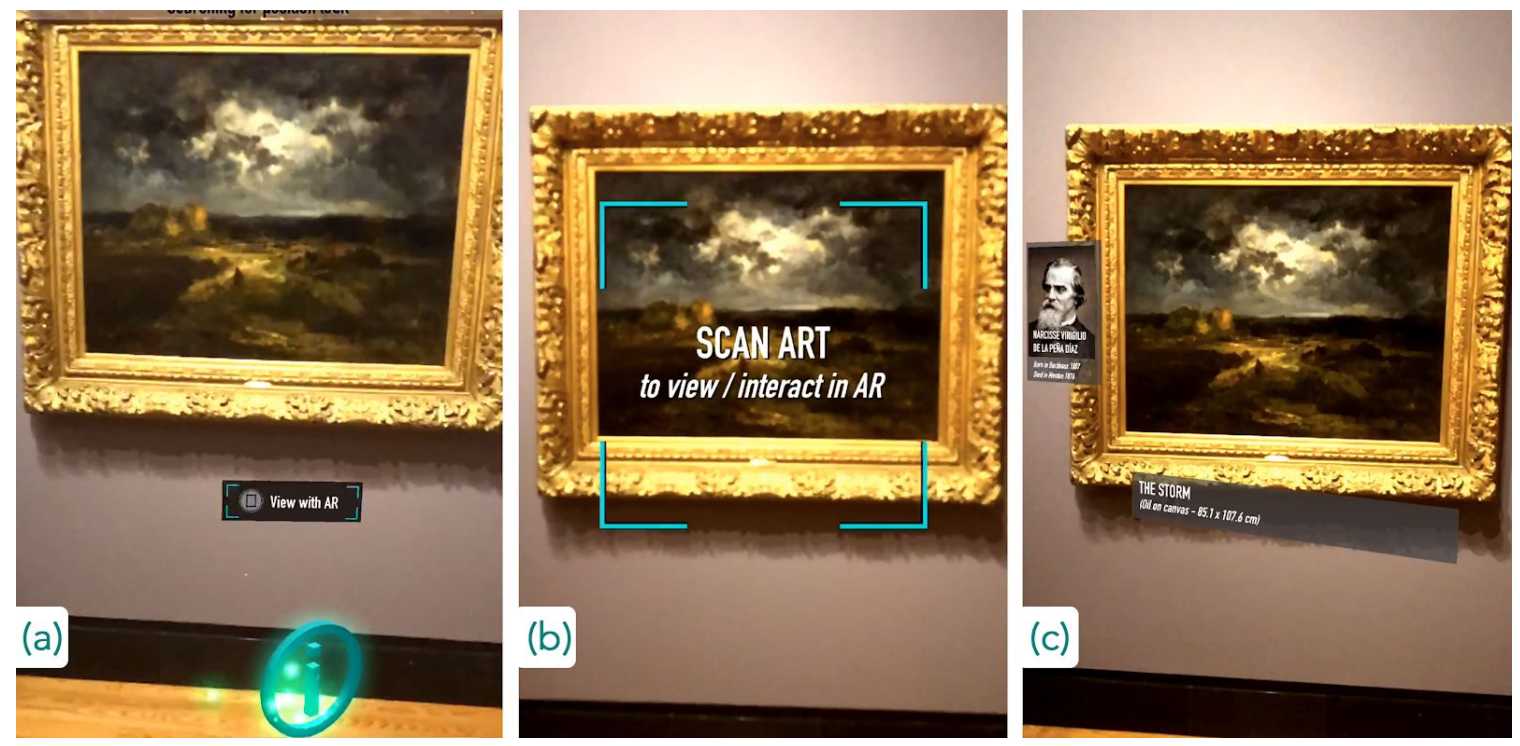

Figure 4.5: (a) "View with $A R$ " button. (b) Scanning the art. (c) AR interactions 
By observing the participants interact with the painting using MRsive and listening to their thoughts as they were thinking aloud, it was clear from most facial expressions that they were very attracted and interested in what they were experiencing. They expressed feelings of surprise and enjoyment. Words like "wow" and "oh cool" were common to most participants. When the multisensory experience was triggered, all of the participants appeared totally focused and almost immersed in what they could see, hear, and feel. Some of them stood closer to the painting to investigate elements more closely. A couple of participants pointed out that the shepherd and sheep are details they noticed because of the audio and that they would normally pass unnoticed at a quick glimpse of the painting. The duration of the interactions was also measured using a chronometer, it ranged between 50 and 88 seconds.

After this experiment, I asked the participants how they would have interacted with this painting without the application. Most participants leaned forward to read the label beside the painting and it was obvious that some of them were struggling to read the text in small font. The label had only the name of the painter and name of the painting. Almost all participants finished reading the label in a couple of seconds and some of them tried to find if the brochure had any extra information without any success (Fig.4.6). 


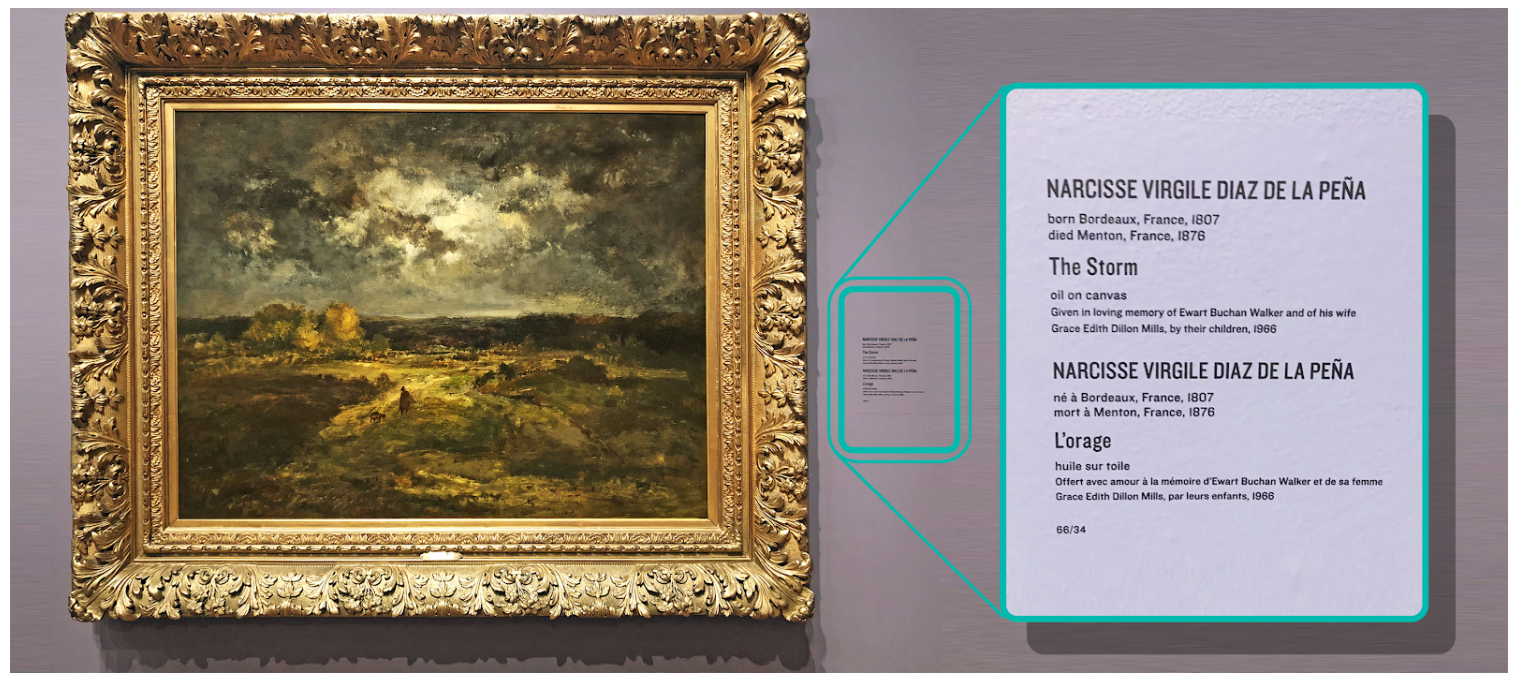

Figure 4.6: The Storm: Oil painting at the AGO that was AR activated through MRsive and the corresponding description label on the side

During the interview, I was able to know more about the visitors' response to the engagement experiment as a whole. Their answers included a lot of thought and interesting insights as well as critiques and suggestions for the next iteration. I also asked them to rate both experiences. On the Likert scale of one to ten, one being not engaging at all and ten being extremely engaging, participants rated the static engagement approach much less than what they rated MRsive (Fig. 4.7).

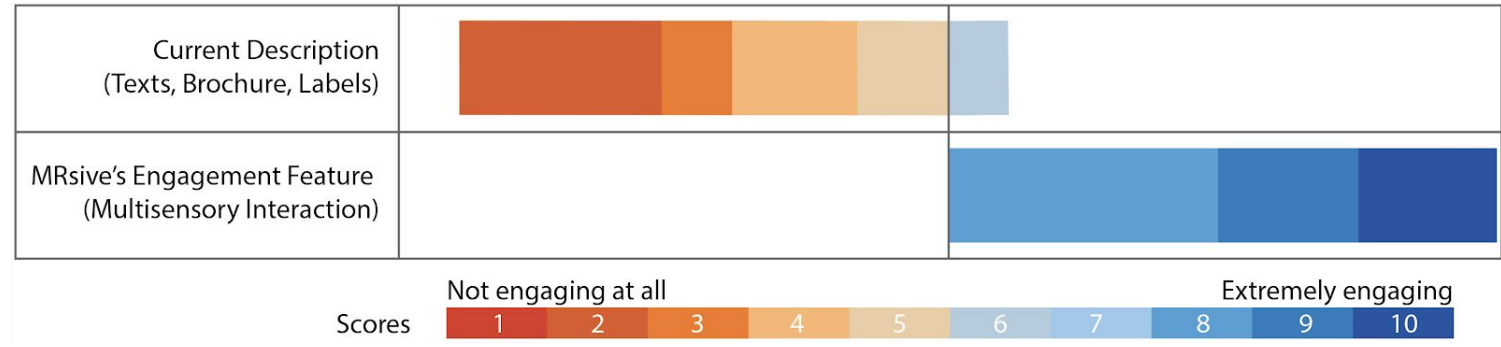

Figure 4.7: Engagements scores of both approaches. Current engagement approaches were rated between 2 and 6 over 10, while MRsive's scores ranged between 8 and 10 . 
Most participants were generally pleased with the multisensory interaction with the painting. "I felt like I am being drawn to the center of the painting, walking behind the shepherd" (participant 1); "The thunder sound and the vibration were a great touch to bring my attention to the story, it made me want to know more about the state the painter painted this in and where" (participant 2); "I wish all the paintings were AR activated" (participant 3), were some of the verbatims that showed the positive impact of the approach on the engagement with the art using AR. Only one participant didn't appreciate the visual approach to the interaction, they said they didn't mind the sound and vibration as long as the painting as a visual medium stayed "unbothered". He explains that he prefers to see the art directly and he considers the device as a distraction or barrier between him as a viewer and the art. Some other participants also pointed out that holding the device up for some time could be tiring.

The results from both experiments, the wayfinding and the engagement, were valuable findings regarding the needs and interests of the participants as well as a clear indication to the successes and limitations of the design of MRsive. Several lessons should be taken into consideration for future iterations of the prototype to make it more successful. 


\subsection{Lessons Learned}

Wayfinding using MRsive is digital and dynamic. Despite the small research group, based on the findings and feedback of most participants, MRsive seemed to have facilitated the navigation and made it more time efficient and accurate when looking for a particular destination. It saved the navigator a considerable amount of time and provided noticeable accuracy in indoor positioning as well as the localization of the selected destination. Despite the scalability of MRsive and the possibility to add preloaded tours to the digital museum experience, it was not clear how it would affect some museum visitors' desire to wander around the space. It is important to note, that such AR tool would be more useful when a visitor has a specific directed wayfinding or engagement goal and it would be valuable in the future to examine user responses to pre-populated tours that provide more freedom in exploring and selecting different complex paths. In general, MRsive seemed to have saved the user cognitive demands that are normally required to navigate spaces using printed maps and signs. The user interface and user experience of the application were intuitive and easy to use. The engagement part of the application was interactive, and the multisensory approach was in the words of participants, engaging, fun, and interesting. It encouraged learning and deeper connection with the art. Brochures and the simple text labels next to art pieces in galleries are not engaging and satisfactory enough for the mind of most museum visitors. The magic and novelty of AR have definitely played a big role in attracting the attention of the participants and encouraged their engagement with the 
art. The AR content then becomes the concern and the democratization of the museums and the art is then a question that need to be addressed. In its current version, MRsive is not interactive to the point that the viewer can add or affect the AR content which gives the curators the control over the interpretation of the exhibits and how they are presented digitally as well as in the physical space. It is important to be aware that the AR platform could become more interactive and allow visitors to add their digital content and this would raise important questions related to appropriation and intellectual property. Ideally, the digital interpretation of the art should be handled and directed by the artists themselves if it is possible. In the next best scenario, when the artist is not present, the content should be curated by the professional curators and controlled by museum professionals to make sure the multisensory translation respects the original physical arts and complements it rather than disturbs it. Those issues were not addressed in this thesis as they are out of scope of the research, nevertheless, it is crucial to take them into consideration going forward in the development of MRsive.

Another learned lesson was related to the hosting device. On the downside, when using a mobile device while moving around, the awareness of the surrounding space and the interaction with other individuals in the space were difficult. This was due to the small screen. Besides, holding the device up around other individuals could be awkward and also tiring for the user's arm. When interacting with the art, the small field of view of the mobile's screen limited the view of the art in its entirety. The surrounding space also faded away while looking at the screen all the time. The screen was an obstacle in the way of the intended immersion. The device itself risked 
becoming a distraction. It was unarguable, that the mobile device is not the ideal platform for a similar AR approach. A head-mounted display, as originally imagined, is the next iteration to experiment with. A wearable device worn on the head may eliminate most of those struggles. Head mounted display based AR offers the possibility of hands-free interactions and the display of graphics within the line of sight. In this approach, the user might worry less about the device and it is worth putting it under the test. From a user interface point of view, the occlusion of virtual elements by physical objects is needed to create a more realistic experience. It is also clear that more art pieces are needed to be AR activated to simulate the experience of a small tour. Furthermore, more languages need to be supported by the application if the solution targets tourists and newcomers.

\subsection{Limitations: Technological, Access, and Skills}

Many limitations stood in the way of the original vision of this project. Some of the limitations were related to logistics, others to scope and time, and many were technological limitations.

My internship at the AGO was a great opportunity to access the museum and conduct my research in locating the needs of the users as well as to the user testing experiments. Nevertheless, the AGO, like any museum has many policies and regulations to be respected. I had to work my way into finding solutions to many roadblocks during my research in the gallery. I am grateful to the manager of the 
digital department and the program coordinator at the AGO for facilitating the logistics of joining the AGO family. At first, I had to go through training before I could interview visitors as an AGO intern. It required time, and I wasn't allowed to record the voice or video record in the gallery during the interviews, and therefore, I resorted to pen and a paper to write down the answers as fast as I could. Unlike video or audio, The collection of data through pen and paper risks missing out on important insights and also distracts the interviewer from better interacting with the participant to lead a smooth and inviting conversation.

Even though the results of the experiments and interviews showed substantial differences when comparing the static approaches to AR approaches, it is hard to prove that these results are reliable and consistent because of the limited number of participants. This is one of the limitations of using the Likert scale with a small evaluation group. Unfortunately, recruiting more participants was out of the scope and time allocated to this project. 12 was the decided number of participants as it is the most commonly reported sample size within the $\mathrm{HCl}$ community (Kaine, 2016). The Likert scale used in the experiments to rate experiences had few limitations, mainly in unpacking the meaning of such subjective values when the differences between results are small or minimal. Luckily the comparisons were obvious due to the big differences in results and revealed the successes and problems. Nevertheless, this is definitely something to note for the future of this research when recruiting the same size of the evaluation group. 
As a background, I am a UX designer and not a programmer or computer scientist. From a technical point of view, the project required a lot of technical skills. Although Unity and Xcode make it easy for non-developers to create AR experiences, many technical obstacles were facing the smooth progression and development of my project, especially that I was working by myself.

Last but not least, I previously mentioned my initial vision for this project and discussed that it is ideal for MRsive to be hosted on a head-mounted display to simulate how this experience would look like when futuristic and practical smart AR glasses are available in the market. Since then I suspected that the portability of the mobile device and the required hand interaction with the screen could be problematic. My intention was to develop for the mobile device as a first initial prototype before developing for AR glasses through the current chunky AR glasses. Unfortunately, not only time and scope were in the way of accomplishing this goal, but also the unavailability of head-mounted displays in the market. Most of these devices are not available to the mass and their developer's version is only available to companies and AR developers. On the other hand, each one of these devices has its own SDK platform and developer kit which makes it difficult to develop content for. Furthermore, many of them are not portable and need to be tethered to a computer which would be another problem, these would not be allowed in the museum gallery. 


\section{Chapter 5. CONCLUSION AND FUTURE WORK}

In the first chapter of this thesis, I introduced the goals and contributions of this work. In this chapter, I revisit the research goals and outline what was accomplished. I highlight again the contributions of this thesis to research and then discuss directions for future work.

\subsection{Revisiting Thesis Goals}

The goals of this thesis relate to research in two areas: indoor wayfinding and engagement in museums. Much of the wayfinding literature have examined the cognitive processes needed in static wayfinding aids and much of the engagement literature have explored the limitations of museum approaches. The main goal of this research is to create and evaluate an AR tool, MRsive, that hypothetically supports the museum visitor's navigation of the museum with less cognitive demands and also facilitates a more fulfilling interaction with arts through one complete museum experience. Under this overarching objective, several subgoals are achieved. Those subgoals are mainly the evaluation of novel technologies such as dynamic indoor localization using computer vision as well as multisensory interaction with arts. 


\subsection{Revisiting Thesis Contributions}

This work makes several contributions to the research of indoor wayfinding and the future of engagement approaches in museums:

(1) A thorough literature review at the intersection of three fields: psychology, cognitive science, and computer science which is necessary for the creation and evaluation of a research project similar to MRsive. Wayfinding, museums and augmented reality are the three overarching themes of this work.

Chapter 2 outlines the relevant notions coming from each field and weave them into a knowledge base to launch the research.

(2) A novel design of an AR tool, MRsive, that facilitates indoor navigation and engagement with arts in a museum.

Chapter 3 presents the detailed system architecture of MRsive which uses computer vision to support indoor positioning and wayfinding, as well as different sensors to create a multisensory interaction with arts. The chapter explains the methodology to create and evaluate the prototype, provides technical diagrams and sample codes. The design is scalable and offers clear potentials to be adapted to different locations, used in many other ways, and hosted on other devices such AR glasses to leverage hands-free interactions and an AR view within the line of sight of the user. 
(3) A confirmation of the struggles and needs of museum visitors.

The need finding stage of chapter 3 discusses the barriers that AGO visitors face when using static wayfinding aids, and static approaches to engage with arts.

(4) Validation of the benefits of AR and its support of wayfinding tasks using responsiveness, accuracy, consistency and intuition.

(5) A confirmation of the positive influence of AR multisensory interactions on engagement and satisfaction of museum visitors in general, providing the digital content is curated by art professionals, museum curators, or ideally the artists themselves.

\subsection{Future Work}

MRsive studied the impact of AR in enhancing wayfinding and engagement with arts in museums. This work has given rise to several future directions divided into three categories: (1) the short-term which is on the design level; (2) the Medium-term revolving around studying the newly generated prototypes; and (3) the long-term level in order to apply the work to other target audiences.

(1) Short-term future work: Most of the short term enhancements are on the design level. The current user interface has a lot of room to be improved. The 
incorporation of occlusion to the AR experience would allegedly make the virtual elements more immersive and realistic (Billinghurst, 2016). 3D interfaces are novel to users and the best practices are still being shaped by the big companies to create universal guidelines. In the meantime, different suggestions and ideas are proposed to make the user experience of the application more intuitive. Some of those ideas are: (1) animating the icons between the different screens of the application; (2) showing the full path on the top view minimap during wayfinding; (3) giving the user more control on the visuals and sound when interacting with the art.

(2) Medium-term future work: As I previously mentioned, the initial vision of MRsive is an AR solution to be hosted on a head-mounted display. The current research studied the impact of augmented reality on indoor wayfinding and engagement with arts, but we learned that the experience seemed to be affected by the device's limitations. It is necessary to use a head-mounted display as a platform for the application in the next iteration to identify the different positive and negative impact of the device on the experience. This future version of MRsive can use the current handheld prototype as a starting point. Such a study can validate the different opportunities that an HMD could offer. With this approach, the user may benefit from a hands-free interaction as an input, and a display of $A R$ virtual elements within the Line of Sight (LOS). The displays of AR glasses also have a limited field of view, nevertheless, the line of sight may be a solution to the distraction that participants of MRsive struggled with when using the mobile device (Fig. 3.4). 
(3) Long-term future work: More future development of MRsive on the long term is worth being explored or at least noted. As a dynamic and digital approach, MRsive has the potential to connect new museum visitors with the recommendations of previous visitors. Using social media guidelines such as a tagging, commenting and liking system is an idea that is worth being explored. Lastly, the now possible space recognition and object detection present valuable opportunities to be explored when targeting visually impaired museum visitors. MRsive is a system that is connected to a camera, a speaker, and a vibration motor among other connections. For the visually impaired, as well as for the participants that were distracted by the screen, a system with computer vision that "sees" the world and is capable of communicating with audio and haptic responses is worth being studied.

\subsection{Closing Remarks}

With the exponential spread of augmented reality devices and the development of computer vision, researchers, engineers and designers should think of how these technologies could benefit humans in their daily life. The future of virtuality and its integration with the physical world is promising and not too distant. This work contributes to exploring the use of AR in museums through a set of lessons. These are learned by observing and interviewing the participants before and after user testing the prototype. The developed solution demonstrated support for indoor wayfinding and 
MRsive: an Augmented Reality Tool for Enhancing Wayfinding and Engagement With Art in Museums

engagement with arts. As discussed in the future works, different possibilities are available in taking this work further. I hope the work presented in this thesis will assist other researchers and designers in understanding the impact of AR on wayfinding and engagements needs, and motivate them to develop similar tools to MRsive or even improve the design to add to the contributions and pave the way toward the museum of the future. 


\section{BIBLIOGRAPHY}

[1] Allen, G. L. (1999) Spatial Abilities, Cognitive Maps, and Wayfinding: Bases for Individual Differences in Spatial Cognition and Behavior. In R. G. Golledge (Ed.), Wayfinding behavior: Cognitive mapping and other spatial processes (pp. 46-80). Baltimore: Johns Hopkins University Press.

[2] Allen, G. L. (2000). Principles and practices for communicating route knowledge. Applied Cognitive Psychology 14(4), 333-359.

[3] Alnabhan, A., \& Tomaszewski, B. (2014). INSAR : Indoor Navigation System using Augmented Reality. Proceedings of the Sixth ACM SIGSPATIAL International Workshop on Indoor Spatial Awareness - ISA '14, 36-43. https://doi.org/10.1145/2676528.2676535

[4] Antle, A. N., \& Wise, A. F. (2013). Getting down to details: Using theories of cognition and learning to inform tangible user interface design. Interacting with Computers, 25(1), 1-20. https://doi.org/10.1093/iwc/iws007

[5] Barron, P., \& Leask, A. (2017). Visitor engagement at museums: Generation Y and 'Lates' events at the National Museum of Scotland. Museum Management and Curatorship, 0(0), 1-18. https://doi.org/10.1080/09647775.2017.1367259

[6] Ben Asr, I., Hallem, Y., \& Lagier, J. (2017). Quel est le rôle de I' application mobile dans la valorisation de I' expérience muséale ?, 87-109.

[7] Billinghurst, M., Clark, A., \& Lee, G. (2017). A Survey of Augmented Reality Navigation, 8(2), 73-272. https://doi.org/10.1561/1100000049 
MRsive: an Augmented Reality Tool for Enhancing Wayfinding and Engagement With Art in Museums

[8] Black, G. (2017). The Engaging Museum. Developing Museums for Visitor Involvement.

[9] Blessing, L. T. M., \& Chakrabarti, A. (1999). Design Research Methodology.

[10] Business / Arts. (2018). Culture Track: Canada.

[11] Caine, K. (2016). Local Standards for Sample Size at CHI.

[12] Cheng, K., \& Pérez-Kriz, S. (2014). Map Design for Complex Architecture: A User Study of Maps \& Wayfinding. Visible Language, 48(2), 6-33. Retrieved from /http://ezproxy.library.nyu.edu:2048/login?url=http://search.ebscohost.com/login.aspx?direct=tr ue $\& \mathrm{db}=$ asu $\& A N=98592915 \&$ site $=$ eds-live

[13] Colledge, R. G. (1999). Wayfinding Behavior: Cognitive Mapping and Other Spatial Processes. Baltimore, The Johns Hopkins University Press: 5-45.

[14] Dalton, R. C., Hölscher, C., \& Montello, D. R. (2019). Wayfinding as a Social Activity, 10(February), 1-14. https://doi.org/10.3389/fpsyg.2019.00142

[15] Damala, A. (2006). Evaluation strategies for mobile museum guides: a theoretical framework. 3rd International Conference ..., (Icom 2001), 1-9. Retrieved from http://areti.freewebspace.com/pdf_files/avicom2006.pdf

[16] Darken, R.P. (1996). Wayfinding in large-scale virtual worlds. George Washington University.

[17] Dirin, A., \& Laine, T. H. (2018). User Experience in Mobile Augmented Reality: Emotions, Challenges, Opportunities and Best Practices. https://doi.org/10.3390/computers7020033

[18] Economou, M., \& Meintani, E. (2011). Promising beginnings? Evaluating museum mobile phone apps. Rethinking Technology in Museums Conference Proceedings, (May 2011), 26-27. 
MRsive: an Augmented Reality Tool for Enhancing Wayfinding and Engagement With Art in Museums

[19] Emo, B., Hoelscher, C., Wiener, J. \& Dalton, R. (2012). Wayfinding and Spatial Configuration: evidence from street corners. Eighth International Space Syntax Symposium, 1-16.

[20] Falk, J. H. (2009). Identity and the museum visitor experience. Walnut Creek, Calif: Left Coast Press.

[21] Folkestad, J., \& O'Shea, P. (2011). An Analysis of Engagement in a Combination Indoor /Outdoor Augmented Reality Educational Game, 7(1), 30-37.

[22] Gabbard, J. L., Hix, D., \& Swan, J. E. (1999). \{U\}ser-\{C\}entered \{D\}esign and $\{E\}$ valuation of $\{$ V\}irtual \{E\}nvironments. \{IEEE\} \{C\}omputer \{G\}raphics and \{A\}pplications, 1966), 51-59. https://doi.org/http://doi.ieeecomputersociety.org/10.1109/38.799740

[23] Gallery-map-level-1.png [Digital image]. (n.d.). Retrieved February 8, 2019, from https://ago.ca/visit/gallery-map

[24] Hannula, M., Suoranta, J., \& Vadén, T. (n.d.). Hannula et al, "Artistic Research Methodology."

[25] Heath, C., \& von Lehn, D. (2008). Configuring "Interactivity": Enhancing Engagement in Science Centres and Museums. https://doi.org/10.1177/0306312707084152

[26] Huey, L. C., Sebastian, P., \& Drieberg, M. (2011). Augmented reality based indoor positioning navigation tool. 2011 IEEE Conference on Open Systems, ICOS 2011, (October), 262-266. https://doi.org/10.1109/ICOS.2011.6079276

[27] Hughes, K. (2015). Museum and gallery wayfinding: tips for signage, maps and apps; How can cultural attractions enhance the visitor experience at a time of shrinking budgets? Inspiration and case studies this way. The Guardian. 
MRsive: an Augmented Reality Tool for Enhancing Wayfinding and Engagement With Art in Museums

[28] Hund, A. M., \& Minarik, J. L. (2006). Getting From Here to There : Spatial Anxiety, Wayfinding Strategies, Direction Type, and Wayfinding Efficiency. Spatial Cognition \& Computation: An Interdisciplinary Journal, 6(3), 179-201. https://doi.org/10.1207/s15427633scc0603

[29] Jersild, A. T. (1927). Mental Set and Shift, (89).

[30] Kim, M. J., Wang, X., Han, S., \& Wang, Y. (2015). Implementing an augmented reality-enabled wayfinding system through studying user experience and requirements in complex environments. Visualization in Engineering, 3(1), 12. https://doi.org/10.1186/s40327-015-0026-2

[31] Kumar, R. (2005). Research_Methodology. Pearson Education (Vol. 2nd edition).

[32] Levent, N., \& Pascual-Leone, A. (2014). The Multisensory Museum.

[33] Levine, M., Marchon, I., \& Hanley, G. (1984). The Placement And Misplacement of You-Are-Here Maps. Environment and Behavior 16 (2): 139-57.

[34] Li, R., \& Klippel, A. (2016). Wayfinding Behaviors in Complex Buildings: The Impact of Environmental Legibility and Familiarity. Environment and Behavior, 48(3), 482-510. https://doi.org/10.1177/0013916514550243

[35] Lobben, A. K. (2004). Tasks, Strategies, and Cognitive Processes Associated With Navigational Map Reading: A Review Perspective. The Professional Geographer, 56(2), 270-281.

[36] Mallot, H. (1999). Spatial cognition: Behavioral competencies, neural mechanisms, and evolutionary scaling. Kognitionswissenschaften, 8, 40-48.

[37] Marck, J. W., Mohamoud, A., Houwen, E., \& Heijster, R. Van. (2013). Indoor Radar SLAM. A Radar Application for Vision and GPS Denied Environments, 1783-1786. 
MRsive: an Augmented Reality Tool for Enhancing Wayfinding and Engagement With Art in Museums

[38] My Visit to the Louvre. App Store (2016). Retrieved 27 April, 2019, from https://itunes.apple.com/ca/app/my-visit-to-the-louvre/id1100629786?mt=8

[39] Montello D.R. (2001) Spatial cognition. In International Encyclopedia of the Social \& Behavioral Sciences, pages 14771-14775. Oxford: Pergamon Press.

[40] Montello, D. R. (2007). The contribution of space syntax to a comprehensive theory of environmental psychology. Paper presented at the 6th International Space Syntax Symposium, Istanbul, Turkey.

[41] Montello, D. R., \& Sas, C. (2006). Human Factors of Wayfinding in Navigation, 1-17.

[42] Mullen, S. P., Palac, D. E., \& Bryant, L. L. (2016). Maps to Apps : Evaluating Wayfinding Technology, 137-151. https://doi.org/10.1007/978-3-319-31072-5

[43] Mulloni, A., Seichter, H., \& Schmalstieg, D. (2011). Handheld augmented reality indoor navigation with activity-based instructions. Proceedings of the 13th International Conference on Human Computer Interaction with Mobile Devices and Services - MobileHCl '11, 211. https://doi.org/10.1145/2037373.2037406

[44] Nicholas, H. (2000). The art and science of wayfinding. Access by Design, 23(85), 5-7.

[45] Passini, R. (1984). Wayfinding in architecture. Van Nostrand Reinhold Nova York; 1992. McGraw-Hill Book CO. New York, USA.

[46] Raubal, M. (2001) Human wayfinding in unfamiliar buildings: a simulation with a cognizing agent. Cognitive Processing (2-3), 363-388.

[47] Robb, L., Harrison, J., \& Adamson, M. (2018). Anthropocene App User Testing. 
MRsive: an Augmented Reality Tool for Enhancing Wayfinding and Engagement With Art in Museums

[48] Roussou, M., \& Katifori, A. (2018). Flow, Staging, Wayfinding, Personalization: Evaluating User Experience with Mobile Museum Narratives. Multimodal Technologies and Interaction, 2(2), 32. https://doi.org/10.3390/mti2020032

[49] Rusakova, V. (2017). The Methods of Prototyping User Interfaces in Educational Applications With Augmented Reality.

[50] Shamsuddin, N. A. A., \& Che Din, S. (2015). Spatial Ability Skills : A correlation between Augmented Reality (AR) and conventional way on wayfinding system. Environment-Behaviour Proceedings Journal, 159-167.

[51] Segd.org. (2019). What is Wayfinding?. Retrieved 2019, from https://segd.org/what-wayfinding

[52] Stein, E. (2014). Fostering Creativity in Self and the Organization. Your Professional.

[53] Stephenson, B., Lorenzo, N., Manikoth, K., Yule, M., \& Chan, T. (2017). A Remedial And Summative Evaluation Of The Reblink Installation At The Art Gallery Of Ontario, (C).

[54] Střelák, D., Škola, F., \& Liarokapis, F. (2016). Examining User Experiences in a Mobile Augmented Reality Tourist Guide. Proceedings of the 9th ACM International Conference on PErvasive Technologies Related to Assistive Environments - PETRA '16, 1-8. https://doi.org/10.1145/2910674.2935835

[55] Tallon, L. (2016). The Future of Mapping and Wayfinding at The Met. Retrieved 2019, from www.metmuseum.org/blogs/digital-underground/2016/future-of-mapping-and-wayfinding

[56] Thomas, B., Close, B., Donoghue, J., Squires, J., Bondi, P. De, \& Piekarski, W. (2002). First Person Indoor / Outdoor Augmented Reality Application : ARQuake, 75-86. 
MRsive: an Augmented Reality Tool for Enhancing Wayfinding and Engagement With Art in Museums

[57] Van Der Vaart, M., \& Damala, A. (2016). Through the Loupe : Visitor engagement with a primarily text-based handheld AR application. Digital Heritage International Congress, 565-572.

[58] Ventura, J., Arth, C., Reitmayr, G., \& Schmalstieg, D. (2014). Global Localization from Monocular SLAM on a Mobile Phone, 20(4), 531-539.

[59] Vilar, E., Rebelo, F., \& Noriega, P. (2014). Indoor Human Wayfinding Performance Using Vertical and Horizontal Signage in Virtual Reality. Human Factors and Ergonomics in Manufacturing and Service Industries, 6(24), 601-615. https://doi.org/10.1002/hfm

[60] Wang, C., Chiang, D.-J., \& Ho, Y.-Y. (2012). 3D Augmented Reality Mobile Navigation System Supporting Indoor Positioning Function. International Conference on Computational Intelligence and Cybernetics (CyberneticsCom), 64-68.

[61] Weiser, M. (1991). The Computer for the 21st Century. Scientific American, 265(3), 94-105.

[62] Wiener, J. M., Büchner, S. J., \& Hölscher, C. (2009). Towards a Taxonomy of Wayfinding Tasks : A Knowledge-Based Approach. Spatial Cognition \& Computation, 9(2), 152-165. https://doi.org/10.1080/13875860902906496

[63] Xiao, R., \& Benko, H. (2016). Augmenting the Field-of-View of Head-Mounted Displays with Sparse Peripheral Displays. CHI 2016, 1221-1232.

[64] Yokoi, K., Yabuki, N., Fukuda, T., Michikawa, T., \& Motamedi, A. (2015). Way-Finding Assistance System for Underground Facilities Using Augmented Reality. The International Archives of the Photogrammetry, Remote Sensing and Spatial Information Sciences - ISPRS Archives, 4O(4W5), 37-41. https://doi.org/10.5194/isprsarchives-XL-4-W5-37-2015

[65] Zhang, Z. (2012). Microsoft Kinect Sensor and Its Effect. IEEE MultiMedia, 19, 4-10. https://doi.org/10.1109/MMUL.2012.24 
MRsive: an Augmented Reality Tool for Enhancing Wayfinding and Engagement With Art in Museums

[66] Zimmerman, J., Forlizzi, J., \& Evenson, S. (2007). Research Through Design as a Method for Interaction Design Research in $\mathrm{HCl}, 493-502$. 


\section{APPENDICES}

\section{Appendix A: Semi-structured Interview Questions (Need Finding Stage):}

\section{WAYFINGING QUESTIONS:}

\begin{tabular}{|lrrrrr}
\hline \multicolumn{3}{|l}{ Interviewer } & \multicolumn{3}{l}{ Date } \\
AM & $12-2$ & $2-4$ & $4-6$ & $6+$ \\
Day & & Weekend & & \multicolumn{3}{l}{ Wed Night }
\end{tabular}

1. On a scale of $1-10$, where 1 is "not at all" and 10 is "extremely", do you find navigation and wayfinding around museums in general straightforward?

$\begin{array}{lllllllllll}1 & 2 & 3 & 4 & 5 & 6 & 7 & 8 & 9 & 10 & 1 \text { a. Follow-up: What makes you say that score? }\end{array}$

2. On a scale of 1-10, where 1 is "not at all" and 10 is "extremely", do you find navigation and wayfinding around the AGO straightforward?

$\begin{array}{lllllllllll}1 & 2 & 3 & 4 & 5 & 6 & 7 & 8 & 9 & 10 & \text { 2a. Follow-up: What makes you say that score? }\end{array}$

3. Which of the following methods did you use to navigate the AGO today? You may select more than one.

- The paper map

- Information guides/Gallery Guides/Staff

- The wayfinding signage located across the

- Other: gallery

- Gallery numbers

3a. Follow-up: If you were in charge of creating a new [map / wayfinding signage / gallery numbers], what would you do differently?

\section{ENGAGEMENT QUESTIONS:}

4. On a scale of $1-10$, where 1 is "not at all" and 10 is "extremely", how engaging do you find the art and its presentation around museums in general?

$\begin{array}{lllllllllll}1 & 2 & 3 & 4 & 5 & 6 & 7 & 8 & 9 & 10 & 4 a \text {. Follow-up: What makes you say that score? }\end{array}$

5. On a scale of $1-10$, where 1 is "not at all" and 10 is "extremely", how engaging do you find the art and its presentation around the AGO?

$\begin{array}{lllllllllll}1 & 2 & 3 & 4 & 5 & 6 & 7 & 8 & 9 & 10 & 5 a \text {. Follow-up: What makes you say that score? }\end{array}$

6. Which of the following methods did you use to engage with the art at the AGO today?

- Text

- Images / Video

- Augmented Reality

6a. Follow-up: If you were in charge of creating an engaging experience with the art what would you do differently? 


\section{Appendix B: Semi-structured Interview Questions (User Testing Stage):}

\section{WAYFINGING QUESTIONS:}

\begin{tabular}{|lrrrr|}
\hline \multicolumn{3}{|l}{ Interviewer } & \multicolumn{3}{l}{ Date } \\
AM & $12-2$ & $2-4$ & $4-6$ & $6+$ \\
Day & & Weekend & & Wed Night \\
\end{tabular}

1. On a scale of $1-10$, where 1 is "not at all" and 10 is "extremely", how intuitive did you find using the wayfinding aids in the AGO to get to the two destinations?

$\begin{array}{llllllllllll}1 & 2 & 3 & 4 & 5 & 6 & 7 & 8 & 9 & 10 & 10 \text {. Follow-up: What makes you say that score? }\end{array}$

2. On a scale of $1-10$, where 1 is "not at all" and 10 is "extremely", how intuitive did you find using "MRsive" to get to the two destinations?

$\begin{array}{llllllllllll}1 & 2 & 3 & 4 & 5 & 6 & 7 & 8 & 9 & 10 & \text { 2a. Follow-up: What makes you say that score? }\end{array}$

3. What would you change in the wayfinding section of "MRsive" if you could? What would you add/subtract?

- User Interface design

- User Experience design

- Language

- Tracking, etc...

\section{ENGAGEMENT QUESTIONS:}

4. On a scale of $1-10$, where 1 is "not at all" and 10 is "extremely", how engaging did you find using the brochure and tombstones to interact with the exhibits in the AGO?
$\begin{array}{llllllll}3 & 4 & 5 & 6 & 7 & 8 & 9 & 10\end{array}$
4a. Follow-up: What makes you say that score?

1

5. On a scale of $1-10$, where 1 is "not at all" and 10 is "extremely", how engaging did you find using "MRsive" to interact with the exhibits in the AGO?
1
$\begin{array}{llllllll}3 & 4 & 5 & 6 & 7 & 8 & 9 & 10\end{array}$
5a. Follow-up: What makes you say that score?

6. What would you change in the engagement section of "MRsive" if you could? What would you add/subtract?

- User Interface design

- User Experience design
- Language

- Tracking, etc.

\section{OVERALL QUESTIONS:}

7. What did you think of using a mobile-based application in a museum?

8. Would you change your mind if this experience is hosted on a Head-mounted display in the shape of normal eyeglasses? Why? 
Appendix C: MRsive's Sample Code

\section{CameraFollow.cs :}

Code controlling the top view map

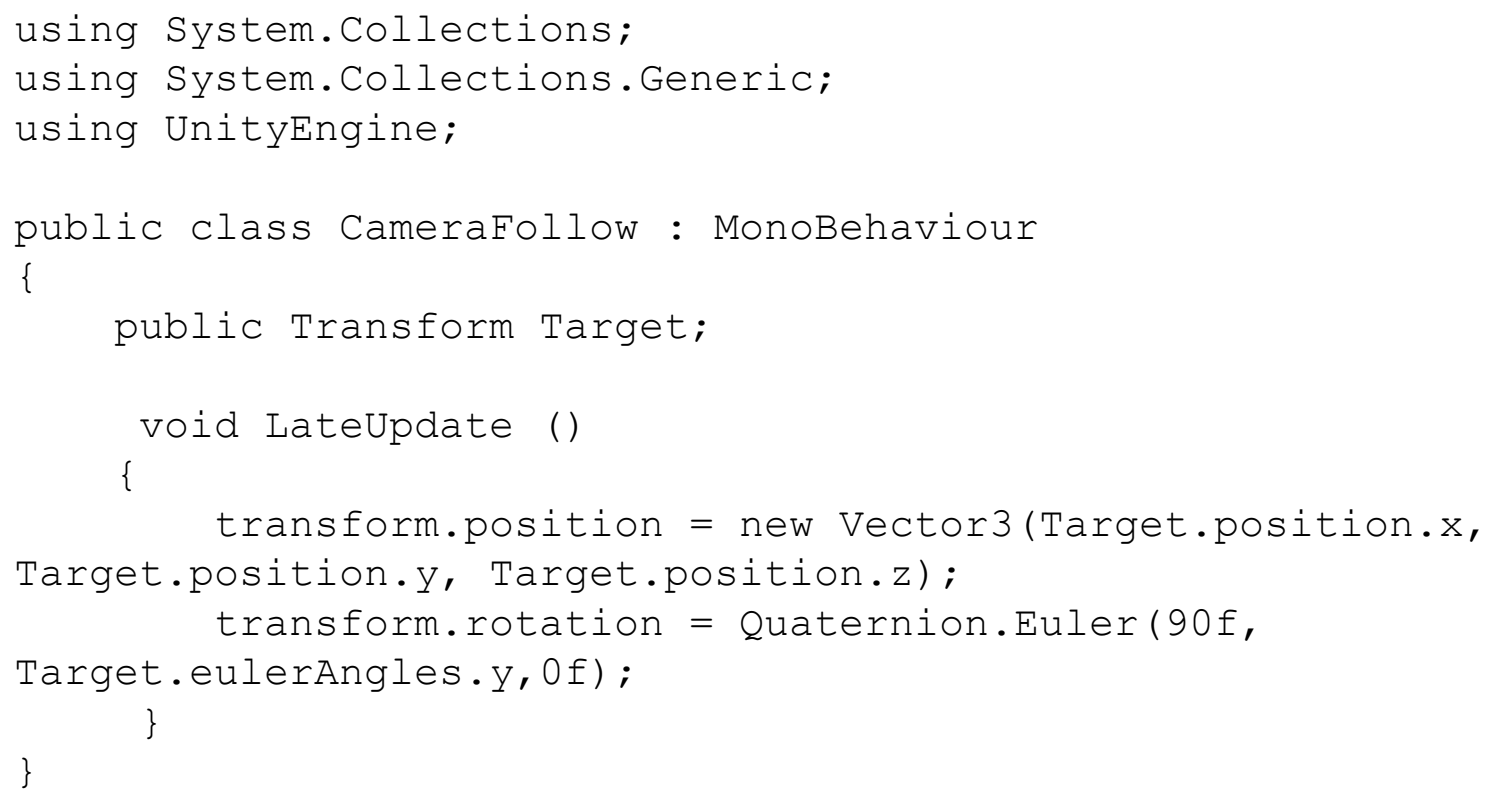

ChangeScene.cs :

Code allowing to jump from wayfinding scene to engagement scene and vice versa

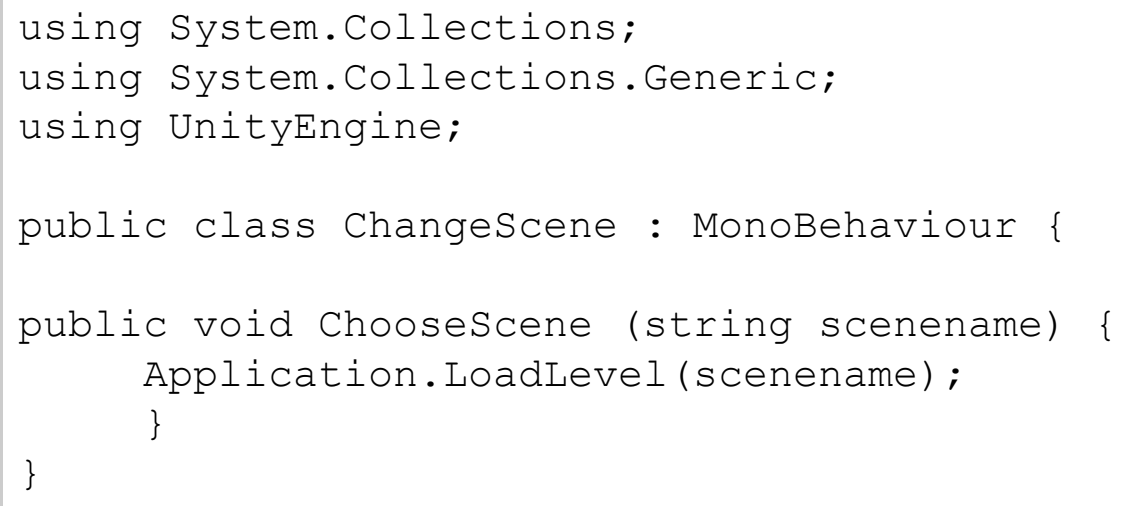


Hide3D.cs :

Code that hides virtual elements when not needed.

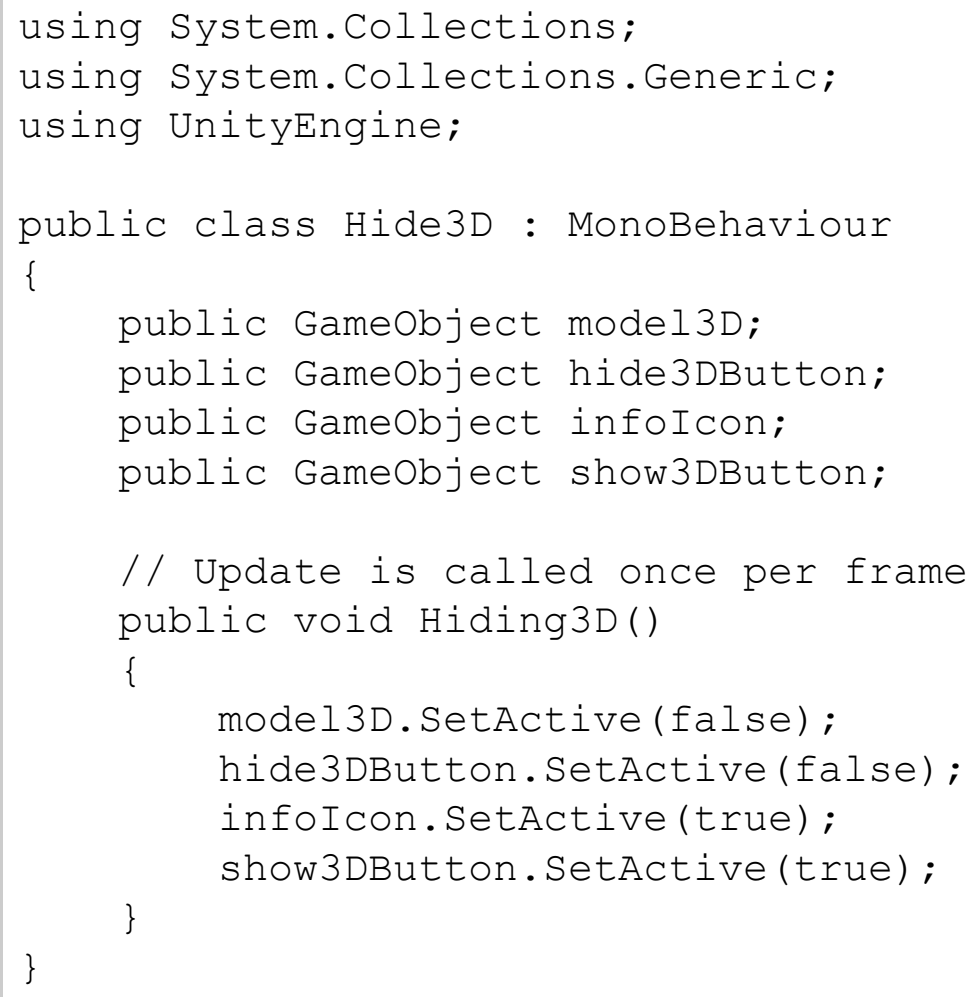

Show3D.cs:

Code that shows virtual elements when needed.

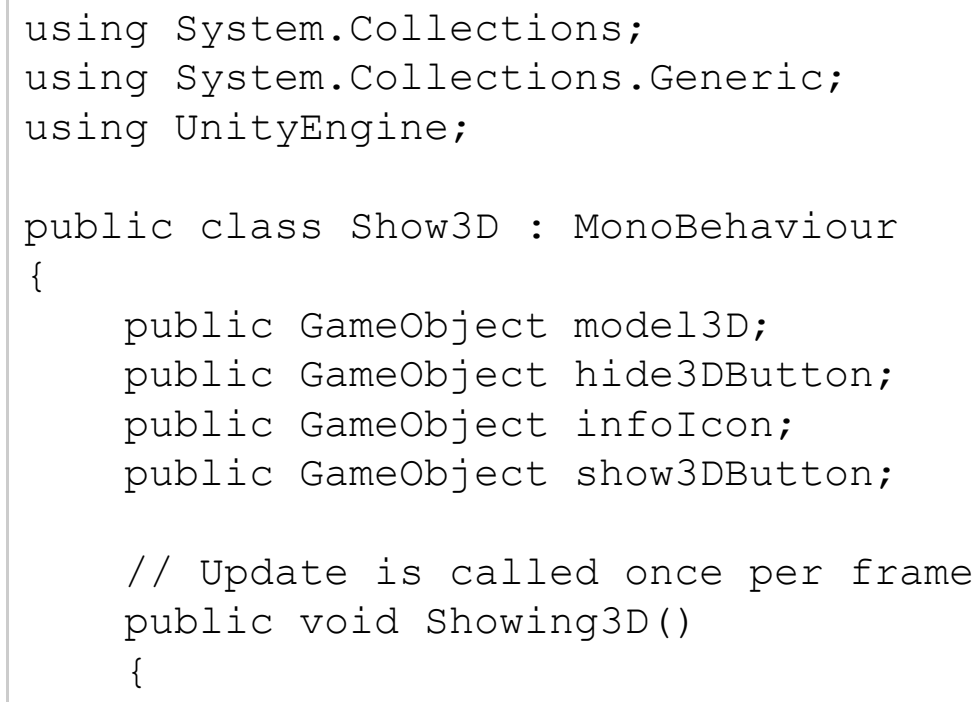




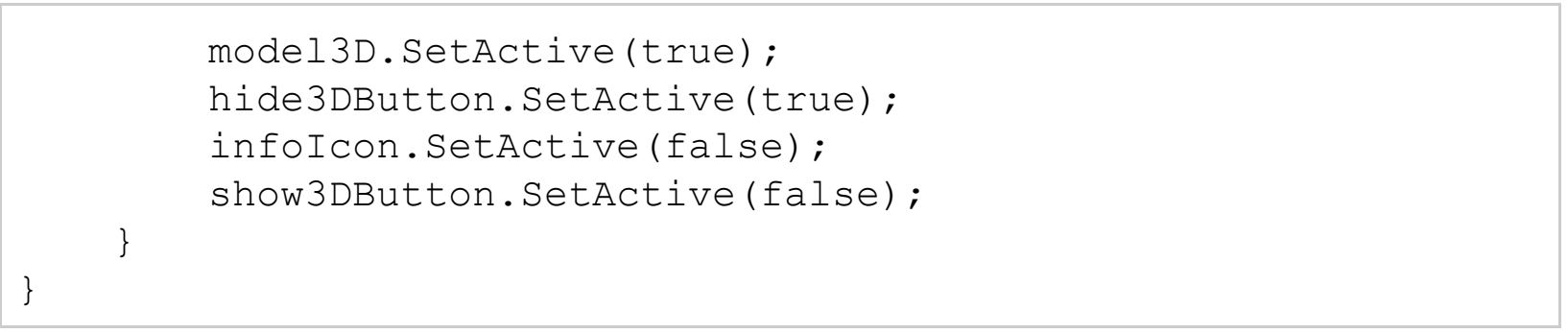

\section{DefaultTrackableEventHandler.cs:}

Tracking algorithm for wayfinding and triggering the different virtual interactions

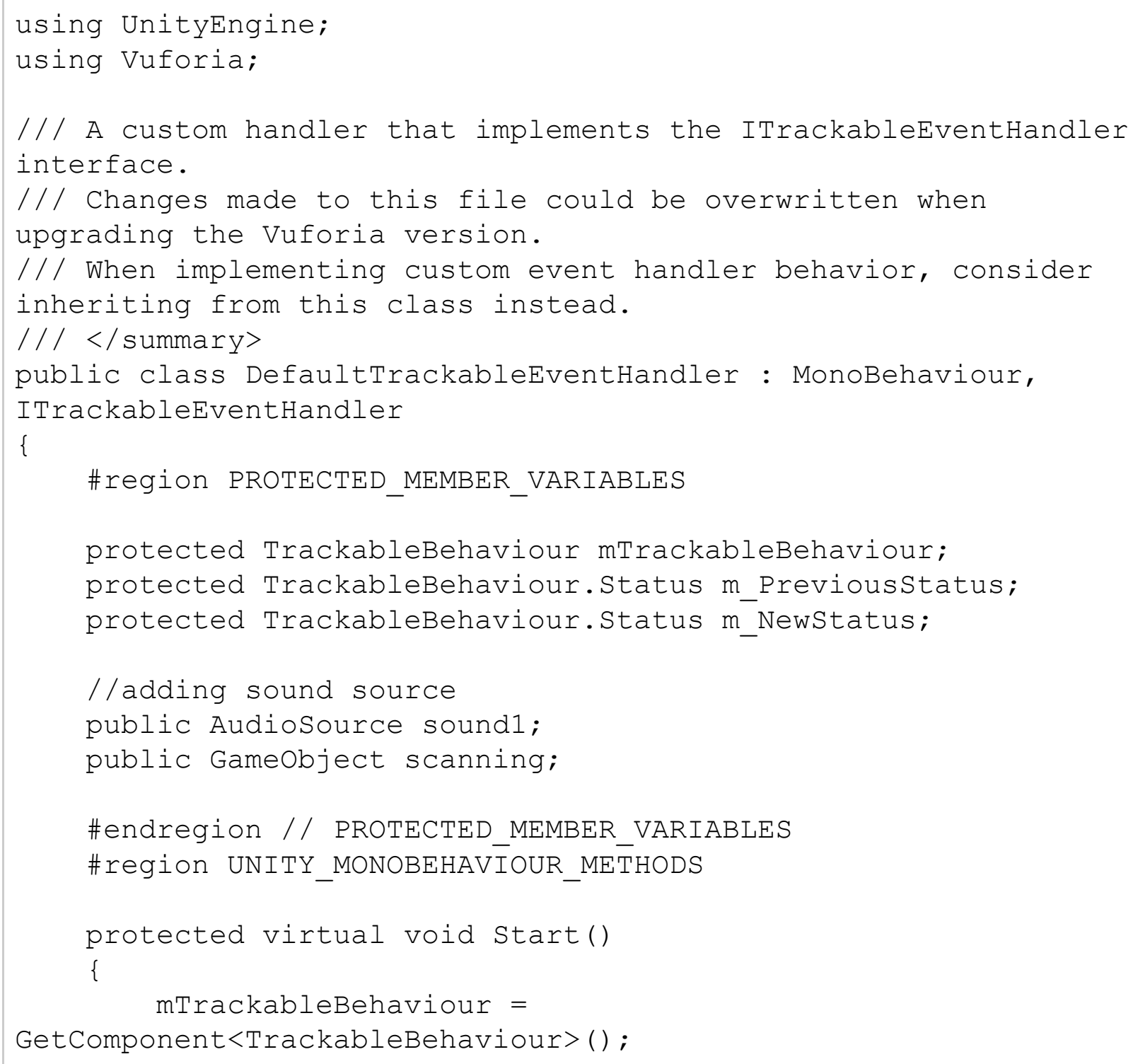




\section{if (mTrackableBehaviour)}

mTrackableBehaviour.RegisterTrackableEventHandler(this);

\}

protected virtual void OnDestroy()

\{

if (mTrackableBehaviour)

mTrackableBehaviour. UnregisterTrackableEventHandler (this) ;

\}

\#endregion // UNITY_MONOBEHAVIOUR_METHODS

\#region PUBLIC_METHODS

/ / < summary $>$

/// Implementation of the ITrackableEventHandler

function called when the

/// tracking state changes.

/// </summary $>$

public void OnTrackablestatechanged(

TrackableBehaviour.Status previousstatus,

TrackableBehaviour. Status newStatus)

\{

m_Previousstatus = previousstatus;

m_NewStatus = newStatus;

if (newstatus == TrackableBehaviour.Status. DETECTED ||

newStatus == TrackableBehaviour.Status.TRACKED ||

newstatus $==$

TrackableBehaviour.Status.EXTENDED_TRACKED)

\{

Debug.Log ("Trackable " +

mTrackableBehaviour.TrackableName + " found");

OnTrackingFound ();

//sound1.Play ();

\}

else if (previousstatus $==$

TrackableBehaviour. Status. TRACKED \&\&

newstatus $==$

TrackableBehaviour.Status.NO_POSE)

\{ 


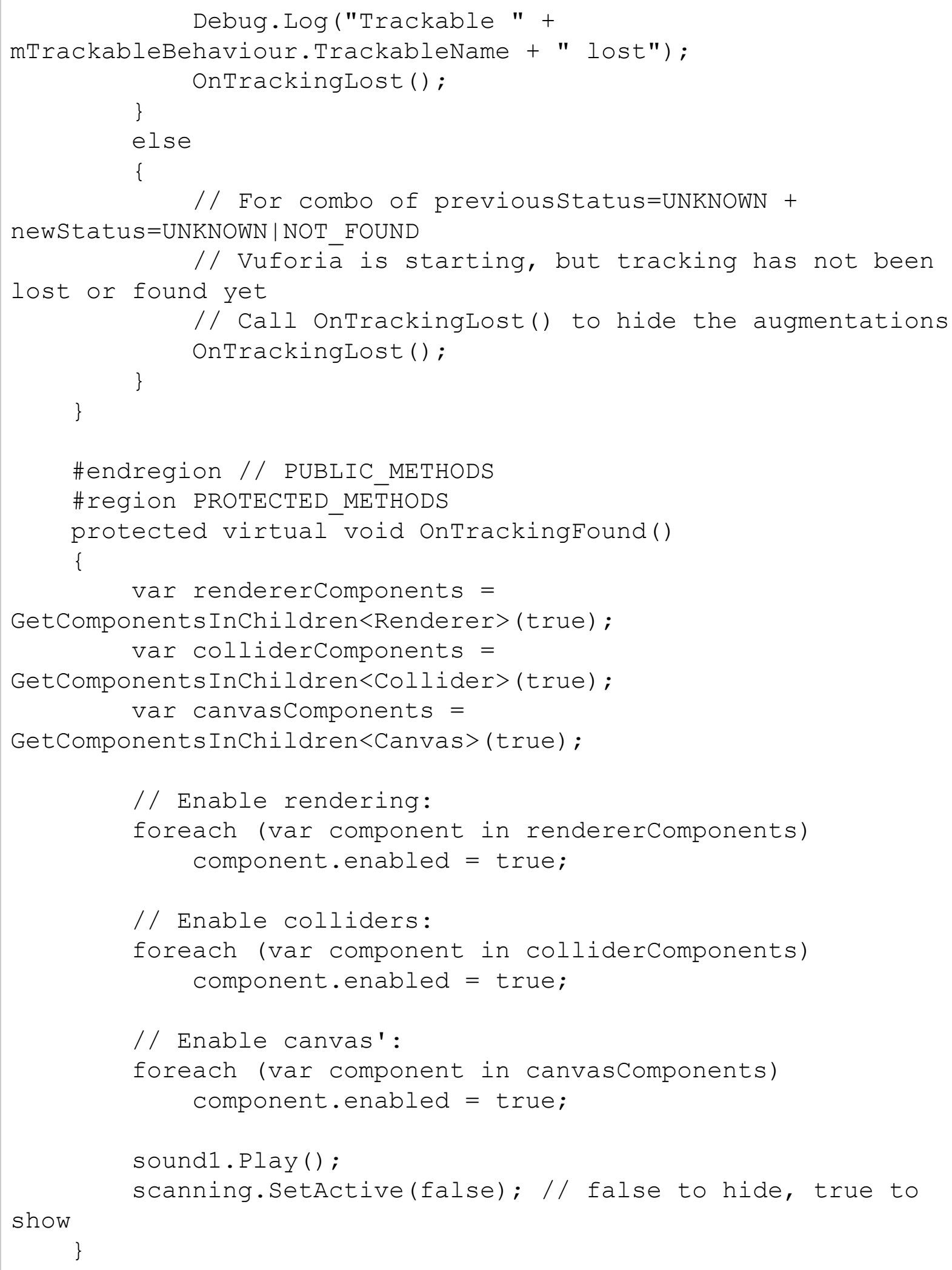




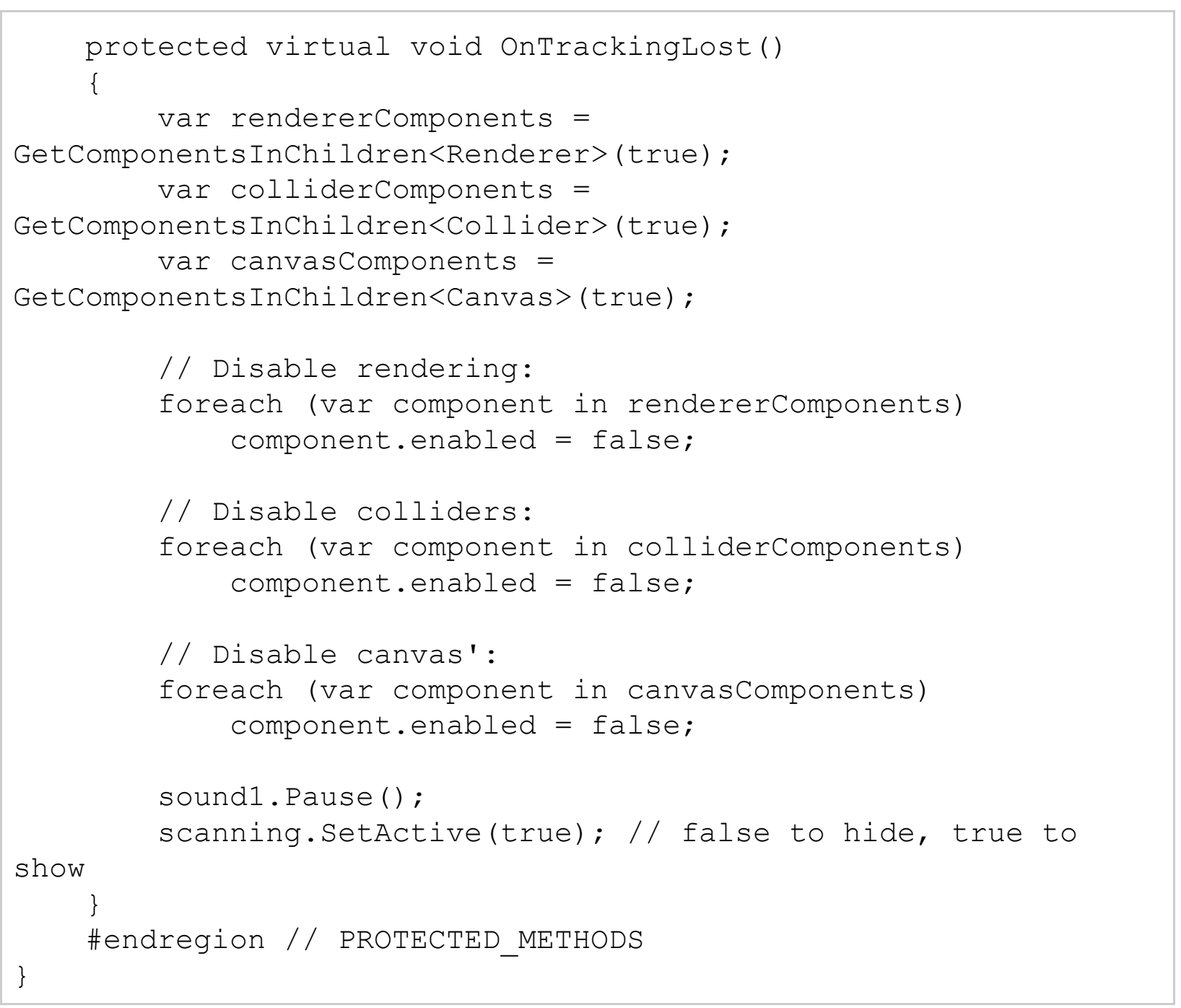


MRsive: an Augmented Reality Tool for Enhancing Wayfinding and Engagement With Art in Museums

Appendix D: Additional Media Files

Screenshots, Images of the experience, Video recording of the experience at the AGO, and the audio file of The Storm's soundscape can be found as external materials at

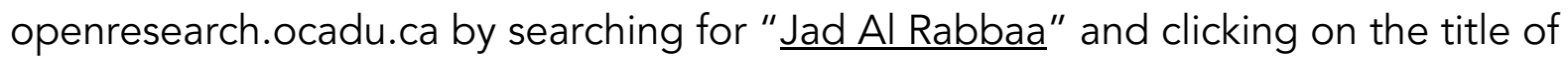
this thesis: "MRsive: an Augmented Reality Tool for Enhancing Wayfinding and Engagement With Art in Museums". 


\section{PUBLICATIONS}

[1] Al Rabbaa, J., Morris, A., Somanath, S. (2019). "MRsive": an Augmented Reality Tool for Enhancing Wayfinding and Engagement With Art in Museums. In HCll 2019. Orlando, Florida: Springer.

[2] Al Rabbaa, J., Karawash, A., Diamond S., Gordon M., Shepko-Hamilton, R., Dong, L., Mariano, G., Samaei, A., Ritchie, H. (2018). TasteGraph: A Visual Analytics Tool for Profiling Media Audiences Tastes. In IEEE VIS 2018. Berlin, Germany. 